\section{لlim}

Center for Urban Transportation Research

College of Engineering University of South Florida 4202 E. Fowler Avenue, CUT100 Tampa, FL 33620-5375

(813) $974-3120, \operatorname{fax}(813) 974-5168$
USF

UNIVERSITY OF National Center for Transit Research 


\section{EDITORIAL BOARD}

Robert B. Cervero, Ph.D.

University of California, Berkeley

Chester E. Colby

E \& J Consulting

Gordon Fielding, Ph.D.

University of California, Irvine

David J. Forkenbrock, Ph.D.

University of lowa

Jose A. Gómez-Ibáñez, Ph.D.

Harvard University

Naomi W. Ledé, Ph.D.

Texas Transportation Institute
William W. Millar

American Public Transportation Association

Steven E. Polzin, Ph.D., P.E.

University of South Florida

Sandra Rosenbloom, Ph.D.

University of Arizona

Lawrence Schulman

LS Associates

George Smerk, D.B.A

Indiana University

Vukan R. Vuchic, Ph.D., P.E.

University of Pennsylvania
The contents of this document reflect the views of the authors, who are responsible for the facts and the accuracy of the information presented herein. This document is disseminated under the sponsorship of the U.S. Department of Transportation, University Research Institute Program, in the interest of information exchange. The U.S. Government assumes no liability for the contents or use thereo
Complimentary subscriptions can be obtained by contacting:

Lisa Maitland, Assistant to the Editor

Center for Urban Transportation Research (CUTR)

University of South Florida

Fax: $\quad 813.974 \cdot 5168$

Email: jpt@cutr.usf.edu

Web: www.nctr.usf.edu/journal.htm

\section{SUBMISSION OF MANUSCRIPTS}

The Journal of Public Transportation is a quarterly, international journal containing origina research and case studies associated with various forms of public transportation and related transportation and policy issues. Topics are approached from a variety of academic disciplines, including economics, engineering, planning, and others, and include policy, methodological, technological, and financial aspects. Emphasis is placed on the identification of innovative solutions to transportation problems.

All articles should be approximately 4,000 words in length (18-20 double-spaced pages). Manuscripts not submitted according to the journal's style will be returned. Submission of the manuscript implies commitment to publish in the journal. Papers previously published or under review by other journals are unacceptable. All articles are subject to peer review. Factors considered in review include validity and significance of information, substantive contribution to the field of public transportation, and clarity and quality of presentation Copyright is retained by the publisher, and, upon acceptance, contributions will be subject to editorial amendment. Authors will be provided with proofs for approval prior to publication.

All manuscripts must be submitted electronically, double-spaced in Word file format containing only text and tables. If not created in Word, each table must be submitted separately in Excel format and all charts and graphs must be in Excel format. All supporting illustrations and photographs must be submitted separately in an image file format, (i.e., TIF, JPG, Al or EPS), having a minimum $300 \mathrm{dpi}$, and include all sources and written permissions. Each chart and table must have a title and each figure must have a caption.

All manuscripts should include sections in the following order, as specified:

Cover Page - title (12 words or less) and complete contact information for all authors First Page of manuscript - title and abstract (up to 150 words)

Main Body - organized under section headings

References - Chicago Manual of Style, author-date format

Biographical Sketch - of each author

Be sure to include the author's complete contact information, including email address, mailing address, telephone, and fax number. Submit manuscripts to the Assistant to the Editor, as indicated above. 


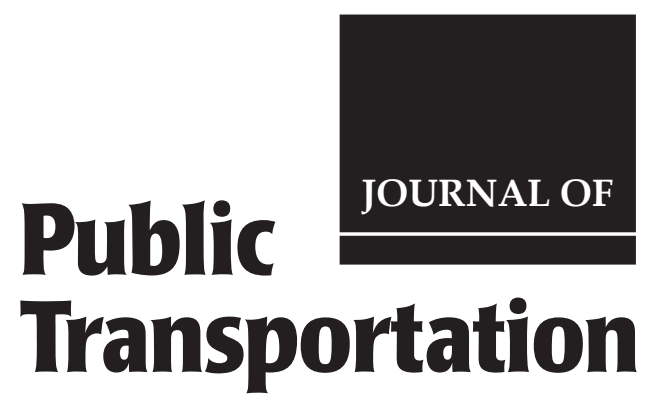

Volume 9, No. 1, 2006

ISSN 1077-291X

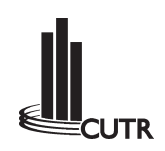

The Journal of Public Transportation is published quarterly by

National Center for Transit Research

Center for Urban Transportation Research

University of South Florida • College of Engineering

4202 East Fowler Avenue, CUT100

Tampa, Florida 33620-5375

Phone: $813 \cdot 974 \cdot 3120$

Fax: $813 \cdot 974 \cdot 5168$

Email: jpt@cutr.usf.edu

Website: www.nctr.usf.edu/journal.htm

(c) 2006 Center for Urban Transportation Research 



\section{CONTENTS}

\section{Psychological Effects of and Design Preferences for Real-Time} Information Displays

Katrin Dziekan, Arjan Vermeulen

Transit Network Sensitivity Analysis

Young-Jae Lee.

A Study of the Impact of APTS on Service Quality Perceptions of Elderly and Disabled Riders

Julian M. Benjamin.

Improving Metropolitan Transportation Efficiency with FAST Miles

Patrick DeCorla-Souza

Smart feeder/Shuttle Bus Service: Consumer Research and Design Y. B. Yim, Avishai (Avi) Ceder.

Our troubled planet can no longer afford the luxury of pursuits confined to an ivory tower. Scholarship has to prove its worth, not on its own terms, but by service to the nation and the world.

-Oscar Handlin 



\title{
Psychological Effects of and Design Preferences for Real-Time Information Displays
}

\author{
Katrin Dziekan, Royal Institute of Technology, Stockholm, Sweden \\ Arjan Vermeulen, HTM, Rail, The Hague, The Netherlands
}

\begin{abstract}
This article investigates the effects of real-time information, located at stops and stations, on the public transportation customer. Perceived wait time, feelings of security, and ease of use were considered to be sensitive indicators. The case of newly implemented traveler information on tramline 15 in the Hague, the Netherlands, was used for a before-and-after evaluation study containing questionnaires given to travelers. One month before and 3 months and 16 months after implementation, the same sample of travelers completed in a questionnaire. Further, four orientations of the displays at tram stops, assembled for testing purposes, were evaluated. The main results were that the perceived wait time decreased by 20 percent, while no effects on perceived security and ease of use were found. Displays installed perpendicular to the tracks and separate from the shelter were ranked highest.
\end{abstract}

\section{Introduction}

Real-time information systems are becoming more and more and ubiquitous in public transportation (PT) (Yeung 2004). A considerable amount of money is being spent on IT-based applications, such as real-time, at-stop displays. Many projects have shown that this kind of information is appreciated by the customers (Infopolis2 1998; GoTiC 2002; Lehtonen and Kulmala 2001; Coogan 2003; 
BMBF 2002; Intermobil 2002), but actual knowledge about the behavioral effects these have on customers or potential customers in the real world is quite sparse (Dziekan 2004). Due to combined implementation measures (such as opening a new tramline or running an accompanying marketing campaign), it is often difficult to separate the effect of real-time information systems on traveler numbers. Very few sources report increases of traveler numbers as a direct effect of installing real-time information systems.

Effects of real-time information displays at stops are considered to be of a more psychological nature (Dziekan 2004). Systems displaying the next train or bus departure time at stops or stations can greatly reduce anxiety. Just the existence of such a system creates trust in the whole PT system and may improve its image. Perceived security at stops is considered to be influenced positively by the new displays (Consortium Infopolis 1999; Kronborg, Lindkvist, and Schelin 2002), and the service is perceived as being more reliable (Infopolis2 1998 Annex F).

Wait time holds a negative quality for transit users (Li 2003; Karlsson 1997). Thus, reducing actual wait time or decreasing the perceived wait time can make PT systems more attractive. Real-time information displays have the potential to shorten the perceived wait time (Infopolis2 1998). Wardman, Hine, and Stradling (2001) found that real-time information at transfer points was very important, especially for occasional users.

Optimizing product utility has a long tradition (Karlsson 1996). Services or products should be "easy to use" in order to match customer needs and thereby increase satisfaction and sales figures (Consortium Infopolis 1999). Focusing on aspects of the experience and thinking of the traveler is a rather new approach in PT (Stradling 2002). In addition to saving time and money, people want to save effort when using PT. Stradling (2002) names three types of effort: physical effort, cognitive effort, and affective effort. While physical effort concerns the physical activity on a journey, cognitive effort is expended on a journey via information gathering and processing for route planning, navigation, progress monitoring, and error correction. Affective effort is the emotional energy expended on a journey in dealing with uncertainty regarding safe and comfortable travel and timely arrival at intermediate and final destinations. This article presents a special measurement developed to show the effects in the ease of use of a tramline as a part of the cognitive and affective effort. Further, it is known from service research that a product recommended to others tends to be of a relatively high quality. So, the willingness to recommend was measured as one aspect of service quality. 
Finally, the placement of the displays was examined. At-stop displays are very often installed perpendicular to the tracks and bus lanes, meaning in the direction of the arriving vehicle (Infopolis2 1998 Annex F). But is this the design travelers prefer? The case of tramline 15 in The Hague offered the possibility of investigating many of the above issues.

\section{Methods}

\section{The Case}

The local PT company, HTM, in the Hague, the Netherlands, installed real-time, at-stop displays along tramline 15 (see Figure 1). This was completed in January 2004 as a part of the MOBIEL project (Vermeulen and de Jong 2003). Additionally, the real-time departure information for the tram was accessible via SMS and the Internet. A before-and-after evaluation offered the possibility to investigate behavioral effects, especially the influence on perceived wait time, perceived security, and influences on ease of use. HTM installed four different design solutions for

\section{Figure 1. Route of Tramline 15 in The Hague (2004)}

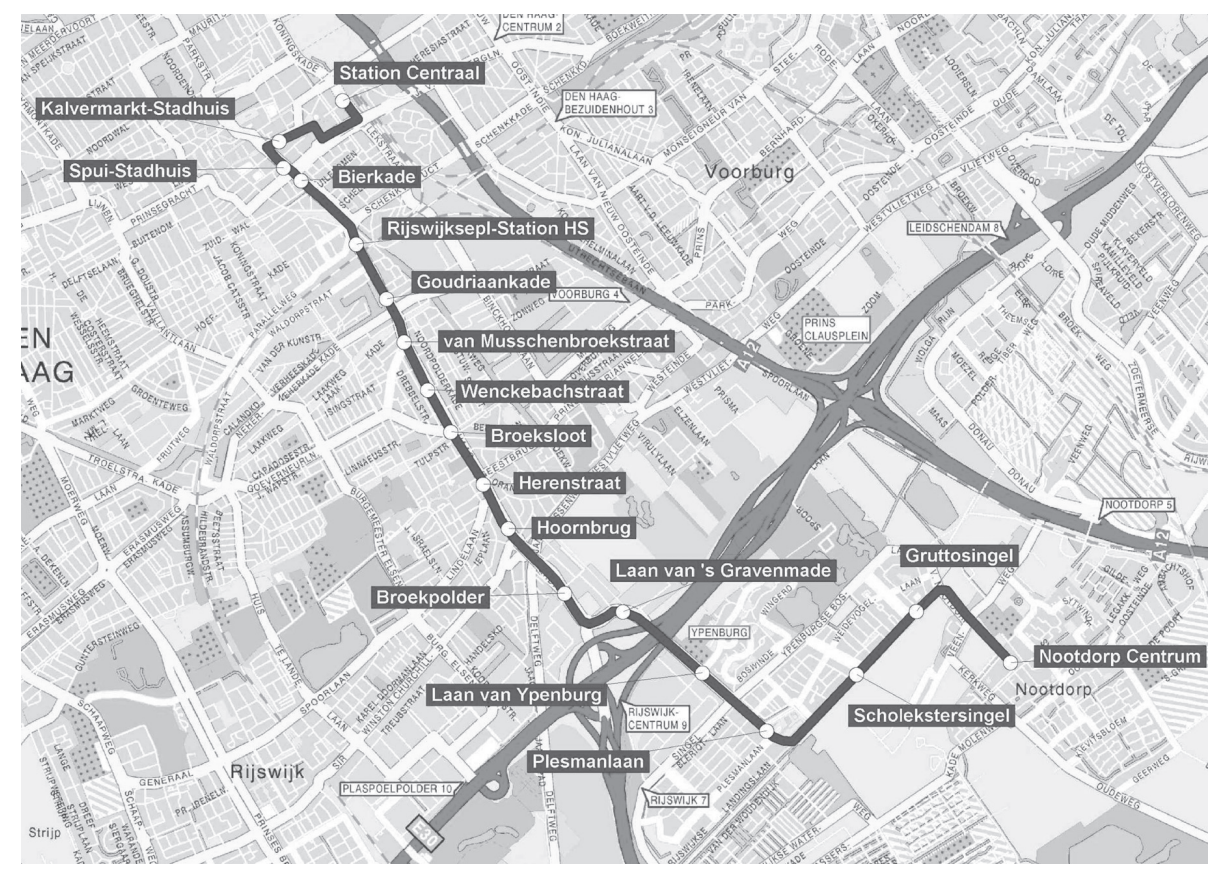


the displays: parallel to the tracks in the shelter, parallel to the tracks and separate from the shelter, perpendicular to the tracks in the shelter, and perpendicular to the tracks standing separately from the shelter (see Figure 2). Traveler reactions and preferences for these different solutions were investigated.

\section{Before-and-After Questionnaire}

In December 2003, one month before the introduction of the real-time, at-stop displays, 840 questionnaires were distributed to individual travelers on line 15. Travelers were asked to complete and return the questionnaires to HTM. By returning the surveys, travelers were given the chance to win a prize of EUR 20 (approximately USD \$24). A total of 370 questionnaires were returned (return rate of $44 \%)$.

The before test contained questions about boarding time for the respective journeys, use frequency per week for line 15, age, and gender. Further, the perceived security at the boarding stop was to be rated by the respondents from 1 (very bad) to 10 (very good). The perceived average wait times at the stops on line 15 were to be stated in minutes. The question asked was: "How long do you have to wait, on average, for a tram on line 15?" Finally, ease of use was evaluated. To make PT easy to use, it seems preferable to keep the cognitive effort for the passengers as low as possible. The hypothesis is that the displays at the stops reduce the cognitive effort and in that way make it more convenient and easier to travel by public transport. Further, the willingness to recommend can be seen as an indicator of good service quality. To measure these two aspects of "ease of use" of a PT journey, the following two scales were developed and used in both before- and after-test questionnaires:

"For the statements below, please indicate how strongly you agree, on a fivepoint scale:

- It is hard to determine when exactly the tram 15 departs.

- If somebody else has to make the same trip as I do right now, I would recommend that they choose line 15."

The answer categories were: fully agree (1), agree (2), neutral (3), disagree (4) and fully disagree (5). 


\section{Figure 2. Four Placement Design Variants of the} Real-Time Information Displays at Stops on Line 15

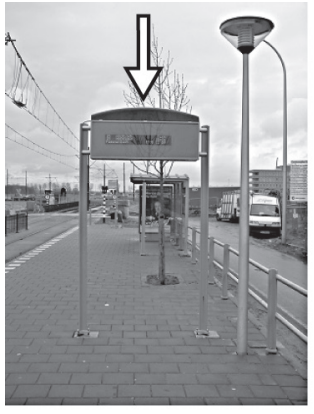

\section{Display separate and} perpendicular to tracks

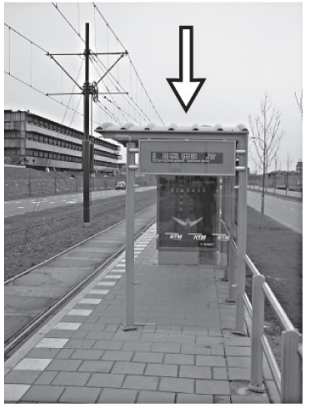

Display in the shelter and perpendicular to tracks

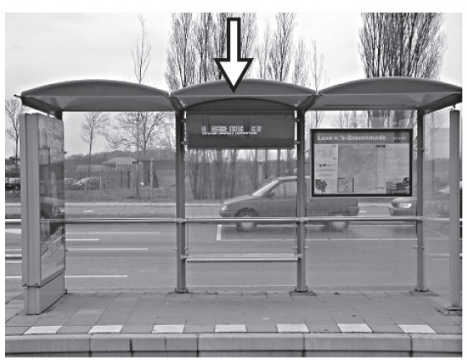

Display in the shelter and parallel to tracks

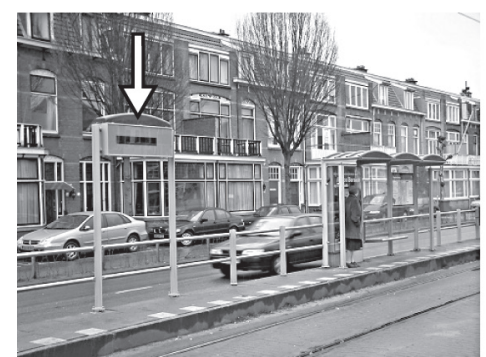

Display separate and parallel to tracks 
The 175 persons who indicated their addresses in the before questionnaire for participation in an after test received a new questionnaire via mail in March 2004. It was assumed that after only three months, people who still live in the same place will not have changed their boarding stop on line 15 or their user frequency. For evaluation and comparison, the questions regarding perceived security, wait time, and ease of use were asked again. Further questions were added regarding highest level of education, car availability, use of the displays, and evaluation of the line's reliability. Finally, photographs from the four different placement types (Figure 2) were presented and ranked by the respondents.

\section{Sample Characteristics}

Based on a detailed comparison of sample characteristics (Dziekan and Vermeulen 2004), it was shown that, apart from the five years' higher average age in the after-test sample, both samples can be considered comparable. Therefore, it can be assumed that the after sample is a representative selection of the before-test sample. Hence, data from the people who participated in both the before test and the after test $(\mathrm{N}=53)$ will be the basis for the before-after analysis of the effects of the real-time information displays and the results presented below.

In the sample, males and females were represented equally; ages ranged from 17 to 79 years (mean 40 years). Sixty-six percent of the respondents had a car available to them. More than one third of those participating in the sample had a university degree; 30 percent finished secondary school as their highest education; 13 percent finished primary school; and 11 percent were skilled workers.

The people in the sample use line 15 very frequently: 55 percent travel four days or more per week on line 15 and only 17 percent use it less than 1 day per week.

A detailed nonrespondents analysis was conducted for the subgroups of participants who returned the before survey but did not receive the after survey and the participants who received the after survey but did not return it.

There were no significant differences between the nonrespondents and the 53 participants in the after survey in terms of gender, boarding stop, boarding time, user frequency, mobile phone ownership, and Internet access. Only the average age was different. Participants in the after sample were, on average, four to eight years older than the nonrespondents. So, the higher average age may have lead to some biases in the measured impacts. 


\section{Results from the Before-and-After Test Effects on Wait Time Perception}

The perceived average wait time at stops along line 15 was estimated in minutes. In the before test, the mean perceived wait time was 6.3 minutes (standard error 0.4 ) and the mean in the after test was 5.0 minutes (standard error 0.3). As illustrated in Figure 3, the average perceived wait time at stops along line 15 was shortened significantly ( $t$-test, significant on the $1 \%$ level) by 1.3 minutes. That means people perceived, on average, a 20 percent shorter wait time.

\section{Figure 3. Average Perceived Wait Time on Line 15 Before and After Installing the Real-Time Information At-Stop Displays $(\mathrm{N}=53)$}

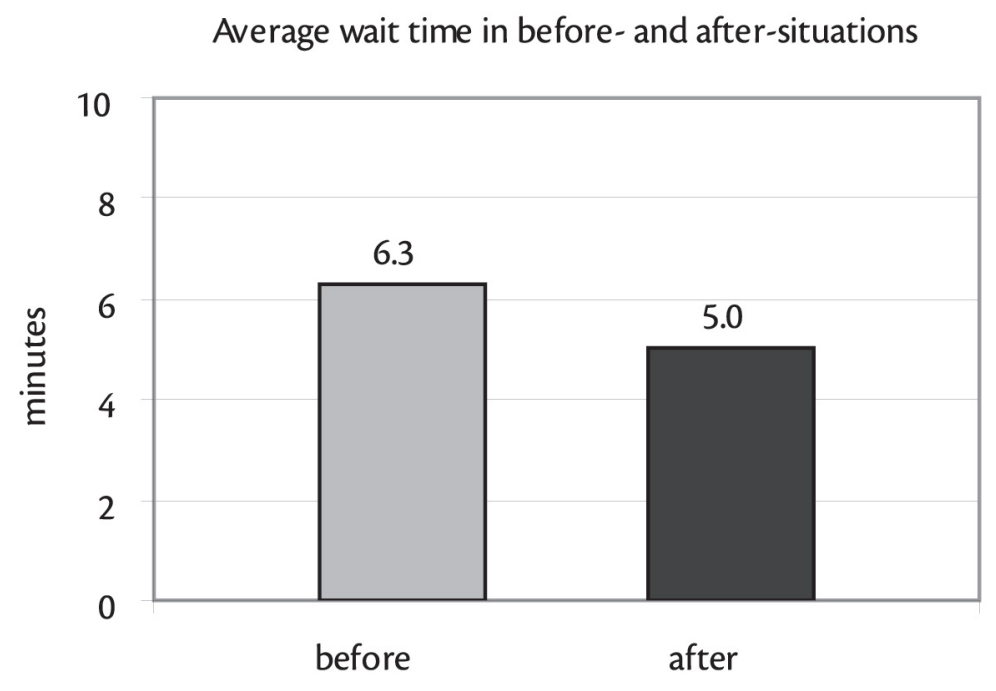

The route and the schedule for the investigated part of line 15 were the same in the before and after situations. Between 6A.M. and 7P.M., the headways were $10 \mathrm{~min}$ utes in length, but HTM reported an average irregularity (schedule deviation) of 10 percent. Thus, the actual average wait time ranged between 4.5 and 5.5 minutes.

Through an analysis of the distribution of wait-time estimation, it can be seen that people tend to round down or up their answers. In the before situation, people used a range from $0-15$ minutes; 35 percent indicated that they waited an average 
of 5 minutes and 21 percent indicated a 10-minute wait. In the after test, however, 40 percent of all respondents indicated a 5-minute wait time and only 9 percent specified 10 minutes, which was also the highest wait time indicated in the after test.

\section{Effects on Security Experience at Stops}

The perceived security at the boarding stop was rated on a scale from 1 (very bad) to 10 (very good). The total average security experience in the before study was 7.9. In the after study, the average perceived security worsened to 7.6 (Figure 4). However, no significant differences between the security experiences for the boarding stops could be calculated.

\section{Figure 4. Average Security Experience at the Boarding Stop in Before-and-After Situations ( $\mathrm{N}=53$ ) (Scale: $1=$ very bad to $10=$ very good)}

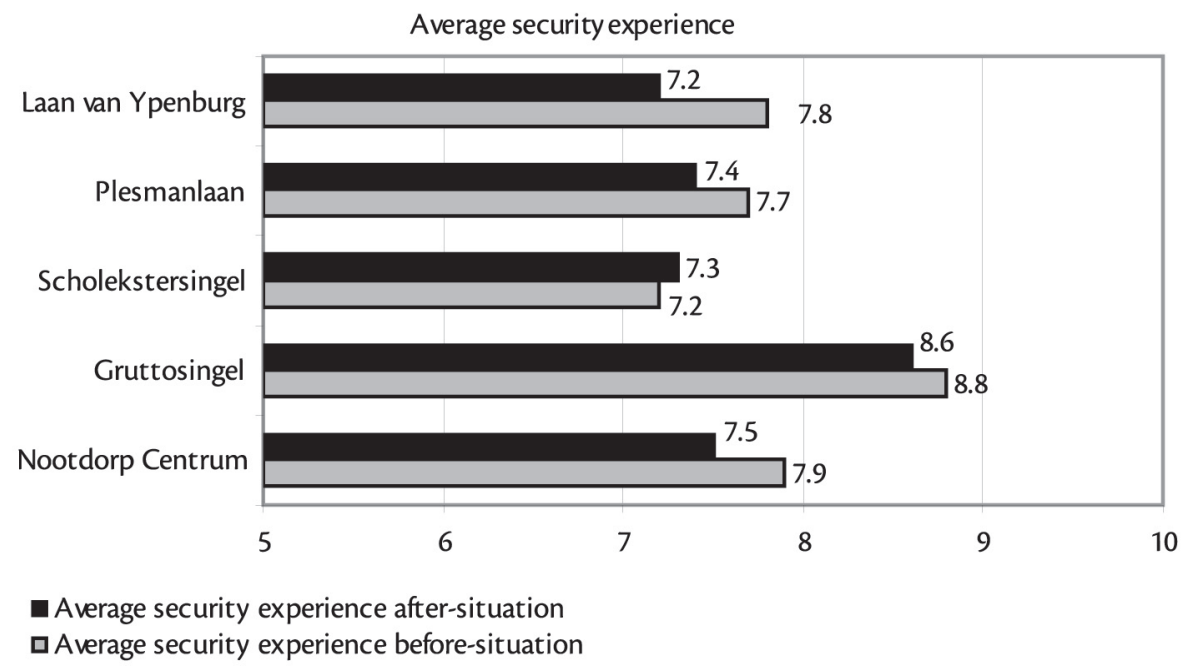

\section{Effects on Ease of Use}

For cognitive effort, the same average values were achieved in the before-and-after tests (Figure 5). The mean for the cognitive effort measurement was 4 in both samples, which means that people do not think it is very difficult to determine when exactly line 15 departs. No significant differences between the before-and-after situations can be reported for cognitive effort. Even without real-time information displays at the stops, it was not considered difficult to determine when the next tram would depart. 


\section{Figure 5. Cognitive Effort Distribution in Before-and-After Test Situations $(\mathrm{N}=53)$}

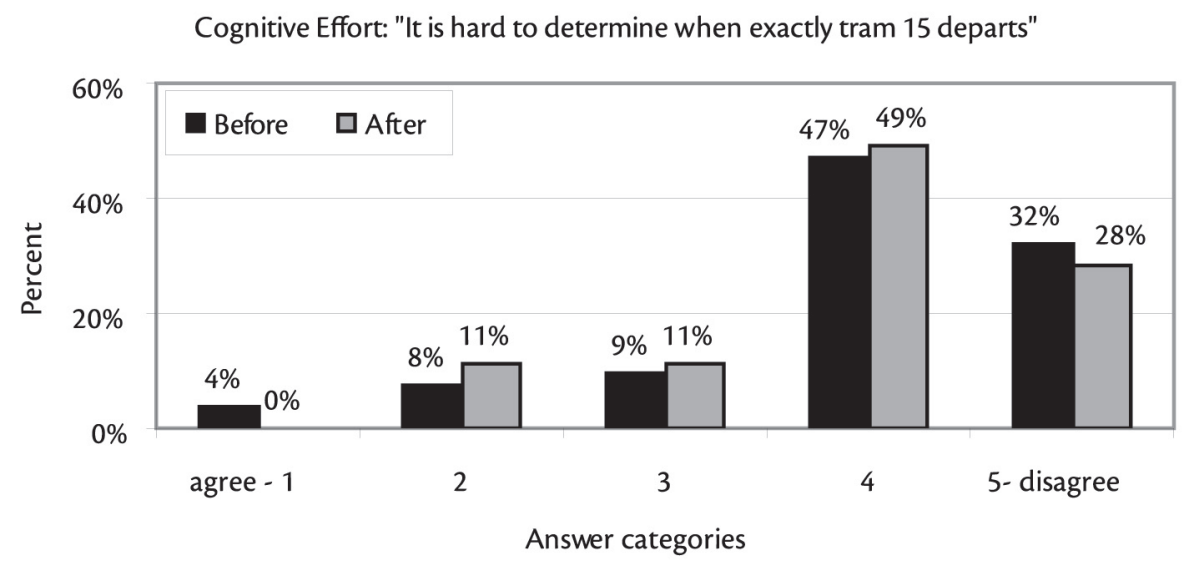

A similar picture-that is, no differences between before-and-after situationscan be reported for the recommendation willingness factor (Figure 6). The mean of the willingness to recommend is also quite high at 1.8 ( $1=$ high willingness to recommend and $5=$ low willingness to recommend).

\section{Figure 6. Recommendation Distribution in Before-and-After Test Situations $(\mathbf{N}=53)$}

Recommendation:"If somebody else has to make the same trip as I do right now, I would recommend that they choose line 15 "

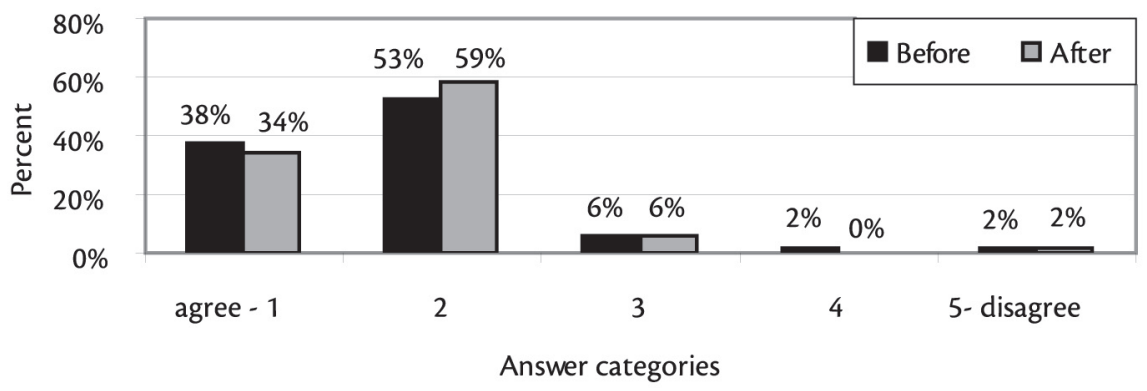


In the analysis of the after-test sample, no significant correlations between cognitive effort, recommendation willingness, perceived wait time, or perceived security were found.

\section{Evaluation of Design Variants of the Placement of Displays}

Along line 15, four different design variants (see Figure 2) were installed to test the convenience of different placements. In the questionnaire, each of the four alternatives was ranked.

To build the final rank order, the rank numbers were weighted: The highest rank received a weight of 3; the second highest, a weight of 2; the third highest, a weight of 1; and the lowest rank, no weight. Figure 7 depicts the score that each design obtained. Results of the ranking are quite clear: Display positions perpendicular to the tracks are preferred in general. Parallel placement is unfavorable. Displays located separate from the shelter and perpendicular to the tracks were most preferred.

\section{Figure 7. Weighted Ranked Scores of Four Placement Design Variants of Real-Time Information Displays at Stops Along Line 15}

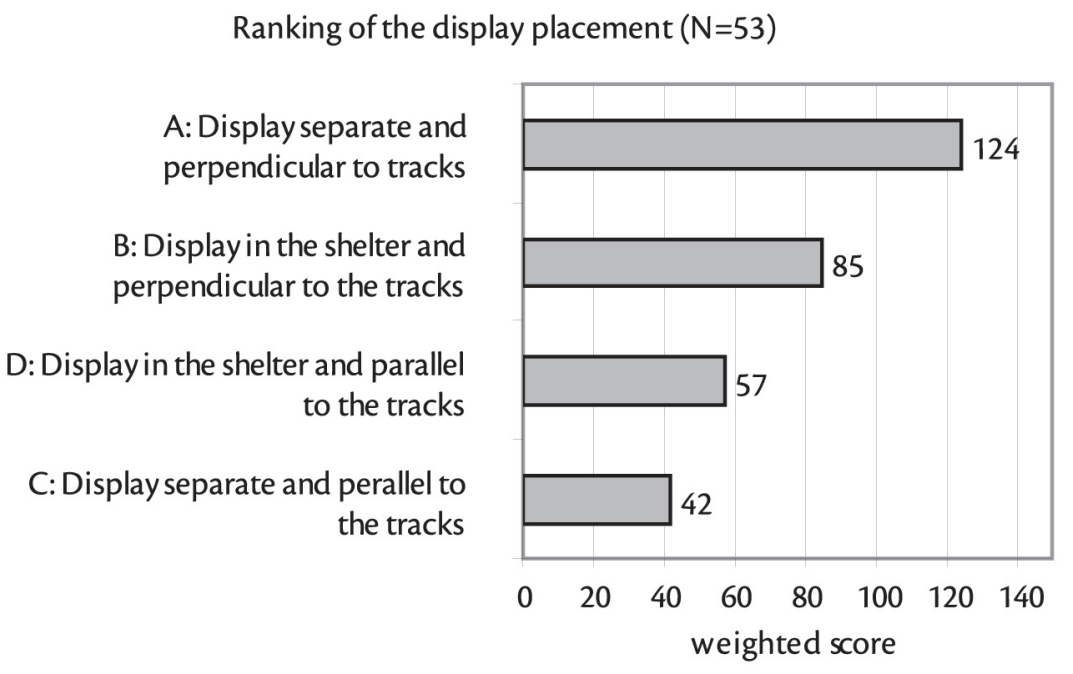




\section{Use of Displays}

The majority (79\%) of respondents in the after situation stated that they had looked at the displays at the stop, but this also means that almost every fifth person had not yet looked at the displays.

More than half of the people who looked at the displays evaluated the information shown as reliable (Figure 8). However, 35 percent felt that the presented information was not reliable; they believed that the tram often arrived later or earlier than displayed.

\section{Figure 8. Perceived Reliability of Information Shown by Displays ( $\mathrm{N}=40$ )}

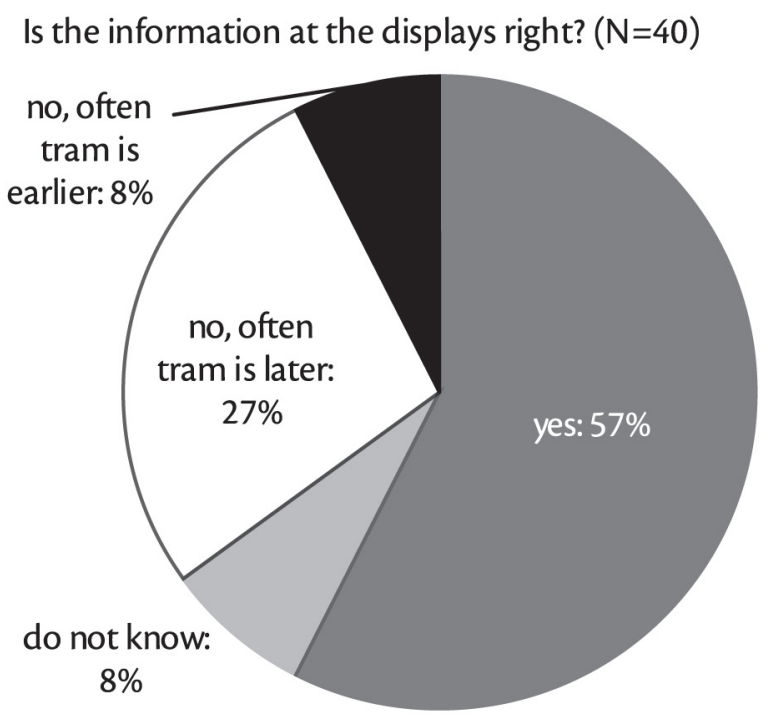

A comparison was calculated between the people who assumed the information was not reliable $(\mathrm{N}=14)$ and those who trusted the information $(\mathrm{N}=23)$. The results showed that the cognitive effort for people who doubted the reliability of the information displays increased, while those who trusted the information had an easier journey. Due to the low number of cases, these differences did not reach a significant level. 


\section{The Second After Test: Long-Term Effects}

To prove long-term effects and to validate the results gained in the first after test, a second wave was conducted 16 months after implementation of the real-time displays. The same after questionnaire was sent out, but without the questions regarding design solutions for the display installations. From 175 questionnaires, 81 were returned (a response rate of 46\%). Again, the nonrespondents were younger on average but all other characteristics were comparable. The total number of people who answered all three questionnaires dwindled to 32 respondents. Table 1 shows the results for the repeated measurements of the 32 people.

\section{Table 1. Values for the Sample $\mathrm{N}=32$, People Who Participated in All Measures}

\begin{tabular}{lccc}
\hline Variable & Before Test & $\begin{array}{c}\text { After Test } \\
\text { (After 3 months) }\end{array}$ & $\begin{array}{c}\text { Second After Test } \\
\text { (After 16 months) }\end{array}$ \\
\hline Security experience $^{1}$ & 8.10 & 7.84 & 7.78 \\
Wait time $^{2}$ & 6.22 & 5.00 & 4.81 \\
Cognitive effort $^{1}$ & 3.87 & 3.84 & 3.84 \\
Recommendation $^{1}$ & 1.59 & 1.75 & 1.56 \\
Looked at displays $^{\text {Good reliability of displays }}$ & - & $72 \%$ & $81 \%$ \\
\hline
\end{tabular}

1 No significant differences (one-sample t-test).

2 Differences between the values in the before-and-after tests as well as in the before and second after test are significant at the 5 percent level (one-sample t-test); between the wait time in the after test and the second after test there is no significant difference.

Generally the results of the second after test confirmed the findings seen in the first after test (as presented in Table 1). The experience of security remained constant over time and neither cognitive effort nor levels of recommendation were impacted. On the other hand, the impact of the real-time displays on decreased perceived wait time could be seen over time. In the after test, 42 percent of the respondents perceived a 5 -minute wait time while only 9 percent believed that they waited an average of 10 minutes. This is in comparison to the before test in which 35 percent of the respondents perceived a 5-minute wait time while 21 percent perceived 10-minute wait time. 
More people looked at the displays in the second post-test and, additionally, more people trusted the information provided by the displays. This could be a hint that HTM improved service quality as a result of overcoming the growing pains of the system.

\section{Discussion and Conclusions}

This study provided evidence for the positive impact of real-time information displays at tram stops on perceived wait times. Some weak points in the methodology that might bias the result should be mentioned. One question forced people to write a number of minutes representing average perceived wait times. It seems, however, that people tended to round that number down or up, for example writing five instead of six minutes. This effect was also seen in the data presented here, so a bias cannot be excluded. This could be because the analysis of the nonrespondents showed that the data used in this article was gained from people who were older than the average traveler on the tramline. However, this investigation showed that perceived wait time decreased and this decrease was stable even after 16 months.

In the before situation-without displays-people believed that they had to wait at the stop for an average of 6.3 minutes. After the implementation of the real-time displays, the same people indicated that they waited an average of 5.0 minutes. How can this effect be explained? One possible explanation is that wait time for public transport is considered negative and wait time is perceived as longer than any other part of journey (Li 2003). It is, therefore, considered unused or wasted time. Further, the traveler is exposed to an unfulfilled goal; he or she has not arrived at the final destination. Finally, an unpredictable setting is expected to result in a longer perceived journey time. Li (2003) called this aspect expectancy. These effects in combination cause discomfort and dissatisfaction that lead to the overestimation of the traveler's temporal judgment. What are the effects, then, of displays that show, quite reliably, the amount of time left until the next departure?

First, the actual wait time may decrease since people arrive at the tram stop closer to the departure time. The provision of real-time information, also by the SMS information service or the Internet travel planner allows people to plan their trips more effectively. Another possibility for decreasing actual wait times is that people may simply walk by the stop, see that there are still several minutes until tram 
departure, and decide to use the remaining time to do something else. Whether this might be applied in this case cannot be concluded from the presented data. Second, it is possible that people may arrive at the stop in the same way as before, but due to the displays, the time spent waiting seems shorter. Thus, perceived wait time decreases. Causes for this might be that the enhanced predictability through the reliable information reduces uncertainty and enhances the experience of being in control of the situation. Hence, the traveler's mood is influenced positively and a good mood allows subjective time to pass faster. Another aspect can be that the display installation enhances the traveling environment by providing higher comfort, which also according to Li (2003), reduces perceived wait time.

What are 1.3 minutes of saved wait time worth in money? To put a value on wait time, several studies were conducted. Wardman (2001) summarized PT values of time cited from a study done in the Netherlands in 1999: The Dutch value of IVT (In-Vehicle-Traveltime) for commuters with respect to buses or trams is reported as 9.93 guilders (EUR 4.51/USD 5.40) per hour. Further, the IVT value of waiting for urban buses is 1.59 guilders/hr and for subway, 1.17 guilders/hr. The overall IVT value of waiting is 1.70 . If, as in our case, the perceived wait time decreased by 1.3 minutes, this would be worth 0.37 guilders ( $1.3 \mathrm{~min} * 9.93$ guilders/60minutes * 1.70). This means that one could raise ticket prices by EUR 0.16 ( 1 Euro $=2.20371$ Guilders) or USD 0.19 without losing passengers or one can gain passengers while prices remain constant. To calculate the amount of expected traveler increase, the concept of travel time elasticities can be applied. Elasticities are defined as the percentage change in consumption of a good caused by a 1 percent change in its price or other characteristics. For example, a PT service elasticity is defined as the percentage change in ridership resulting from each 1 percent change in service, such as frequency. A negative sign indicates that the effect operates in the opposite direction from the cause (Victoria Transport Policy Institute 2005; Litman 2004).

Perceived wait time at stops was reduced by 20 percent. On average, we assume the total travel time (walk time, wait time, and IVT) of an urban transit trip to be 45 minutes. Thus, the displays caused a decreased travel time of 2.88 percent (1.3minutes/45minutes). Each 1 percent in reduced travel time causes a 0.8 percent increase in ridership if we use an average travel time elasticity of -0.8 which is recommended by Mackie et al. (2003). That means that in our case, a widespread real-time information system could theoretically cause an increase in ridership of about 2.3 percent. 
Cost for the real-time at-stop information on tram line 15 was about EUR 200.000 (approximately USD 240.000). An internal calculation at HTM showed that a 20 percent increase in service frequency on this tram line to 8-minute headways, which would lead to a similarly reduced perceived wait time as was achieved by the displays, would cost EUR 1.1 million (USD 1.32 million) (Vermeulen and Dziekan 2005). Thus, real-time information seems to be a worthwhile investment.

The experience of security at the stops was not positively influenced by the new displays. In fact, the security experience in this sample was nearly constant. Reasons for this unexpected result could be gleaned from the methodology. This factor was not controlled in that the questionnaire was not completed in direct relation to behavior (meaning directly in the situation at the stop when the security was perceived), which could have led to biases. This bias could possibly also have influenced all other variables measured in this questionnaire, which was not completed directly in the immediate situation in question. Further, the way in which the security question was worded ["Which grade ( $1=$ very bad to $10=$ very good) would you give to your boarding stop regarding perceived security?"] may have led respondents to mistakenly consider other aspects of security (e.g., lighting). That is, the question did not specifically ask if the presence of real-time displays changed the feeling of security and since this is not an obvious contributor to perceived security, it may have been overlooked.

That the questionnaires were not filled in with direct relation to the behavior could also be a reason why ease-of-use values did not show any changes. On one hand, people might have misinterpreted or overanalyzed the question. In that case, the method itself to measure ease of use must be revised. On the other hand, the values in the before test were already so positive that a ceiling effect might be observed here. Thus, other methods, such as comparing traveler numbers, must be used to evaluate the effects. But in this case, a comparison of traveler numbers is not useful because many people have been moving into the newly built living quarters along line 15 . So, the rising traveler numbers cannot be based solely on the real-time information system. It also might be that ease of use does not play such a salient role in the experience of the travel chain. There might be other factors, such as habits (Aarts 1996; Verplanken, Aarts, and van Knippenberg 1997), former experiences, or attitudes toward PT that influence the experience of the cognitive effort of using a PT system.

The majority of the respondents looked at the real-time information displays at the stops. However, the reliability of the displays was perceived as unsatisfactory. 
Real-time information is calculated by a central computer that receives position information from the trams every 20 seconds. Potential sources for errors in the information include: problems with the GPS units in the trams, problems with sending and receiving the radio signals, and a deficient calculation algorithm. Here, the PT agency should put more effort into winning and preserving its customers' trust in the system by assuring that the system always works reliably, which was not the case in the starting phase of the project. Otherwise, all positive effects of this measurement will be neutralized or may even make the travelers more worried about the reliability of the information provided.

The design solution in which displays were perpendicular to the tracks and separate from the shelter was preferred. The perpendicular position allows passengers to read the displays, even from within the arriving vehicle. This offers the future possibility of receiving information about service connections and transfer options at each stop. Passengers could further benefit by learning more about the service which they might previously have been unaware. The position separate from the shelter might have received a positive response since it can be seen from far away when approaching the stop.

The main result, that real-time information displays at stops reduce the perceived wait time significantly, can be generalized more fully to stops of trams and trains with headways of about 10 minutes. Buses tend to have poor schedule adherence, and thus the importance of such displays, by reducing uncertainty, may be even higher. The same might be true for lower frequency tram or bus lines; here, the information about the next departure is even more important than for lines with short headways

Further, the result that placement of displays perpendicular to tracks is the most customer-friendly variant can be seen as proof of the design solution that was already adopted by most of the systems in metropolitan areas around the world. One further recommendation is that the displays should be visible from all sides, even for people just passing by, for example pedestrians or motorists. In that way, displays play a positive role for marketing and communicating the service offered by PT. New technologies offer an added value to the customer, especially psychologically, and have the potential to change their behavior and contribute to solving mobility problems. 


\section{Acknowledgments}

The authors would like to thank HTM for providing resources for this study. Further, Vägverket (the Swedish Road Administration) and Banverket (the Swedish Rail Administration) supported this work through financing the research project "Behavioural Response to IT-Based Traveller Information in Public Transport." Thanks also to the reviewers for their valuable comments on the manuscript and to Johanna S. Weinstock for language corrections.

\section{References}

Aarts, Henk. 1996. Habits and decision making: The case of travel mode choice. Katholieke Universiteit Nijmegen, Nijmegen.

BMBF. 2002. Mobility in conurbations-First results. Bonn: Federal Ministry of Education and Research (BMBF).

Consortium Infopolis. 1999. Needs of travellers: An analysis based on the study of their tasks and activities. No. WP 3.2 / DEL 3 / 1999. Brussels: Commission of the EC.

Coogan, Matthew A. 2003. Recent developments in integrated passenger information systems in North America. Paper presented at the 3rd UITP Conference on Travel Information, Gothenburg/Sweden.

Dziekan, Katrin. 2004. Customer perceptions and behavioural responses to ITbased public transport information-Literature review and what the experts say (No. TRITA-INFRA 04-012). Stockholm: Royal Institute of Technology Stockholm.

Dziekan, Katrin, and Arjan Vermeulen. 2004. The added value of real-time information and effects to customer behaviour-A before-after study of the implementation of a new real-time information system. Project Report. Stockholm/ The Hague: KTH/HTM.

GoTiC. 2002. Effects of real-time information in Gothenburg. Research Report No.

19. Gothenburg Transport Information Centre.

Infopolis2. 1998. Review of current passenger information systems (Deliverable 1): Commission of the European Community. Available at: http://www. ul.ie/ infopolis/library/del/del1.html (2005-10-19). 
Intermobil. 2002. Leitprojekt intermobil Region Dresden -Meilensteinbericht $M$ 500/3 - AP 551 - Akzeptanz- und Wirkungsanalyse der im AP 500 entwickelten Komponenten des Mobilitätsmanagements. Dresden: ISUP.

Karlsson, Mari Anne. 1996. User requirements elicitation. A framework for the study of the relation between user and artefact. Unpublished Doctoral thesis. Chalmers University of Technology, Göteborg, Gothenburg.

Karlsson, Mari Anne. 1997. Users on public transport and new information technology (Deliverable: Quartet Plus INFO 1. Field Trials and User Studies). Göteborg: Department of Consumer Technology, Chalmers University of Technology.

Kronborg, Peter, Anders Lindkvist, and Eva Schelin. 2002. Fungera transportinformatik i praktiken? 14 fallstudier i syfte att undvika misstag i framtiden. No. 2002:18. Stockholm: TFK (Institut för transportforskning).

Lehtonen, Mikko, and Risto Kulmala. 2001. The benefits of a pilot implementation of public transport signal priorities and real-time passenger information. Paper presented at the InformNorden International Conference, Tampere, Finland.

$\mathrm{Li}$, Yuen-Wah. 2003. Evaluating the urban commute experience: A time perception approach. Journal of Public Transportation 6(4): 41-67.

Litman, Todd. 2004. Transit price elasticities and cross-elasticities. Journal of Public Transportation 7(2): 37-58.

Mackie, P. J., A. S. Fowkes, M. Wardman, G. Whelan, J. Nellthorp, and J. Bates. 2003. Value of travel time savings in The UK. Summary Report. Leeds: Report to Department of Transportation.

Stradling, Steven G. 2002. Transport user needs and marketing public transport. Municipal Engineer 151: 1. Special Issue on Sustainable Transport Policy.

Wardman, Mark. 2001. Public transport values of time. Unpublished manuscript, Leeds.

Wardman, Mark, Julian Hine, and Steven G. Stradling. 2001. Interchange and travel choice. Vol. 1. Edinburgh: Scottish Executive Central Research Unit.

Vermeulen, Arjan, and M. R. de Jong. 2003. Mobile information-Real-time travel information in practice. Verkeerskunde 1: 46-49. 
Vermeulen, Arjan, and Katrin Dziekan. 2005. The added value of real-time information and effects to customer behaviour. Paper presented at the InformNorden International Conference, Reykjavik.

Verplanken, Bas, Henk Aarts, and Ad van Knippenberg. 1997. Habit, information acquisition, and the process of making travel mode choice. European Journal of Social Psychology 27: 539-560.

Victoria Transport Policy Institute. 2005. Transportation elasticities, 2005. Available at: http://www.vtpi.org/tdm/tdm11.htm (2005-10-19).

Yeung, Tony. 2004. Editorial to "Using IT tools to improve service." Public Transportation International 53(6): 2-3.

\section{About the Authors}

KATRIN DZIEKAN (katrin@infra.kth.se) is a scientific researcher at the Royal Institute of Technology, Department Transportation and Logistics, Stockholm, Sweden. Her main research field is user perspective on orientation and information aspects in public transport systems. Her other interests are psychological aspects in public transport, travel mode choice, public transport marketing, and mobility needs.

ARJAN Vermeulen (a.vermeulen@htm.net) is head of the Rail Department at HTM, the public transport operator in the Hague, the Netherlands. He is responsible for the total process of timetable making, policy development, and the financial administration of the Rail Division. 
Journal of Public Transportation, Vol. 9, No. 1, 2006 


\title{
Transit Network Sensitivity Analysis
}

\author{
Young-Jae Lee, Morgan State University
}

\begin{abstract}
Transit network conditions change everyday. While those changes should be considered for modifying a transit network, formulating and optimizing the whole transit network may be a costly, difficult task.

This article uses a developed transit network design model to examine how optimal transit networks should be developed based on changes in input elements of the transit network. Three major inputs-demand, travel speed, and transfer penalty-are chosen for the sensitivity analysis. Different optimal transit networks and their characteristics are generated, and the relationship between inputs and outputs is discussed. Using the sensitivity analysis, three typical transit networks-transferoriented transit, transfer-avoidance transit, and directly-connected transit-are introduced. Optimal types of transit networks are suggested based on transit network situations.
\end{abstract}

\section{Introduction}

It is not easy to design an optimal transit network because of complexity in formulation and optimization. Although current techniques of optimization enable operators to design more efficient transit networks, optimizing whole networks is extremely costly and presents difficulties in implementing changes.

The situation around the transit network changes everyday. Although those changes appear small, after a certain period of time they can become big enough 
to alter the transit network. However, designing a totally new transit network is not easy because of the complexity of the optimization process and the users' ability to adapt to a totally new transit network. Thus, rather than designing a new transit network, in many situations modifying an existing one is a better alternative. In modifying a transit network, it is important to understand the relationship between transit network design inputs and outputs. To produce outputs using different inputs for the transit network, it is necessary to build a model to generate a transit network. In this research, Lee's model (Lee 1998; Lee and Vuchic 2005) is used.

With Lee's model, first basic network inputs are applied. Then, to pursue sensitivity analysis, different inputs are used to compare the outputs, so the relationship between inputs and outputs can be analyzed. Finally, using the results of the sensitivity analysis, three typical types of the transit networks are developed.

\section{The Model for the Transit Network Design}

Much research has been done to improve transit network design. Numerous scholars, including Newell (1979) and Baaj and Mahmassani (1991), have pointed out that traditional mathematical programming has difficulties in generating an optimal transit network due to nonlinearity and nonconvexity of the model, combinatorial explosion, multiobjective nature, and spatial layout of routes. With the improvement of search algorithms and computer technology, important heuristic research has been done (Hasselström 1981; Baaj and Mahmassani 1991; Shih, Mahmassani, and Baaj 1998; Ceder and Israeli 1998; Pattnaik, Mohan, and Tom 1998; Chien, Yang, and Hou 2001). All of these studies are based on the combinatorial search approach.

One key point of the combinatorial approach is efficient generation of sample spaces, which are candidate routes and candidate sets of routes. Depending on the generated sample spaces, the optimality of the results is basically decided, even if an improvement procedure follows. Also, the number of generated candidate routes and candidate sets of routes are critical in this method. If the numbers are too large, then this method becomes close to the all-enumeration method. If they are too small, it is hard to generate good routes and sets of routes for the sample spaces. Thus, this approach tends to rely on the network designer's knowledge to obtain a good simplified sample space. Also, consistency and generalization of the network designer's knowledge are required. Another key point is the flexibility of 
the methodology in respect to handling constraints. Although the combinatorial search approach may yield good results with given fixed inputs, it is not flexible enough to include certain dynamic inputs, particularly those such as variable transit demand.

Lee's model uses the iterative approach to solving the transit network design problem. This approach is flexible enough to deal with dynamic characteristics of transit network design. To execute this methodology, the computer software TRANED (TRAnsit NEtwork Designer) was programmed with C++.

\section{Algorithm of the TRANED}

Unlike auto travel, which increases auto travel time with increased auto travel demand due to congestion, increased transit travel demand decreases transit travel time due to the higher service frequency. However, to have more transit riders under fixed transit demand, circuitous routing is unavoidable. Circuitous routing results from a trade-off relationship between in-vehicle travel time and waiting time in a transit network. The methodology of this research is based on the "concentration of flow" concept, which was introduced and used by Rea (1971) and Hasselström (1981), although they limited its usage to the realization and applications as mentioned.

The iterative approach in this article looks for the minimum total travel time network starting from generating the minimum in-vehicle travel time network. The transit network is gradually improved by increasing in-vehicle travel time while decreasing waiting time. This algorithm consists of three major steps: generation of an initial network, assignment, and network improvement. They are followed by a supporting step, network analysis. These steps are iterated until the optimal transit network is generated, as shown in Figure 1. The generated optimal transit network provides direct connections to major travel flows, while also providing shorter waiting times to minor travel flows by generating circuitous travel paths.

The first step involves generating the initial network with the minimum number of routes using the shortest path algorithm (Dijkstra 1959; Whiting and Hillier 1960; Dantzig 1967). This step provides minimum in-vehicle travel time paths to all origin-destination pairs. For this procedure, the shortest paths for all origin-destination pairs are generated; included paths are then eliminated to avoid unnecessary overlapping paths.

The second step repeats the transit assignment procedure, which concentrates transit travel flow to certain routes. This procedure allows higher frequencies of 


\section{Figure 1. Final Procedure for Transit Network Design for the Basic TRANED Model}

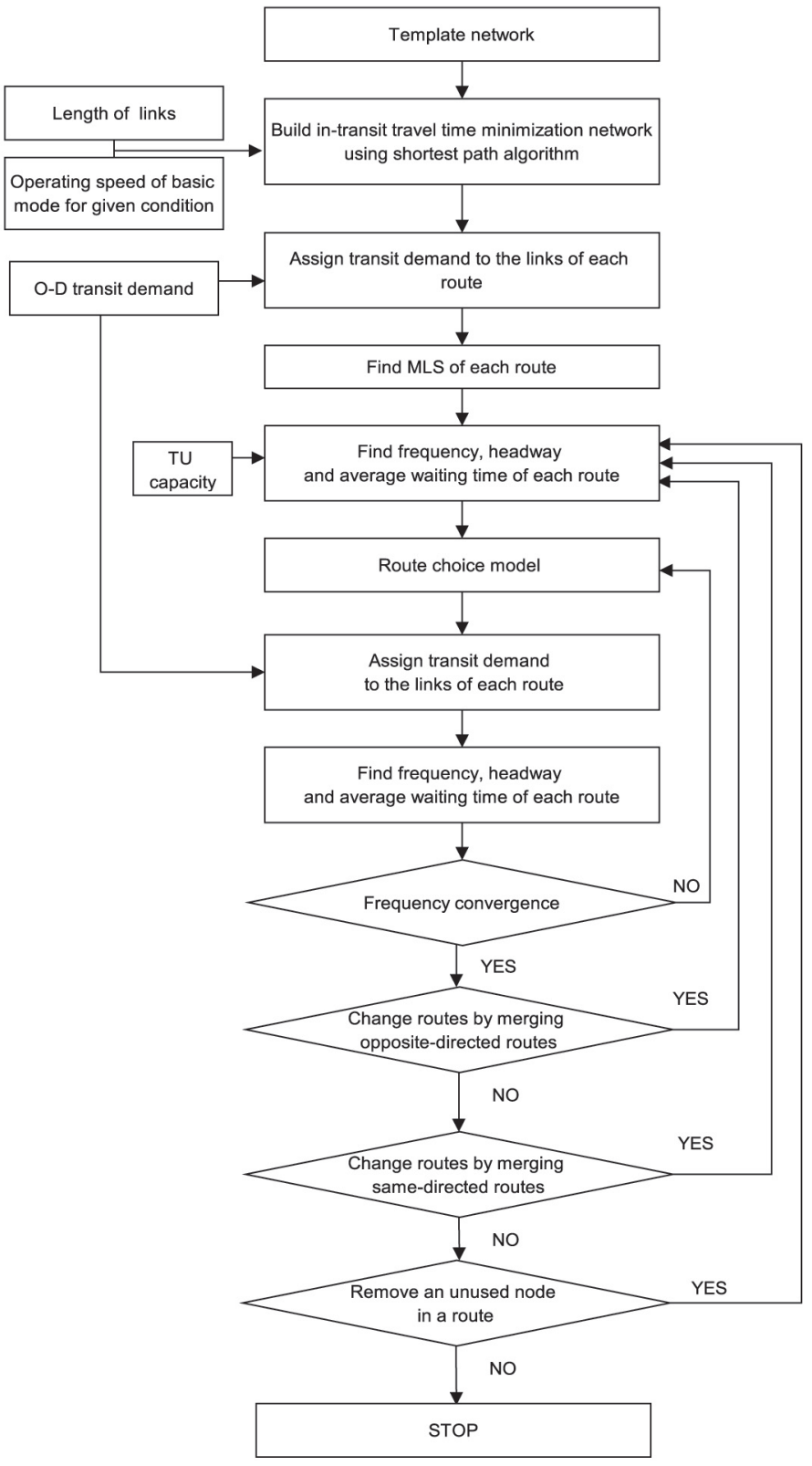


certain routes and shorter total travel time. As a result, less efficient routes are eliminated from the network.

The third step improves the transit network by changing the alignments of routes. After building an initial network and adjusting it to assignment procedure, some alignment changes of certain routes for the improvement of the network should be considered for reducing users' travel times. After stabilizing frequencies of routes in the transit network through repeated assignment procedures, routes are reviewed and alignments are changed where necessary. Less frequent routes require longer waiting times that cause longer travel times so they would be considered first. Since the network consists of selected routes, routes in Baaj and Mahmassani's initial network may need to be split and branches changed in addition to merging routes (1991). However, the procedure in this analysis merges routes and removes unused nodes for network improvements, because the initial network of this study starts from all shortest travel time routes.

There are two cases for merging routes. One involves merging routes that have shared trucks and same-directed branches; the other has shared trucks and opposite-directed branches. If branches of two routes go from the same station of the shared trunk section, it is called same-directed branches. If branches of two routes go from the different stations of the shared trunk section, it is referred to as opposite-directed branches.

Network analysis is the supporting step to generate outputs resulting from the above steps. The outputs of each step, such as number of routes, total travel time, and frequency of routes, are compared to those of the previous step.

The results of this procedure were generated and compared with other research (Mandle 1979; Baaj and Mahmassani 1991) to prove the validation of the methodology (Lee 1998). The results show that transit networks generated by TRANED generally require less travel time for users.

This basic model is simple; however, because of the flexibility of the mathematical programming of the iterative approach, this methodology can add various realistic constraints to the basic model. Additional constraints to those in the basic model are operational and financial limitations, coordination with existing service (intermodal coordination), express service, schedule information for users, and variable transit demand. 


\section{Inputs and Outputs of the Transit Network}

To generate a transit network using Lee's model, input elements for the model required are as follows:

- Template network (basic network with links and nodes);

- Origin-destination travel demand;

- Distance or in-vehicle travel time on each link by mode;

- Transit unit (TU) capacity of given mode;

- Relative weight for waiting time compared to in-vehicle travel time;

- Transfer penalty; and

- Relative weight for transfer time compared to in-vehicle travel time.

For the purpose of analyzing the network generated by TRANED, the following network characteristics are also computed by TRANED in addition to the basic output-network configuration and frequencies of routes:

- Network configuration or route configurations [-];

- Frequencies of routes [vehicle/h];

- Total in-vehicle travel time in the network [person-minutes/h];

- Total waiting time in the network [prs-min/h];

- Total transfer time in the network [prs-min/h];

- Total transfer penalties in the network [prs-min/h];

- Total travel time in the network [prs-min/h];

- Total travel time except in-vehicle travel time [prs-min/h];

- Travel demand without transfer [prs];

- Travel demand requiring transfer [prs];

- Total travel demand [prs];

- Degree of circuity [\%];

- Number of routes [-];

- Total route length in the network $[\mathrm{km}]$;

- Average route length $[\mathrm{km}]$; and

- Total vehicle operational time in the network [veh-min/h]. 
Most of the outputs are self-explanatory, but some require additional explanation. The degree of circuity is the parameter showing the indirectness of travel. There are two types of circuities: physical circuity and time circuity. While physical circuity represents circuity of routes, time circuity represents circuity of travel. The main differences between the two are transfer time and penalty. While physical circuity does not include transfer time and penalty as extra costs, time circuity considers them as extra costs due to the indirectness of a route. Time circuity, used in this study, is the ratio of the extra travel time after boarding a transit vehicle due to the indirectness of routes, possible transfer time, and transfer penalties to the shortest in-vehicle travel time (equation 1). Degree of circuity in the network is the average of an individual user's degree of circuity.

where:

$$
\mathrm{DOC}[\%]=100 \cdot \frac{\Delta t_{i}+t_{t}+p}{\min t_{i}},
$$

$\Delta t_{i} \quad$ represents additional in-vehicle travel time (difference between real in-vehicle travel time and in-vehicle travel time of shortest path)

$t_{i} \quad$ equals transfer time

$p \quad$ represents transfer penalty

$\min t_{i} \quad$ is in-vehicle travel time of shortest path

Total vehicle operational time in the network, which is the accumulation of the vehicle operating time in the network, is calculated as follows. (The 2 in the equation means two-directional service, which is conventional in most transit service.) where:

$$
\text { Total vehicle operational time }(\mathrm{TOT})=2 \sum_{k} f_{k} \cdot l_{k},
$$

$k \quad$ is the route number

$f$ equals frequency

$l$ is the length of route in minutes or operating time for one direction 


\section{Basic Network}

The network and other inputs to be used in this example come from Rea's study (1971), although the demand and the length of links are modified to provide more realistic results. The configuration of the network and basic inputs are shown in the Figure 2.

As other input elements for the model, TU capacity, transfer penalty, and relative weight for waiting time and transfer time must be defined. For TU capacity, 60 spaces, used in Rea's paper, is also applied. For simplicity, no transfer penalty is applied for the basic case. That means there are no additional fares, additional access times, and other qualitative inconveniences related to transfers. As a relative weight of the waiting time to in-vehicle travel time, the ratio of 1 is used, which means the values of waiting time and in-vehicle travel time are the same for the simplicity as well.

\section{Figure 2. Inputs for the Basic Case}

\section{(a) Template network}

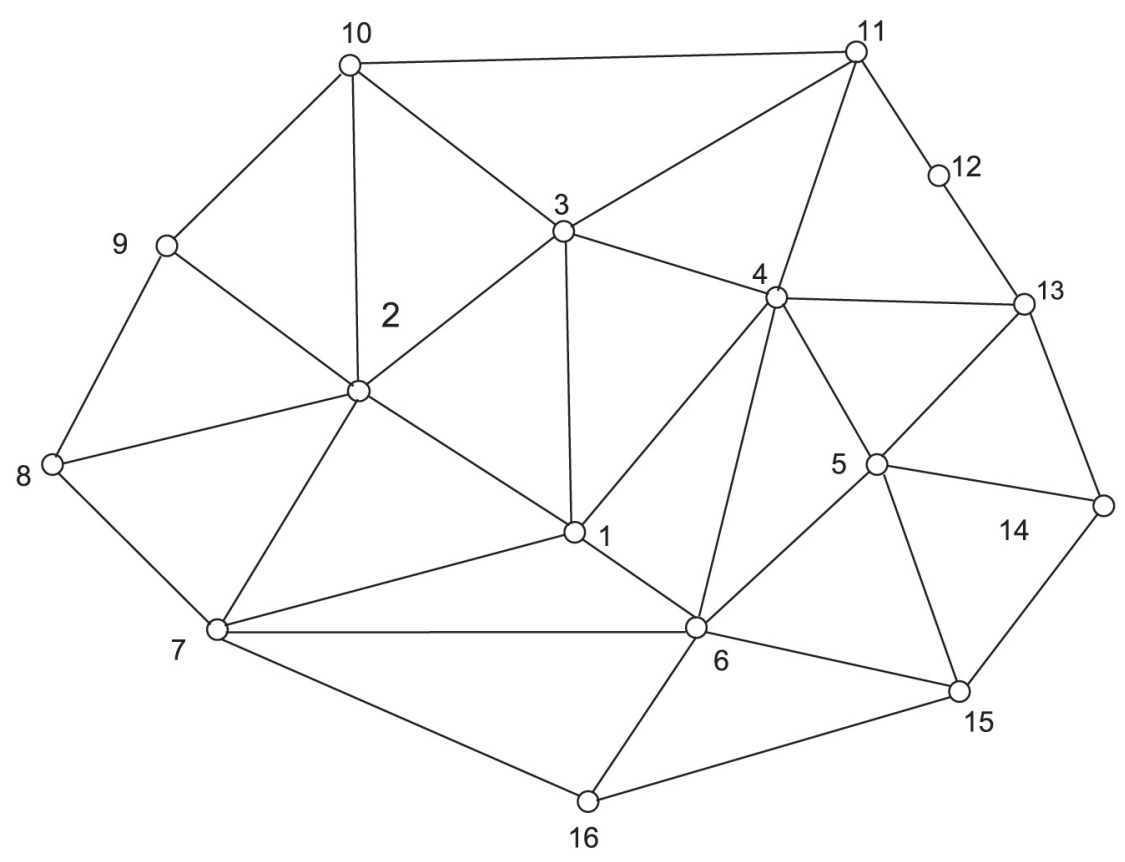




\section{(b) Travel time of each link}

(min)
\begin{tabular}{|l|l|l|l|l|l|l|l|l|l|l|l|l|l|l|l|l|}
\hline Node & $\# 1$ & $\# 2$ & $\# 3$ & $\# 4$ & $\# 5$ & $\# 6$ & $\# 7$ & $\# 8$ & $\# 9$ & $\# 10$ & $\# 11$ & $\# 12$ & $\# 13$ & $\# 14$ & $\# 15$ & $\# 16$ \\
\hline$\# 1$ & 0 & 2.36 & 2.78 & 2.36 & 0 & 2.23 & 2.38 & 0 & 0 & 0 & 0 & 0 & 0 & 0 & 0 & 0 \\
\hline$\# 2$ & 2.36 & 0 & 2.00 & 0 & 0 & 0 & 2.84 & 2.48 & 2.00 & 2.22 & 0 & 0 & 0 & 0 & 0 & 0 \\
\hline$\# 3$ & 2.78 & 2.00 & 0 & 2.00 & 0 & 0 & 0 & 0 & 0 & 2.00 & 2.48 & 0 & 0 & 0 & 0 & 0 \\
\hline$\# 4$ & 2.36 & 0 & 2.00 & 0 & 2.00 & 2.84 & 0 & 0 & 0 & 0 & 2.28 & 0 & 2.78 & 0 & 0 & 0 \\
\hline$\# 5$ & 0 & 0 & 0 & 2.00 & 0 & 2.00 & 0 & 0 & 0 & 0 & 0 & 0 & 2.36 & 2.98 & 2.28 & 0 \\
\hline$\# 6$ & 1.12 & 0 & 0 & 2.84 & 2.00 & 0 & 3.34 & 0 & 0 & 0 & 0 & 0 & 0 & 0 & 2.48 & 2.00 \\
\hline$\# 7$ & 2.48 & 2.84 & 0 & 0 & 0 & 3.34 & 0 & 2.36 & 0 & 0 & 0 & 0 & 0 & 0 & 0 & 2.78 \\
\hline$\# 8$ & 0 & 2.48 & 0 & 0 & 0 & 0 & 2.36 & 0 & 1.96 & 0 & 0 & 0 & 0 & 0 & 0 & 0 \\
\hline$\# 9$ & 0 & 2.00 & 0 & 0 & 0 & 0 & 0 & 2.28 & 0 & 2.00 & 0 & 0 & 0 & 0 & 0 & 0 \\
\hline$\# 10$ & 0 & 2.22 & 2.00 & 0 & 0 & 0 & 0 & 0 & 2.00 & 0 & 3.62 & 0 & 0 & 0 & 0 & 0 \\
\hline$\# 11$ & 0 & 0 & 2.48 & 2.28 & 0 & 0 & 0 & 0 & 0 & 3.62 & 0 & 1.12 & 0 & 0 & 0 & 0 \\
\hline$\# 12$ & 0 & 0 & 0 & 0 & 0 & 0 & 0 & 0 & 0 & 0 & 1.12 & 0 & 1.12 & 0 & 0 & 0 \\
\hline$\# 13$ & 0 & 0 & 0 & 2.78 & 2.36 & 0 & 0 & 0 & 0 & 0 & 0 & 1.12 & 0 & 2.98 & 0 & 0 \\
\hline$\# 14$ & 0 & 0 & 0 & 0 & 2.98 & 0 & 0 & 0 & 0 & 0 & 0 & 0 & 2.98 & 0 & 2.48 & 0 \\
\hline$\# 15$ & 0 & 0 & 0 & 0 & 2.28 & 2.48 & 0 & 0 & 0 & 0 & 0 & 0 & 0 & 2.48 & 0 & 3.38 \\
\hline$\# 16$ & 0 & 0 & 0 & 0 & 0 & 2.00 & 2.78 & 0 & 0 & 0 & 0 & 0 & 0 & 0 & 3.38 & 0 \\
\hline
\end{tabular}

\section{(c) Origin-destination demand}

\begin{tabular}{|l|l|l|l|l|l|l|l|l|l|l|l|l|l|l|l|l|}
\hline Node & $\# 1$ & $\# 2$ & $\# 3$ & $\# 4$ & $\# 5$ & $\# 6$ & $\# 7$ & $\# ~ 8$ & $\# 9$ & $\# 10$ & $\# 11$ & $\# 12$ & $\# 13$ & $\# 14$ & $\# 15$ & $\# 16$ \\
\hline$\# 1$ & 0 & 10 & 10 & 10 & 10 & 10 & 0 & 0 & 0 & 0 & 0 & 0 & 0 & 0 & 0 & 0 \\
\hline$\# 2$ & 60 & 0 & 40 & 60 & 40 & 40 & 20 & 20 & 20 & 20 & 20 & 20 & 20 & 20 & 20 & 20 \\
\hline$\# 3$ & 60 & 40 & 0 & 60 & 40 & 40 & 20 & 20 & 20 & 20 & 20 & 20 & 20 & 20 & 20 & 20 \\
\hline$\# 4$ & 10 & 10 & 10 & 0 & 10 & 10 & 0 & 0 & 0 & 0 & 0 & 0 & 0 & 0 & 0 & 0 \\
\hline$\# 5$ & 60 & 40 & 40 & 6 & 0 & 40 & 20 & 20 & 20 & 20 & 20 & 20 & 20 & 20 & 20 & 20 \\
\hline$\# 6$ & 60 & 40 & 40 & 60 & 40 & 0 & 20 & 20 & 20 & 20 & 20 & 20 & 20 & 20 & 20 & 20 \\
\hline$\# 7$ & 80 & 20 & 20 & 80 & 20 & 20 & 0 & 10 & 10 & 10 & 10 & 10 & 10 & 10 & 10 & 10 \\
\hline$\# 8$ & 80 & 20 & 20 & 80 & 20 & 20 & 10 & 0 & 10 & 10 & 10 & 10 & 10 & 10 & 10 & 10 \\
\hline$\# 9$ & 80 & 20 & 20 & 80 & 20 & 20 & 10 & 10 & 0 & 10 & 10 & 10 & 10 & 10 & 10 & 10 \\
\hline$\# 10$ & 80 & 20 & 20 & 80 & 20 & 20 & 10 & 10 & 10 & 0 & 10 & 10 & 10 & 10 & 10 & 10 \\
\hline$\# 11$ & 80 & 20 & 20 & 80 & 20 & 20 & 10 & 10 & 10 & 10 & 0 & 10 & 10 & 10 & 10 & 10 \\
\hline$\# 12$ & 80 & 20 & 20 & 80 & 20 & 20 & 10 & 10 & 10 & 10 & 10 & 0 & 10 & 10 & 10 & 10 \\
\hline$\# 13$ & 80 & 20 & 20 & 80 & 20 & 20 & 10 & 10 & 10 & 10 & 10 & 10 & 0 & 10 & 10 & 10 \\
\hline$\# 14$ & 80 & 20 & 20 & 80 & 20 & 20 & 10 & 10 & 10 & 10 & 10 & 10 & 10 & 0 & 10 & 10 \\
\hline$\# 15$ & 80 & 20 & 20 & 80 & 20 & 20 & 10 & 10 & 10 & 10 & 10 & 10 & 10 & 10 & 0 & 10 \\
\hline$\# 16$ & 80 & 20 & 20 & 80 & 20 & 20 & 10 & 10 & 10 & 10 & 10 & 10 & 10 & 10 & 10 & 0 \\
\hline
\end{tabular}


The TRANED solution algorithm changes the optimal transit network through iterations (Table 1).

\section{Sensitivity Analysis}

Three major input elements are used in the sensitivity analysis: demand, travel times on the links, and transfer penalties. The results depend not only on one input component but also on other input components, which means the choice of values for the basic inputs is very important. For example, depending on the size of demand, the sensitivity of another input, such as transfer penalty, can vary greatly. Depending on other given inputs, the output may be more or less sensitive for a specific input.

Because of different inputs, generated transit networks and their characteristics are fairly different. Generated networks cannot be compared directly, so their characteristics should be compared. Among outputs introduced previously, total travel time (TTT), number of routes (NOR), total route length (TRL), average route length (ARL), degree of circuity (DOC), ratio of direct demand without transfer to total transfer (DWOT), total vehicle operating length (TVOT), and some other new outputs are chosen for the comparison.

Unlike analyzing a single network, sensitivity analysis of different networks with different inputs requires adjustment of outputs for the comparison. While some outputs can be directly compared, direct comparison does not mean anything when outputs are directly dependent on inputs. For example, when transit operating speed decreases, in-vehicle travel time is surely increased regardless of the transit network configuration. Also, when transit demand increases, total travel time in the network is increased because of the increased number of passengers. In these cases, outputs should be adjusted for comparing transit networks.

To adjust direct impact of inputs to compare generated network configurations, several versions of outputs are introduced for the sensitivity analysis. These versions are created by assuming that basic inputs are applied to the transit networks generated with different inputs. For example, with all other inputs the same, doubled transit operating speed creates different optimal network configuration compared to that with the basic operating speed. Also, the network with the doubled operating speed requires about half of the total travel time due to reduced in-vehicle travel time just by itself. So, to find out the difference between two network configurations, the same operating speed (basic speed) should be applied to two differently generated networks and the outputs should be compared. 
Table 1. Outputs of the Basic Case

\section{(a) Changes in Routes of the Basic Case}

\begin{tabular}{|l|l|l|}
\hline Iteration & Procedure & Routes \\
\hline Initial & & $\# 1$ to \#28 \\
\hline 1 & Assignment & $\# 1, \# 2, \# 3, \# 5, \# 6, \# 7, \# 8, \# 9, \# 11, \# 12, \# 13, \# 14, \# 15, \# 16, \# 19, \# 23$ \\
\hline 2 & Assignment & $\# 1, \# 2, \# 3, \# 6, \# 7, \# 8, \# 11, \# 12, \# 13, \# 14, \# 16$ \\
\hline 3 & Assignment & $\# 1, \# 3, \# 6, \# 7, \# 8, \# 11, \# 12, \# 14, \# 16$ \\
\hline 4 & Assignment & $\# 1, \# 3, \# 6, \# 7, \# 8, \# 11, \# 12, \# 14$ \\
\hline 5 & Assignment & $\# 1, \# 3, \# 6, \# 7, \# 8, \# 11, \# 12, \# 14$ \\
\hline 6 & Assignment & $\# 1, \# 3, \# 6, \# 7, \# 8, \# 11, \# 12$ \\
\hline 7 & Assignment & $\# 3, \# 6, \# 7, \# 8, \# 11, \# 12$ \\
\hline 8 & Assignment & $\# 3, \# 6, \# 7, \# 8, \# 11, \# 12$ \\
\hline 9 & Assignment & $\# 3, \# 6, \# 7, \# 8, \# 11, \# 12$ \\
\hline 10 & Assignment & $\# 3, \# 6, \# 7, \# 8, \# 11, \# 12$ \\
\hline 11 & Merging & $\# 3(7-1-4-11-12-13), \# 7, \# 8, \# 11, \# 12$ \\
\hline 12 & Assignment & $\# 3(7-1-4-11-12-13), \# 7, \# 8, \# 11, \# 12$ \\
\hline 13 & Assignment & $\# 3(7-1-4-11-12-13), \# 7, \# 8, \# 11, \# 12$ \\
\hline 14 & Assignment & $\# 3(7-1-4-11-12-13), \# 7, \# 8, \# 11, \# 12$ \\
\hline 15 & Merging & $\# 3(7-1-4-11-12-13), \# 7(10-9-2-1-6-16-15-14), \# 11, \# 12$ \\
\hline 16 & Assignment & $\# 3(7-1-4-11-12-13), \# 7(10-9-2-1-6-16-15-14), \# 11, \# 12$ \\
\hline 17 & Assignment & $\# 3(7-1-4-11-12-13), \# 7(10-9-2-1-6-16-15-14), \# 11, \# 12$ \\
\hline
\end{tabular}

\section{(b) Network Characteristics of the Basic Case}

\begin{tabular}{|l|l|l|r|r|r|r|r|r|r|r|}
\hline $\begin{array}{l}\text { Iteration } \\
\text { Number }\end{array}$ & $\begin{array}{l}\text { In-vehicle } \\
\text { Travel } \\
\text { (p.-min) }\end{array}$ & $\begin{array}{l}\text { Waiting } \\
\text { Time } \\
\text { (p.-min) }\end{array}$ & $\begin{array}{l}\text { Transfer } \\
\text { Time } \\
\text { (p.-min) }\end{array}$ & $\begin{array}{l}\text { Total } \\
\text { Travel } \\
\text { Time } \\
\text { (p.-min) }\end{array}$ & $\begin{array}{l}\text { Direct } \\
\text { Demand } \\
\text { (prs/h) }\end{array}$ & $\begin{array}{l}\text { Transfer } \\
\text { Required } \\
\text { Demand } \\
\text { (prs/h) }\end{array}$ & $\begin{array}{l}\text { No. of } \\
\text { Routes }\end{array}$ & $\begin{array}{l}\text { Degree } \\
\text { of } \\
\text { Circuity } \\
(\%)\end{array}$ & $\begin{array}{l}\text { Length } \\
\text { of } \\
\text { Network } \\
\text { (km) }\end{array}$ & $\begin{array}{l}\text { Total } \\
\text { Vehicle } \\
\text { Operating } \\
\text { Time } \\
\text { (veh-min/h) }\end{array}$ \\
\hline Initial & 22577.5 & 105421.0 & 0.0 & 127998.5 & 5160 & 0 & 28 & 0.0 & 97.6 & 671.0 \\
\hline $1^{*}$ & 24805.4 & 49649.9 & 5823.3 & 80278.6 & 4180 & 980 & 16 & 35.7 & 58.0 & 789.7 \\
\hline $2^{*}$ & 25794.0 & 31214.2 & 8296.3 & 65304.5 & 3250 & 1910 & 11 & 51.0 & 41.4 & 884.3 \\
\hline $3^{*}$ & 25727.6 & 26906.2 & 8122.5 & 60756.3 & 3250 & 1910 & 9 & 49.9 & 35.4 & 825.5 \\
\hline $4^{*}$ & 25777.6 & 23919.8 & 7382.4 & 57079.8 & 3150 & 2010 & 8 & 46.9 & 31.9 & 845.2 \\
\hline $5^{*}$ & 26101.6 & 25261.9 & 7483.1 & 58846.6 & 3030 & 2130 & 8 & 48.6 & 31.9 & 853.3 \\
\hline $6^{*}$ & 26306.0 & 21824.6 & 7820.5 & 55951.1 & 2920 & 2240 & 7 & 51.2 & 28.9 & 861.2 \\
\hline $7^{*}$ & 26583.2 & 18406.0 & 8308.3 & 53297.5 & 2720 & 2440 & 6 & 54.4 & 25.1 & 864.2 \\
\hline $8^{*}$ & 26386.4 & 17973.2 & 8195.4 & 52555.0 & 2720 & 2440 & 6 & 53.2 & 25.1 & 894.6 \\
\hline $9^{*}$ & 26386.4 & 17927.1 & 8177.5 & 52491.0 & 2720 & 2440 & 6 & 53.1 & 25.1 & 898.1 \\
\hline $10^{*}$ & 26386.4 & 17973.2 & 8195.4 & 52555.0 & 2720 & 2440 & 6 & 53.2 & 25.1 & 894.6 \\
\hline $11^{* * *}$ & 26943.2 & 16514.6 & 7679.1 & 51136.9 & 2720 & 2440 & 5 & 53.3 & 21.9 & 898.7 \\
\hline $12^{*}$ & 26943.2 & 16400.9 & 7661.5 & 51005.6 & 2720 & 2440 & 5 & 53.3 & 21.9 & 882.2 \\
\hline $13^{*}$ & 26943.2 & 16447.1 & 7679.3 & 51069.6 & 2720 & 2440 & 5 & 53.3 & 21.9 & 878.7 \\
\hline $14^{*}$ & 26943.2 & 16400.9 & 7661.5 & 51005.6 & 2720 & 2440 & 5 & 53.3 & 21.9 & 882.2 \\
\hline $15^{* * *}$ & 29623.2 & 12591.4 & 6163.2 & 48377.8 & 2840 & 2320 & 4 & 58.5 & 20.5 & 1081.8 \\
\hline $16^{*}$ & 29462.4 & 13034.7 & 6352.8 & 48849.9 & 2840 & 2320 & 4 & 58.6 & 20.5 & 1012.1 \\
\hline $17^{*}$ & 29429.6 & 13087.6 & 6366.3 & 48883.5 & 2840 & 2320 & 4 & 58.5 & 20.5 & 1002.3 \\
\hline
\end{tabular}


Also, when different sizes of demand are applied for the sensitivity analysis, travel time per person or per trip (TTT/trip) is used as adjusted values for the same reason.

The adjusted versions of outputs, which are adjusted total travel time (ATTT), adjusted total vehicle operating time (ATVOT), etc, will be explained in detail with sensitivity analysis.

\section{Changes in Demand Level}

Different demand levels, which are the basic demand and the following multiples of $0.5,1.5,2,2.5$, and 3 , are applied and their results are compared, while other inputs remain the same.

Figure 3 shows the basic relationships between different sizes of demand and the outputs. As expected, in Figure 3(a), total travel time in the network (TTT) increases with the increased number of passengers, but the adjusted total travel time-I (ATTT-I) in the network decreases. As mentioned previously, the adjusted total travel time-l is defined as the value, which assumes the same demand level of the basic case but the same frequencies of the network with the different demand. As shown in the figure, the two curves cross at the same point where demand level is 100 percent, which is the basic case. A decreasing adjusted total travel time-I curve with increased demand shows increased efficiency of the transit system for users. The in-vehicle travel time/trip (IVT/trip) and other than in-vehicle travel time (waiting time and transfer time)/trip (OIVT/trip) are plotted with the secondary $\mathrm{Y}$-axis. These curves show that with increased demand, not only waiting time (WT) and transfer time (TT) decrease, which is rational and surely expected, but also in-vehicle travel time (IVT) decreases. Because both components of travel time decrease, adjusted total travel time-I decreases with increased demand. The adjusted total travel time curve-II (ATTT-II) in the figure, which is plotted with the primary $\mathrm{Y}$-axis, represents the total travel times estimated with basic demand but applied to networks generated by a range of demand. While the adjusted total travel time-I uses the frequencies of given demand, the adjusted total travel timeII uses the adjusted frequency based on the basic demand. Since the networks are generated to minimize the total travel time for each demand level, the basic case (network) with the basic demand provides the least total travel time of all cases (networks). This shows the consistency of the results generated by TRANED.

In Figure 3(b), the percentage of direct demand (DWOT), degree of circuity (DOC), and the number of routes (NOR) are plotted. While the curve for the number of 
routes uses the secondary $\mathrm{Y}$-axis, the other two curves use the primary $\mathrm{Y}$-axis. As shown, the number of routes increases with increased demand. Consequently, demand for direct trips also increases while the degree of circuity decreases with increased demand level.

In Figure 3(c), the total route length in the network (TRL), average route length (ARL), total vehicle operating time (TVOT), and adjusted total vehicle operating time (ATVOT) are analyzed. The first two results are plotted with the primary $\mathrm{Y}$-axis and the last two are plotted with the secondary $\mathrm{Y}$-axis. With the increased number of routes, the total length of network increases, while the average length of route does not decrease much. Total vehicle operating time increases with increased length of the network, and that is as expected to serve more passengers. However, its adjusted version shows the reverse result. Using the demand of the basic case, the networks generated by using increased demand actually require shorter total vehicle operating time.

An interesting and important result is analyzed in Figure 3(d). Two curves, average travel time per passenger (TTT/trip) and average vehicle operating time per passenger (TVOT/trip), are plotted with the primary and secondary $\mathrm{Y}$-axes. It was found that not only average travel time per passenger, but also average vehicle operating time per passenger decrease with increased demand level. This shows that increased transit demand offers a more efficient transit network for both users and operators.

Larger demand level results in higher frequencies, and reduces the necessity of circuitous routing and transferring. Consequently, the number of routes (NOR) increases, demand without transfer (DWOT) increases, directness of travel increases, and average total travel time per passenger and vehicle operating length per passenger decrease. From the indications above, in general, overall efficiency of the network increases as demand increases, and this verifies the commonly held assumption that the marginal cost of transit does decrease with increasing ridership.

\section{Changes in Travel Speed}

This section addresses the relationship between travel times on the links (or operating speed) and the network characteristics generated with the otherwise same inputs. To reflect different operating speeds, different travel times on the links ( 0.5 , $0.75,1,1.25,1.75$, and 2 times the basic in-vehicle travel times) are applied to the model while keeping all other inputs as before. 
Figure 3(a). Analysis with Different Demand Levels

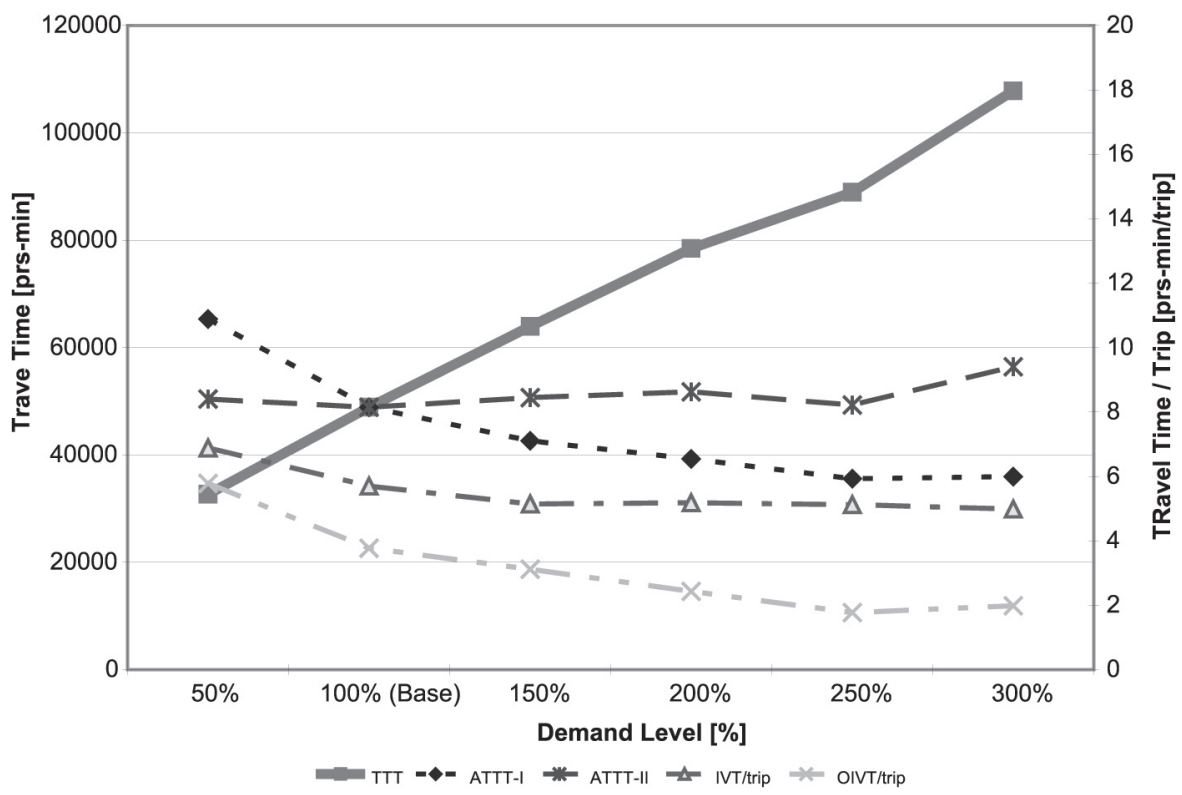

Figure 3(b)

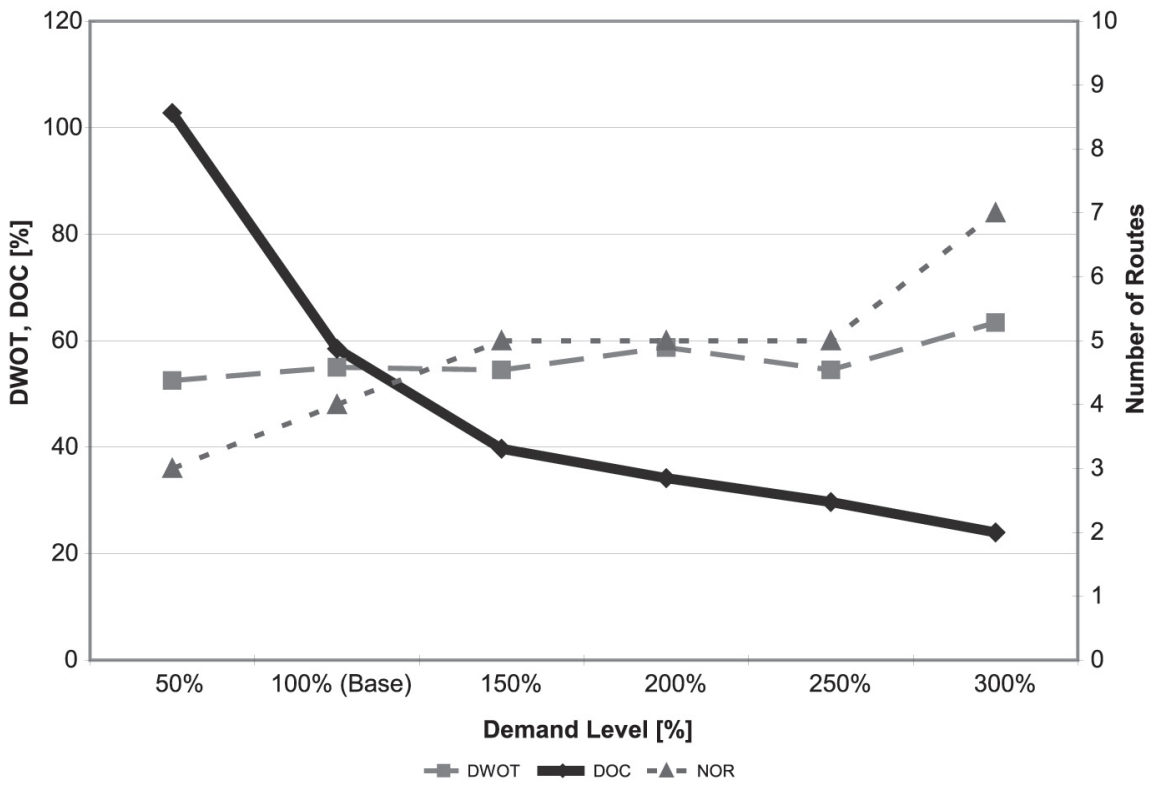


Figure 3(c)

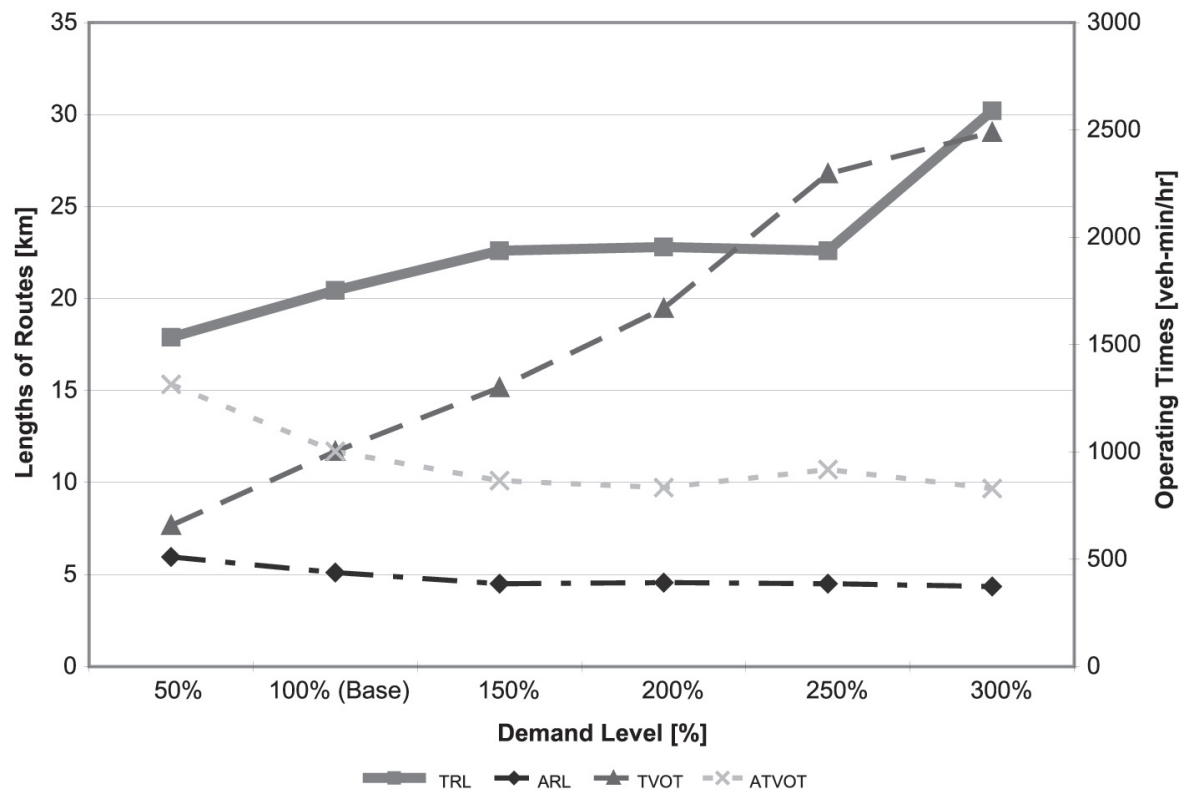

Figure 3(d)

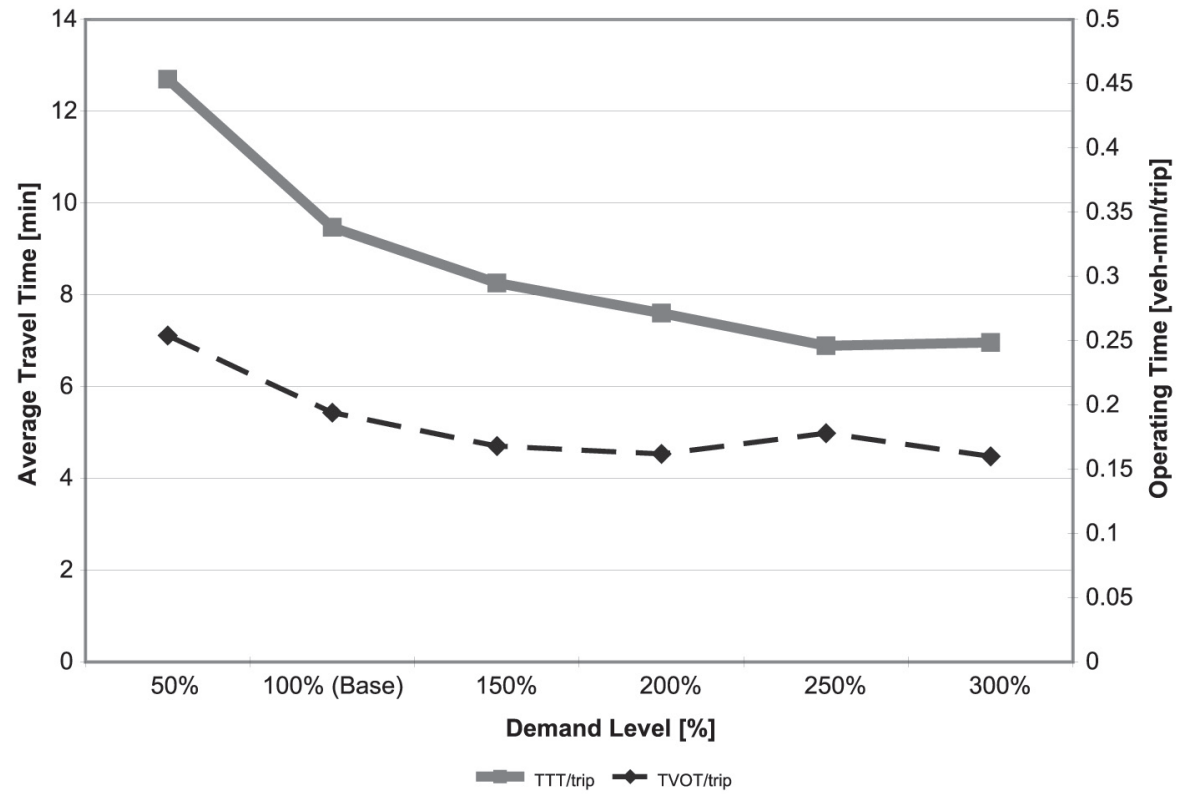


Figure 4 illustrates the basic relationships between speeds and outputs. As shown in Figure 4(a), the curve for the total travel time in the networks (TTT) obviously increases with lower operating speed and longer in-vehicle travel times on the links, as expected. As another characteristic for the network analysis, the curve for the adjusted total travel time (ATTT) is plotted in Figure 4(a), which is the total travel time using the basic operating speed with the networks generated based on the other operating speeds. Since only the network of the basic case is generated with basic in-vehicle-travel time, and the other networks are generated with other in-vehicle travel times, as plotted, the basic case has the minimum adjusted total travel time. This result shows that the networks generated with different in-vehicle travel times and their results are reliable and consistent.

Total travel time outputs, total travel time, and adjusted total travel time are plotted on the primary $\mathrm{Y}$-axis. The ratio of in-vehicle travel time to total travel time (IVT/TTT) and its adjusted version (AIVT/TTT) are plotted on the secondary Y-axis.

While the ratio of in-vehicle travel time to total travel time (IVT/TTT) increases due to increased in-vehicle travel times on the links, the ratio of adjusted in-vehicle travel time to adjusted total travel time (AIVT/TTT) decreases because of the effort to minimize in-vehicle travel time by the network generation procedure.

In Figure 4(b), the percentage of demand without transfer (DWOT) and the degree of circuity $(D O C)$ are plotted on the primary $Y$-axis, while the number of routes $(N O R)$ is plotted on the secondary $Y$-axis. Because of increased in-vehicle travel times on the links, the network provides less circuitous routing and more routes, which require less in-vehicle travel time. As expected, demand without transfer increases and the degree of circuity decreases.

Figure $4(\mathrm{c})$ shows the total route length in the network (TRL) and the average route length $(A R L)$ plotted against in-vehicle travel times. As discussed for Figure $4(b)$, to avoid longer in-vehicle travel time, more direct networks are generated with decreased operating speed. Consequently, the average route length decreases. However, because of the increased number of routes, the length of network increases moderately with increased in-vehicle travel times of the network.

The two curves in Figure 4(d) are total vehicle operating time (TVOT) plotted with the primary $\mathrm{Y}$-axis, of which the unit is vehicle- $\mathrm{min} / \mathrm{h}$ and total vehicle operating distance (TVOD) plotted with the secondary $Y$-axis, of which the unit is vehicle$\mathrm{km} / \mathrm{h}$, both plotted against in-vehicle travel times. While total vehicle operating 
Figure 4(a). Analysis with Changed In-Vehicle Travel Time or Operating Speed

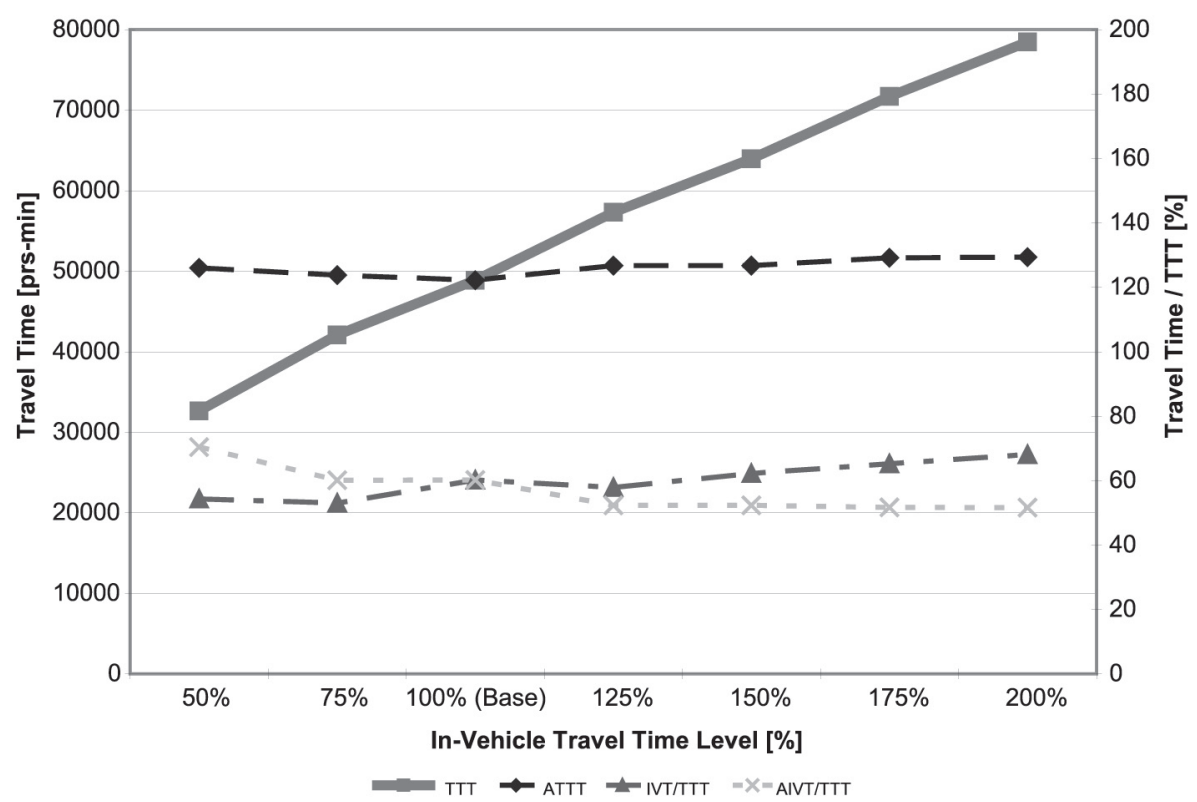

Figure 4(b)

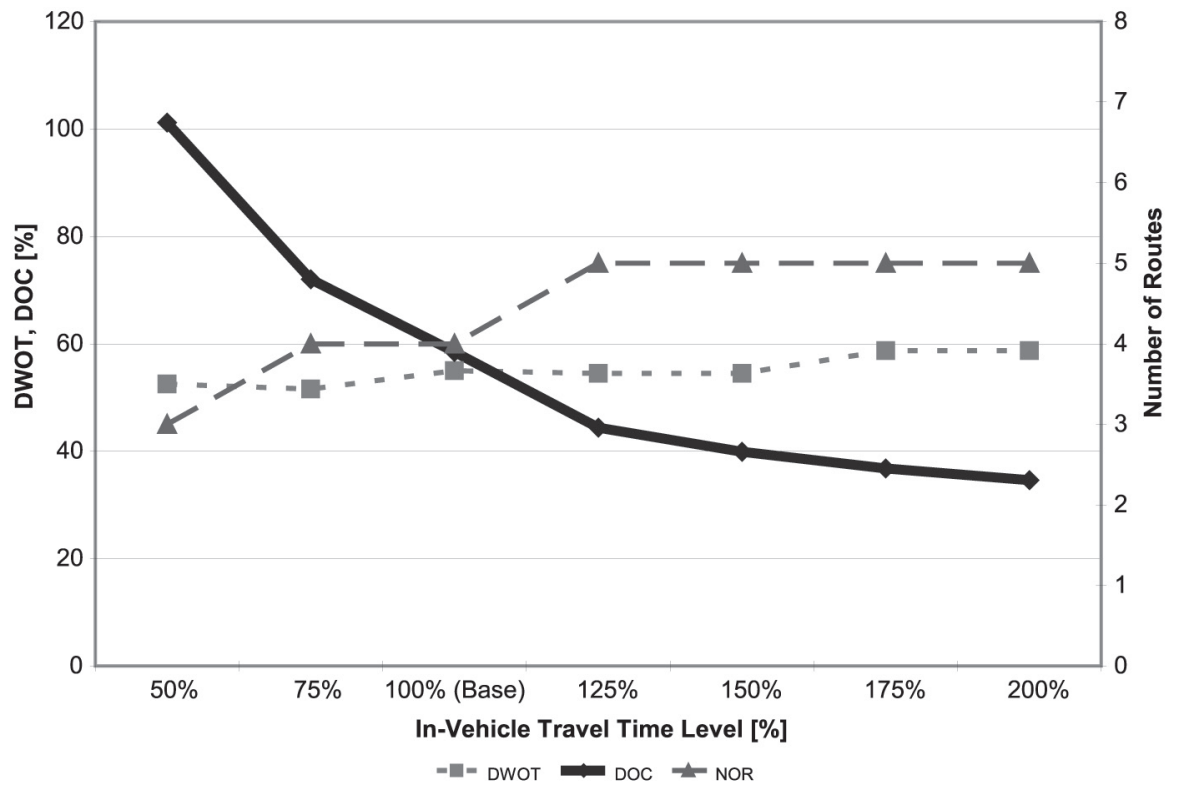


Journal of Public Transportation, Vol. 9, No. 1, 2006

Figure 4(c)

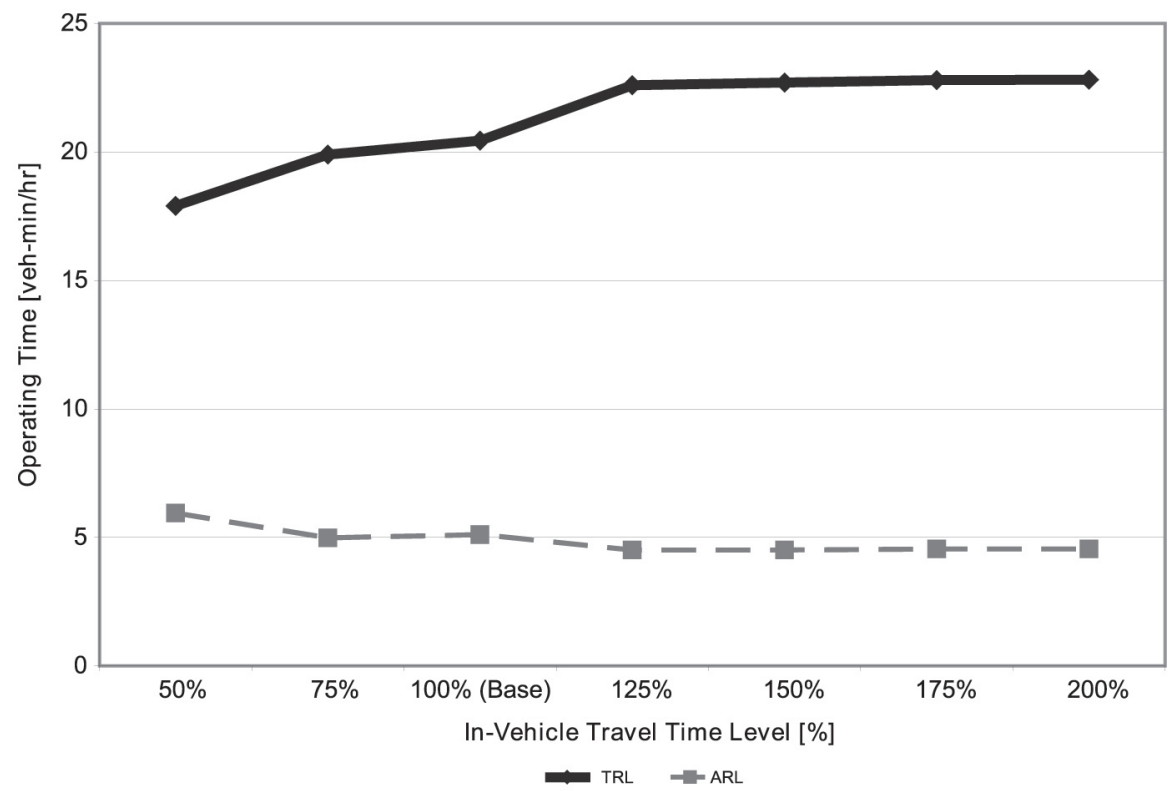

Figure 4(d)

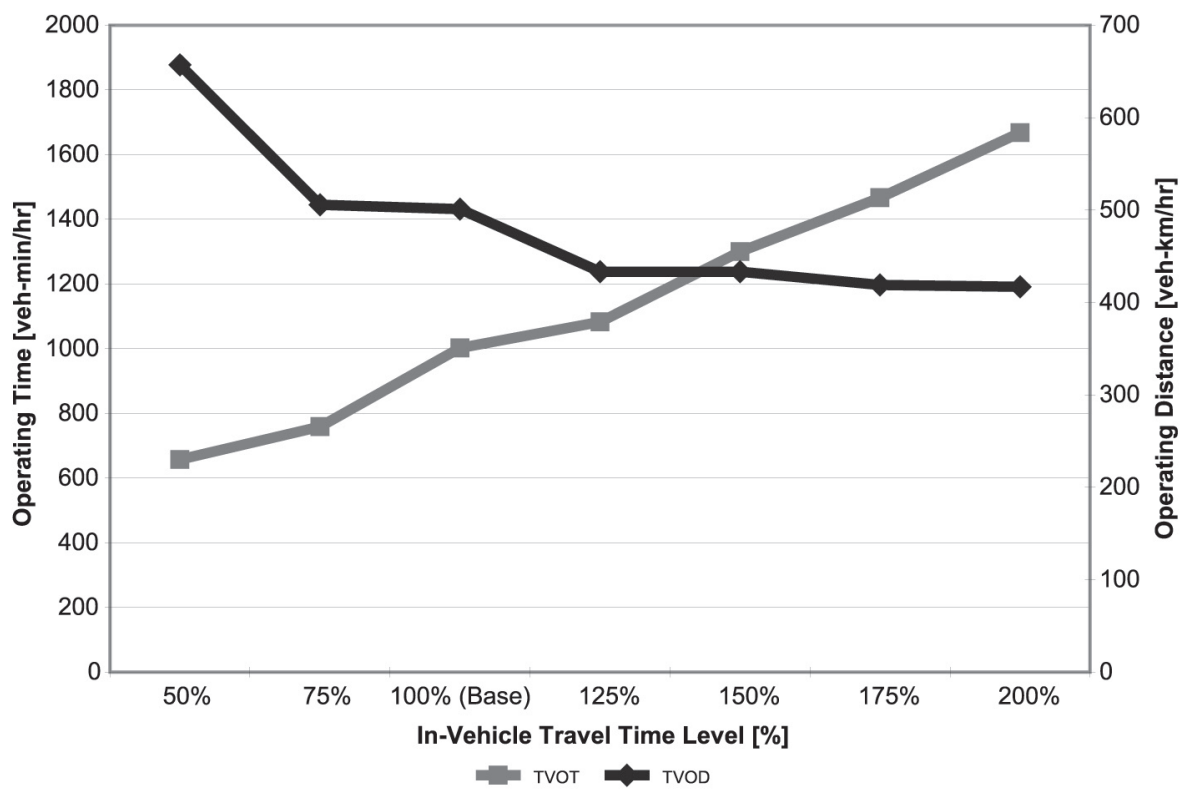


time increases due to increased link costs (in-vehicle time), because of less circuitous routing, total vehicle operating length decreases.

When in-vehicle travel time increases due to the slower speed or congestion, for users' travel time minimization, more routes with shorter length should be formed to provide more direct service.

\section{Changes in Transfer Penalties (Lower Demand Case)}

Depending on other given inputs, the output may be more or less sensitive for a specific input. Especially when the demand size is different, the results of the sensitivity analysis for the transfer penalties can vary greatly. For the sensitivity analysis for the transfer penalties, two cases-lower demand and higher demand-are discussed.

In this section, in addition to waiting time at the transfer station, additional transfer penalties are applied. These penalties can account for an additional fare, access time to a transfer station, and the inconvenience involved in transferring. They are given as equivalent minutes (10, 20, and 30 minutes) of in-vehicle travel time.

In Figure 5(a), total travel time (TTT) and its adjusted version (ATTT) are plotted with the primary $\mathrm{Y}$-axis. While the total travel time includes transfer penalties in addition to in-vehicle travel time (IVT), waiting time (WT) and transfer time $(T T)$, the adjusted version does not include transfer penalties, which means that it represents travel time only. Total travel time (TTT) increases with increased transfer penalty, except for the transfer penalty of 30 minutes, which is an inconsistent result, but within a range of acceptable error. The adjusted total travel time (ATTT) also increases with increased transfer penalty. These two curves show that not only increased transfer penalty, but also that actual travel time components cause total travel time increases. This can be explained by the fact that when the transfer penalty increases significantly, transit networks are inefficiently generated to avoid large transfer penalties.

The ratio of in-vehicle travel time to total travel time (IVT/TTT) and its adjusted version (IVT/ATTT), which does not include transfer penalty in total travel time, are plotted in Figure 5(a) against the secondary $\mathrm{Y}$-axis. With increased transfer penalty, the portion of in-vehicle travel time in the network increases. That is due to circuitous and longer routing to avoid transfers, and will be explained in detail in below.

Network characteristics are plotted in Figure 5(b). To avoid transfers and their penalties, transit networks are generated using fewer but more circuitous routes. 
Thus, both types of degree of circuity, with (DOC) and without (ADOC) taking transfer penalty into account, increase with increased transfer penalty as plotted on the primary $\mathrm{Y}$-axis. The number of routes $(N O R)$ as plotted against secondary $Y$-axis decreases with increased penalty.

Direct-trip demand without transfers (DWOT) increases with increased transfer penalty, while demand requiring transfers (DRT) decreases, as shown in Figure 5(c), as expected.

Because of circuitous routing and fewer routes to avoid both transfers and their penalties, the average route length $(A R L)$, which is plotted with the primary $Y$-axis in Figure 5(d), increases with increased transfer penalty. Although the number of routes (NOR) decreases, the total route length of the network (TRL) increases due to significantly increased average route length as plotted with the primary $\mathrm{Y}$-axis in the figure. Due to inefficient routing and service, total vehicle operating time in the network (TVOT), which is plotted with the secondary Y-axis, also increases with increased transfer penalty.

Overall, with increased transfer penalty, the transit networks in this example have fewer routes (Figure 5[b]), but increased total route length and increased average route length (Figure $5[\mathrm{~d}]$ ). This means that transit networks are generated as providing more circuitous routes to reduce the number of transfers in the network when higher transfer penalties are assumed. This increased circuity is also reflected in the increased adjusted degree of circuity (ADOC) in Figure 5(b). However, when demand is large enough to provide high frequencies for many routes without circuitous routing and when travel times on the links are long, direct service is preferred and the results may be substantially different.

\section{Changes in Transfer Penalties (Higher Demand Case)}

This section addresses the sensitivity analysis for the transfer penalties with a higher demand. One and a half times the previous demand and two-thirds operating speed were applied with the various transfer penalties which were applied before. The analysis results are shown in Figure 6. The same type of analysis which was shown in Figure 5 is applied, but the results are different in some aspects. 
Figure 5(a). Analysis with Different Penalites-Lower Demand Case

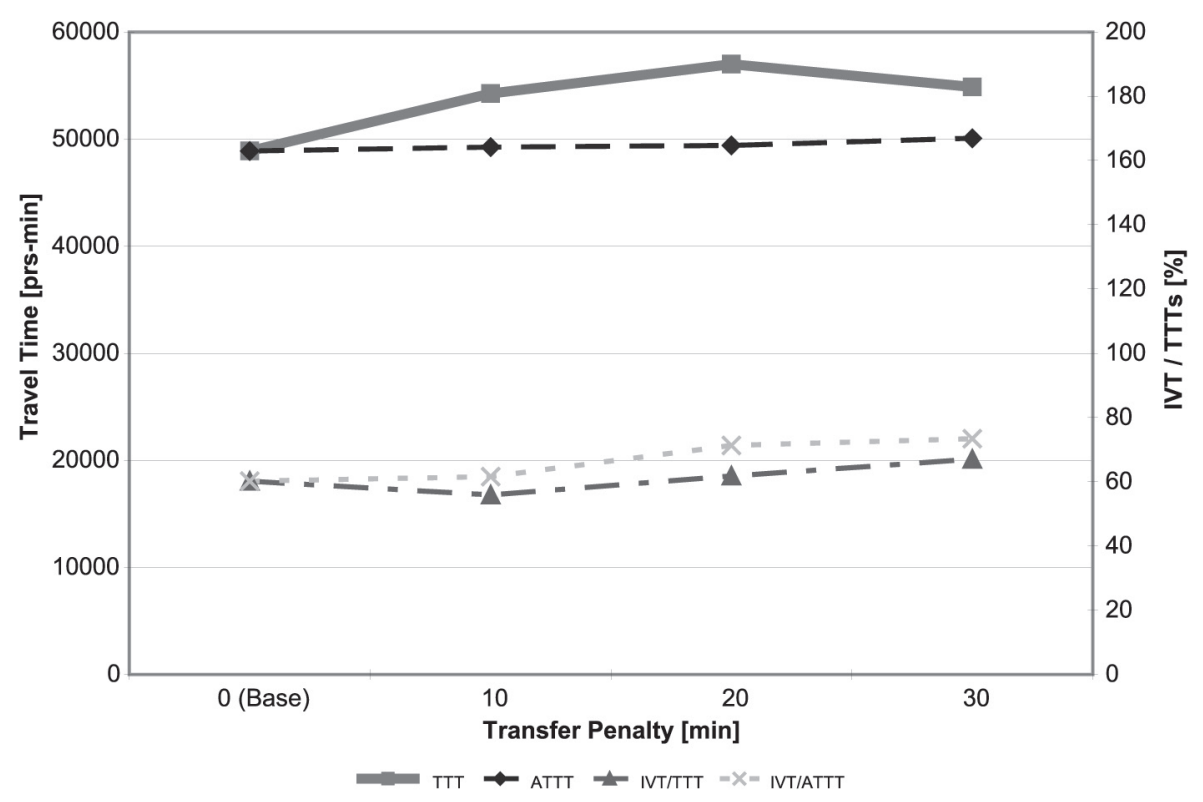

Figure 5(b)

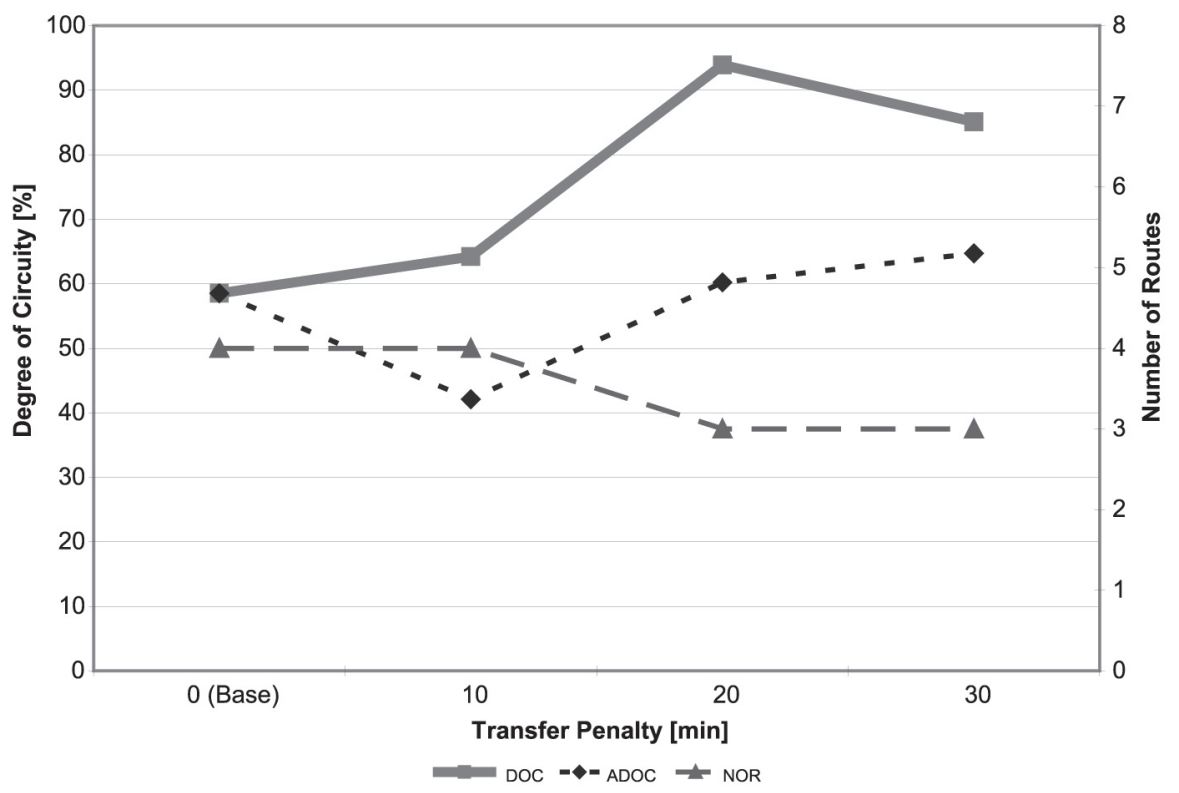


Journal of Public Transportation, Vol. 9, No. 1, 2006

Figure 5(c)

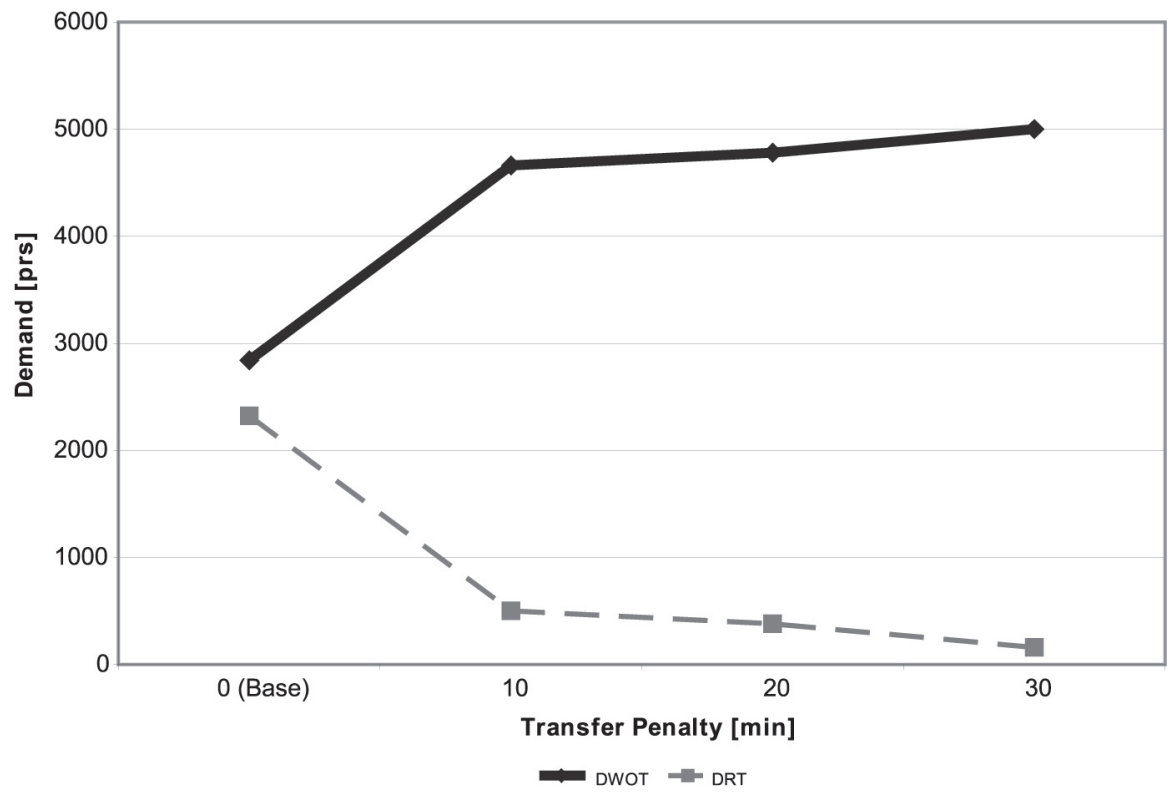

Figure 5(d)

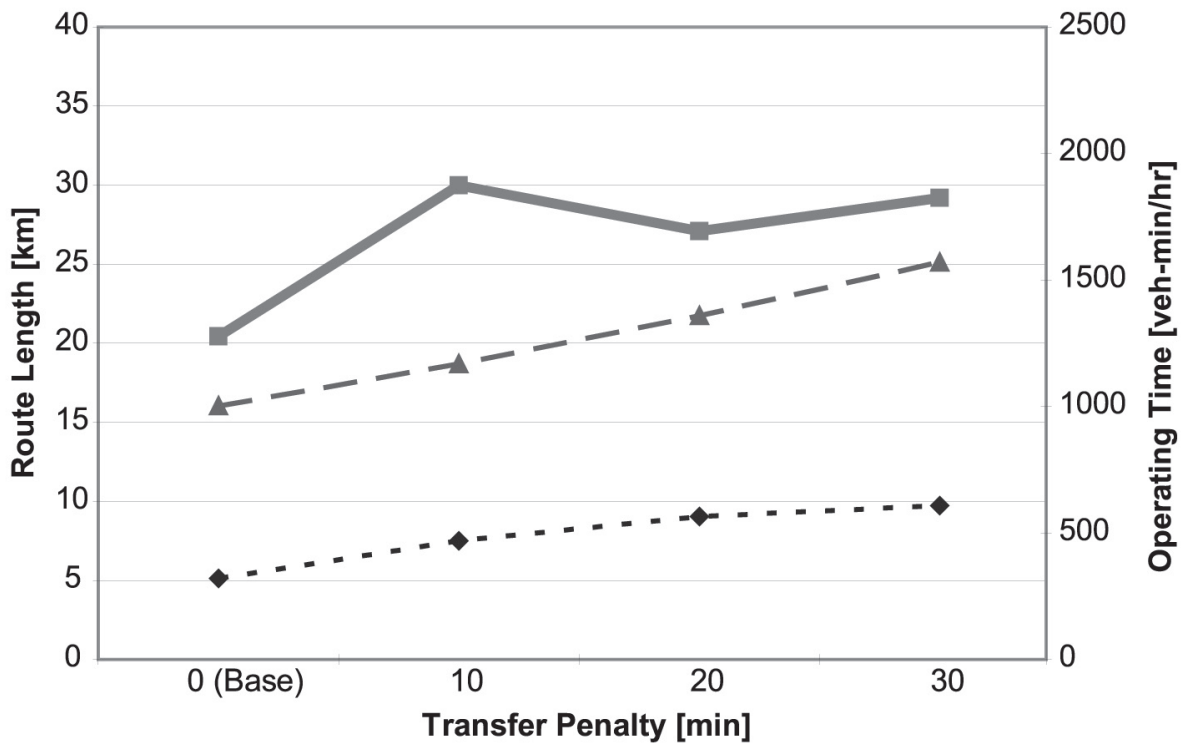

TRL $=-A R L=$ TVOT 
In Figure 6(a), total travel time in the network (TTT), which includes transfer penalties, and its adjusted version (ATTT) excluding transfer penalties are plotted with the primary $\mathrm{Y}$-axis. As shown in the figure, travel times increase with increased transfer penalties. Increased total travel time including transfer penalties is a predictable result due to the increased travel costs the transfer penalties impose. However, as before, adjusted total travel time (ATTT), which excludes the transfer penalties, also increases because the transit networks are generated inefficiently compared to the basic case to avoid transfers.

While the ratio of in-vehicle travel time to total travel time (IVT/TTT) and its adjusted version (IVT/ATTT), which are plotted with secondary $Y$-axis, increase in the lower demand range (Figure 5[a]), they decrease with increased transfer penalties in the higher demand range (Figure 6[a]). This can be explained by the fact that in the higher demand range, as transfer penalties increase, a network with more direct routes can be generated, thus reducing the percentage of in-vehicle travel time to total travel time and the number of transfers. Meanwhile, in the lower demand range, networks with circuitous routes were generated to reduce transfer penalties (TP) and waiting time (WT), thus increasing in-vehicle travel time (IVT).

In Figure 6(b), while the degree of circuity (DOC), which contains transfer penalty, increases with increased transfer penalty, its adjusted version (ADOC), which does not include transfer penalty, decreases. Because of the increased transfer penalty, users spend more total travel time (costs) including the increased transfer penalty. However, when the transfer penalty is excluded, users' combined in-vehicle travel time and transfer time decrease due to the higher number of routes in the network. The number of routes (NOR) increases with increased transfer penalty, as plotted with the secondary $Y$-axis. These results are opposite those developed for lower demand (Figure 5[b]), except for the degree of circuity. Since the degree of circuity takes into account transfer penalties, increased transfer penalties always cause an increased degree of circuity.

As shown in Figure 6(c), to avoid high transfer penalties, demand requiring transfer decreases (DRT), while direct trip demand without transfer (DWOT) increases. This is similar to the lower demand case of Figure 5(c).

In Figure 6(d), total route length (TRL) and average route length $(A R L)$ are plotted with the primary $\mathrm{Y}$-axis. With an increased number of routes to avoid transfers, the total route length in the network increases, but the average route length also increases, despite an increased number of routes (NOR). This shows that to avoid 
transfers, not only the number of routes, which represents the network extensiveness, but also the average route length, which represents circuity, increase. Due to the higher demand, more routes in the network are competitive without consolidation; however, circuitous routing is still necessary to avoid transfers as much as possible. Consequently, total vehicle operating time (TVOT), which is plotted with the secondary $Y$-axis, increases with increased transfer penalty.

Figure 6(a). Analysis with Different Transfer PenaltiesHigher Demand Case

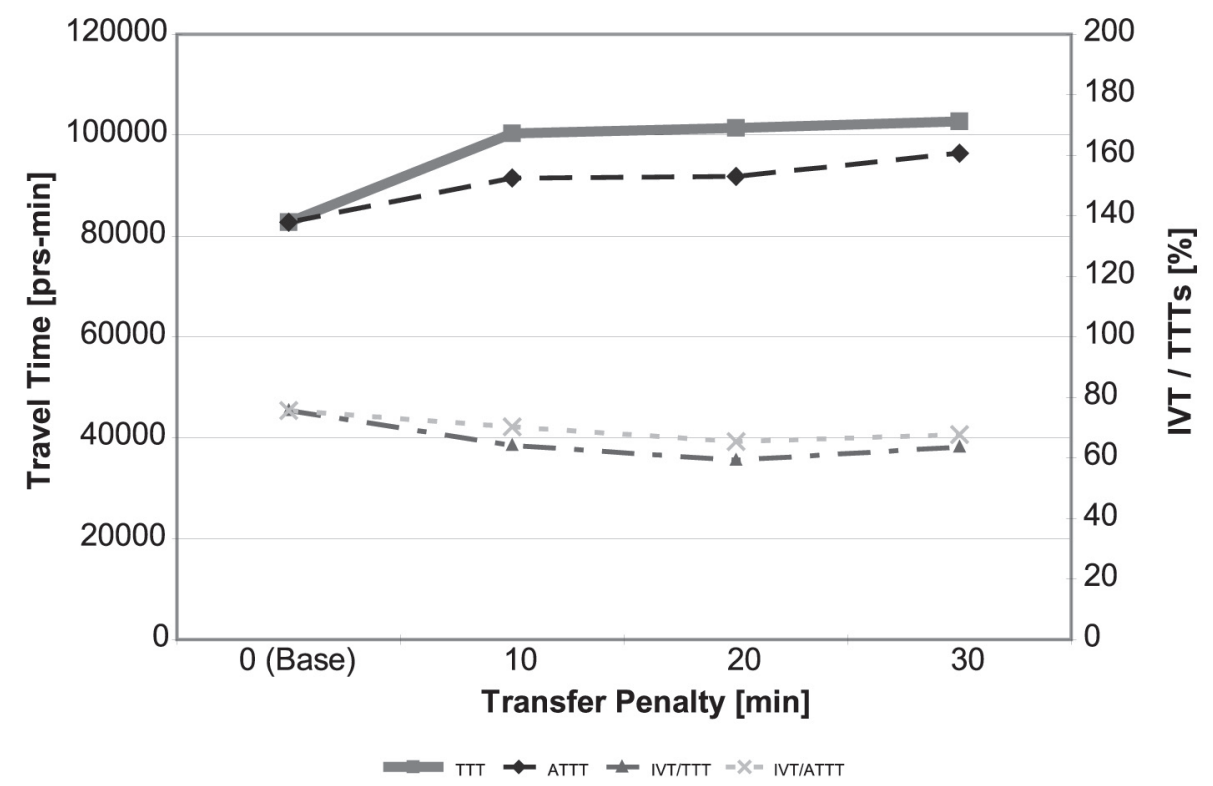




\section{Figure 6(b)}

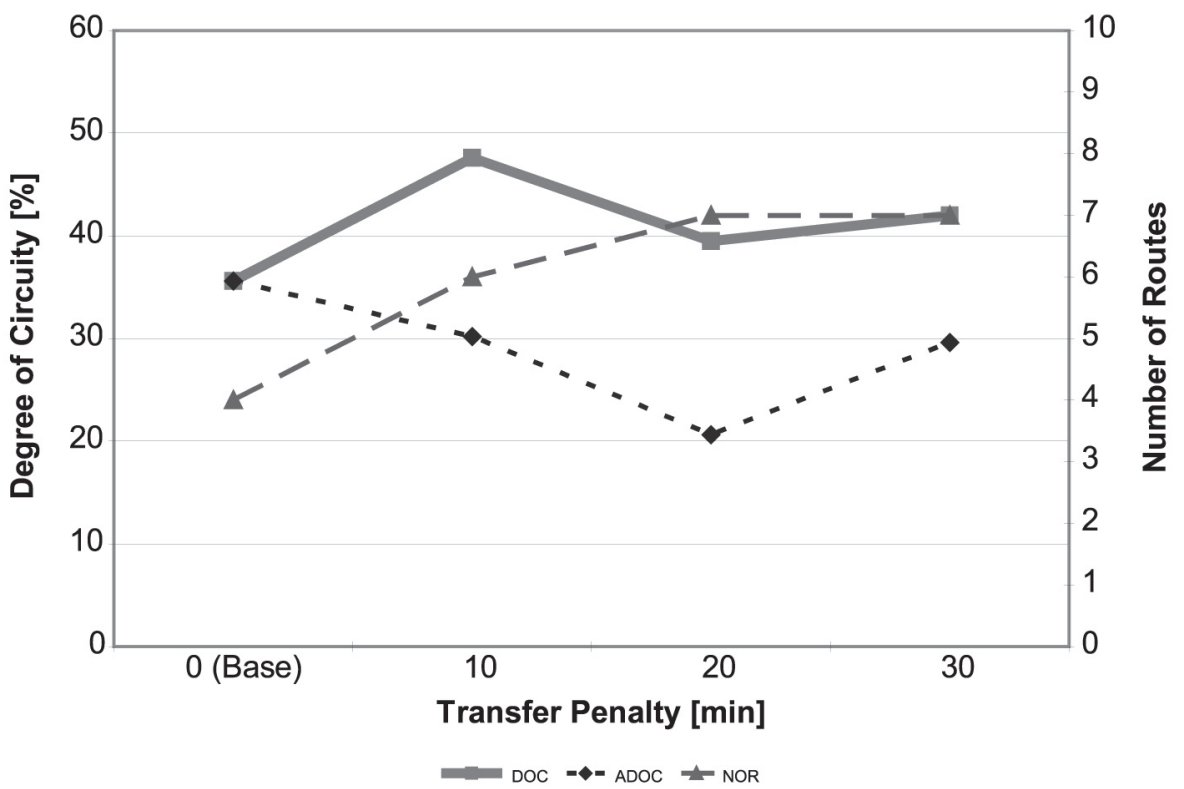

Figure 6(c)

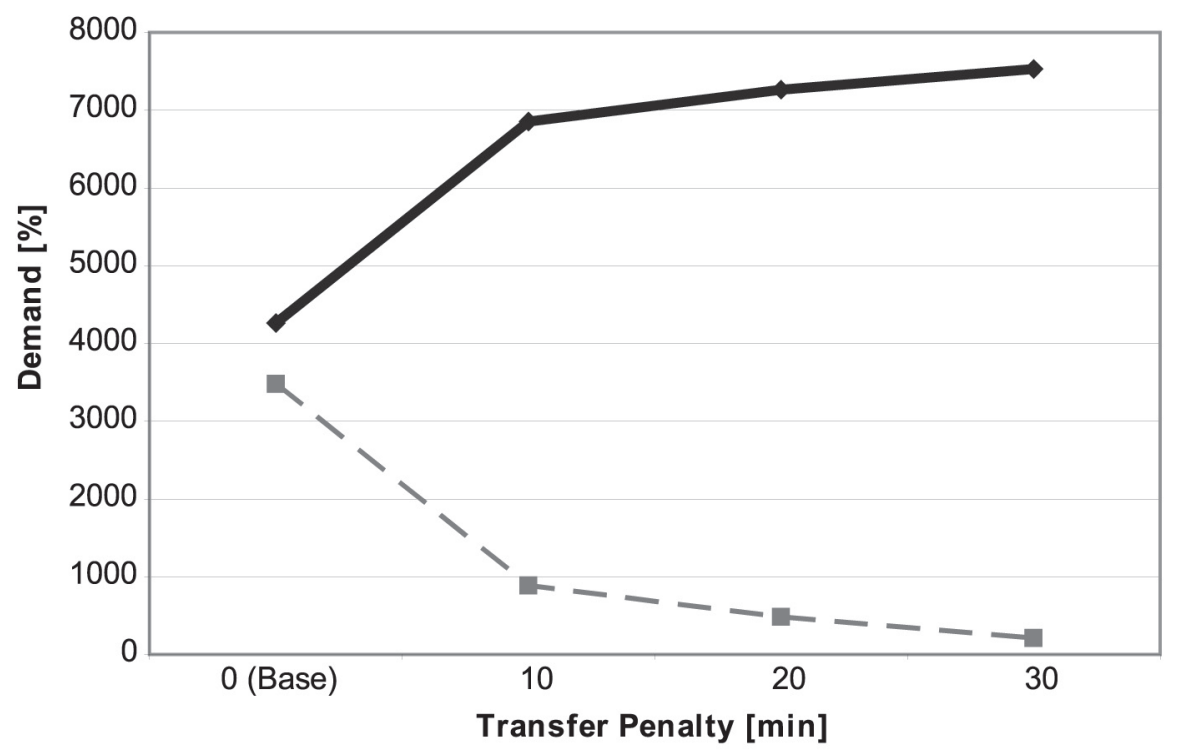

DWOT $=$ DRT 
Figure 6(d)

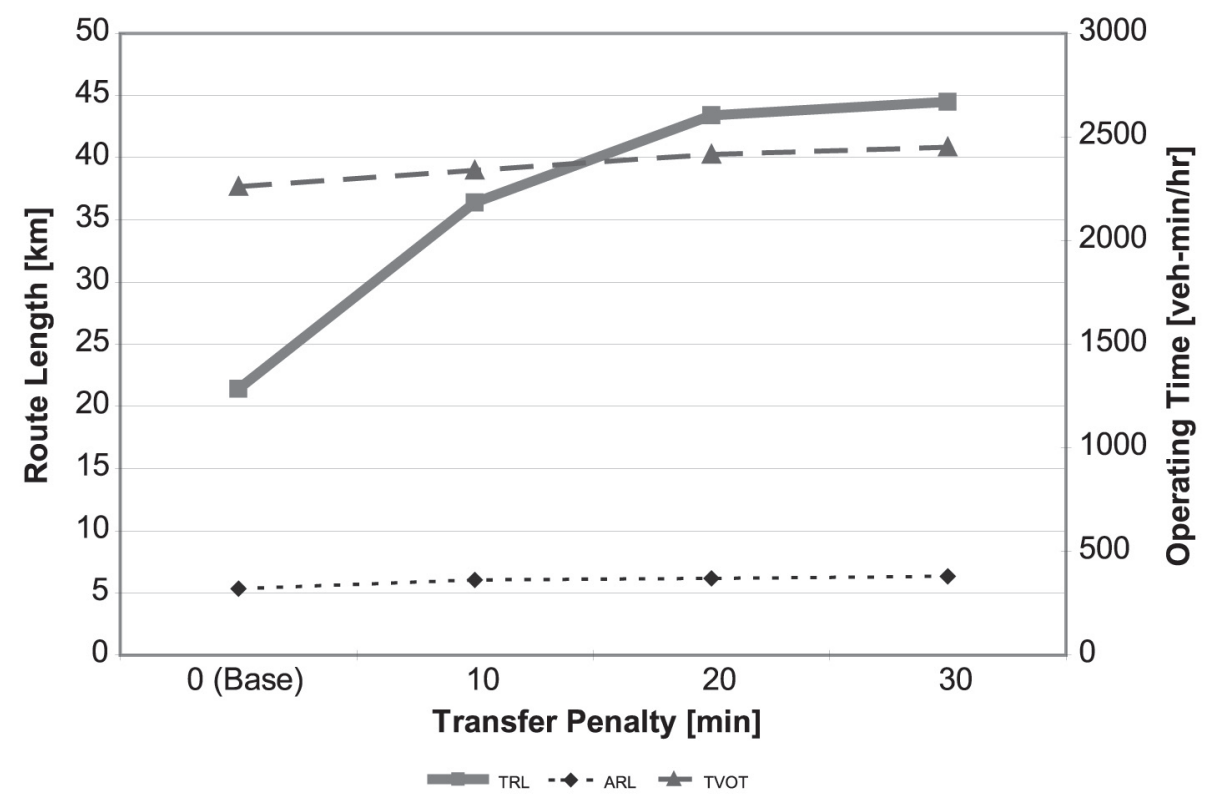

In conclusion, for different sizes of demand, the effects of transfer penalty on the network and its characteristics are defined as follows. First, with increased transfer penalties, generated networks become more inefficient both in terms of total travel time (TTT) for the users and total vehicle operating time (TVOT) for the operator. The major difference between different demand levels is the network configuration including the number of routes (NOR) and average route length $(A R L)$. If demand level is low, fewer routes are necessary to be generated with longer average route length, because not only the transfer penalty but also the waiting time should be considered. However, for the higher demand case, waiting time may not be a big concern because of higher frequencies, so a greater number of routes are generated to avoid transfers, while average route length is still increased to reduce transfers and waiting time.

\section{Three Typical Types of Transit Networks}

A few items were found to be in common from the various sensitivity analyses. First, the results matched with the logical expectation, so it is shown that TRANED can make reasonable networks. 
Second, the transit network is generated by considering and minimizing the most critical components among travel time components-in-vehicle travel time, waiting time, transfer time, and transfer penalty. Although determining a critical component is not easy, when a condition for an existing network is changed, the changed condition can be considered a critical component. In addition to taking care of the most critical component, the network affects the other components, too. For example, increased demand is directly related to decreased waiting time, but the revised network provides not only reduced waiting time, but also reduced in-vehicle travel time. In another case, increased travel times on the links (decreased operating speed) generate a revised network which requires not only increased in-vehicle travel time, but also increased other travel time, which is the sum of waiting time and transfer time.

Third, the main factor that affects the network configuration consistently is the relationship between in-vehicle travel time and waiting time. This research has shown that demand level is directly related to the changes of waiting time, and that in-vehicle travel time depends on operating speed. As shown previously, efforts to minimize total transfer penalties created networks with the lowest demand for transfers, as expected. However, two different types of networks were generated under two different demand levels because the transfer penalty is not part of the relationship between in-vehicle travel time and waiting time. On the contrary, even with different amounts of transfer penalties, increased demand still generates the same type of network, which has a higher number of routes with shorter lengths.

Fourth, under user travel time minimization, the network which consists of shorter and greater number of routes is generally more efficient for the operator in terms of total vehicle operating time in the network than one with fewer but longer routes. That is, a greater number of shorter routes can optimize vehicle operating time with more direct routing and more sectionalized frequencies.

From the above discussions, general ideas for a transit network can be extracted. Three different types of transit networks are shown in Figure 7. The first type shown in Figure 7(a) is a transfer-oriented network. This network has shorter (direct) and fewer routes with relatively high frequencies, resulting in many transfers. However, it does provides moderate in-vehicle travel time and shorter waiting time.

The transfer-avoidance network, shown in Figure $7(b)$, consists of fewer routes with relatively high frequencies, resulting in longer average route length than that of the transfer-oriented network. The transfer-avoidance network provides fewer 


\section{Figure 7. Three Typical Types of Transit Networks}

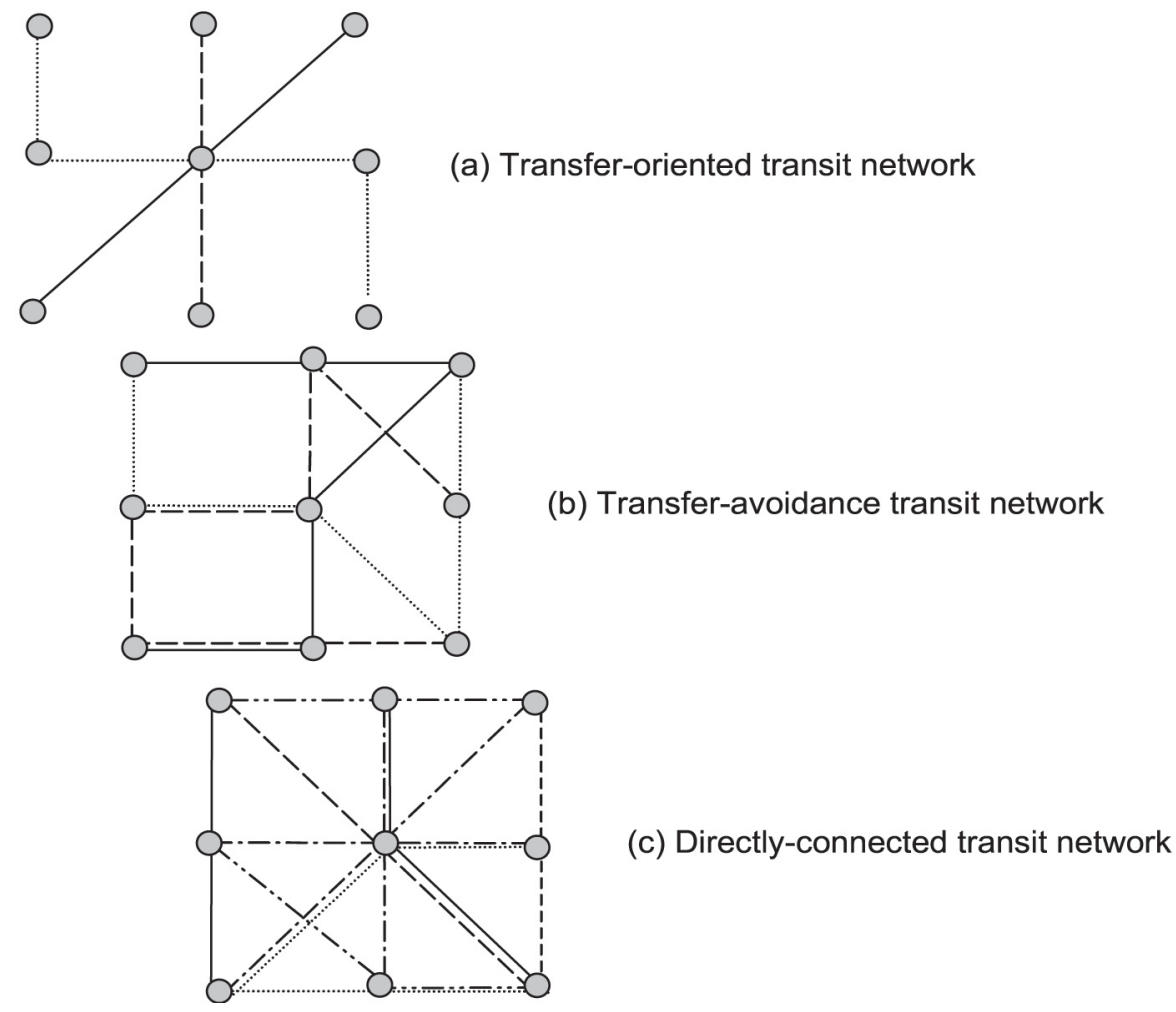

Table 2. Conceptual Relationship among Network Types and Critical Inputs

\begin{tabular}{|l|c|c|c|c|c|c|}
\hline \multirow{2}{*}{} & \multicolumn{2}{|c|}{ Demand } & \multicolumn{2}{c|}{ Travel speed } & \multicolumn{2}{c|}{$\begin{array}{c}\text { Transfer } \\
\text { penalty }\end{array}$} \\
\cline { 2 - 7 } & High & Low & High & Low & High & Low \\
\hline Transfer-oriented network & $\mathrm{O}$ & $\mathrm{O}$ & $\mathrm{O}$ & - & $\mathrm{X}$ & $\mathrm{O}$ \\
\hline Transfer-avoidance network & $\mathrm{X}$ & $\mathrm{O}$ & - & $\mathrm{X}$ & $\mathrm{O}$ & - \\
\hline Directly-connected network & $\mathrm{O}$ & $\mathrm{X}$ & $\mathrm{O}$ & $\mathrm{O}$ & $\mathrm{O}$ & $\mathrm{O}$ \\
\hline
\end{tabular}

$\mathrm{O}=$ good or adequate

$\mathrm{X}=$ inferior or incompatible

- = no strong relationship 
transfers due to longer and more circuitous routes. It also provides less transfer time and less waiting time due to higher frequencies. However, more in-vehicle travel time due to more circuitous and longer routes is required instead.

The directly-connected network, shown in Figure $7(\mathrm{c})$, consists of a greater number of routes with shorter lengths. It provides the shortest in-vehicle travel time of all three types of networks and fewer transfers due to the greater number of directlyconnected routes. However, it requires the longest waiting time of all three types because of relatively lower frequencies.

The type of network is dictated by a combination of three critical inputs-demand level, travel time on link (transit speed) and transfer penalty. Their relationships based on analysis in this research are summarized in Table 2.

As shown in the table, when the demand is high enough to provide a directly-connected network, the first or third type of network should be generated. If a high transfer penalty is added, the transfer-avoidance network and the directly-connected network become the candidates. If the demand is low and transit operating speed is also low, then the transfer-oriented network is the best choice. These relationships are conceptual, but useful when the parameters representing conditions of a city are changed.

\section{Conclusions}

The results presented in this research were quite clear and predictable, showing that Lee's model and TRANED generate reasonable transit networks and that they respond to different inputs soundly.

With increased demand, the network becomes more efficient as reflected by the improvement of all indicators. Not only waiting time decreases due to increased service frequencies, but also in-vehicle travel time decreases due to more direct services. The number of routes and passengers without transfer also increase. While the total route length and the total vehicle operating length increase, the average route length, average total travel time per trip, and average vehicle operating length per trip all decrease with increased demand.

With decreased transit operating speed, which causes increased in-vehicle travel times on the links, the generated network responds similarly to the increased demand case. Because of slower travel, the ratio of in-vehicle travel time to waiting time becomes greater, similarly, higher demand increases this same ratio through 
decreased waiting time. Thus, direct service is preferred to avoid much longer invehicle travel time due to circuitous routing. It also causes a greater number of routes with shorter average route length. The network requires longer total vehicle operating time due to increased in-vehicle travel time, but shorter vehicle operating distance due to more direct service.

In the case of increased transfer penalties, the generated transit network is less efficient to avoid them. It creates a longer network length and more circuitous routes. Consequently, increased transfer penalties result in increased total travel time and total vehicle operating time. However, as expected, demand requiring transfers decreases with increased transfer penalties.

One notable finding of these sensitivity analyses is that the characteristics of a transit network with different transfer penalties are affected substantially by the size of demand. With lower demand, to avoid transfers fewer routes with much longer lengths were generated; however, with higher demand, a greater number of routes with little increase in length were produced.

As results of the sensitivity analysis, three typical types of transit networks-transfer-oriented network, transfer-avoidance network and directly-connected network-were generated and examined. These conceptual networks can provide general ideas for changing networks with changed inputs.

The transfer-oriented network consists of shorter (direct) and fewer routes with relatively high frequencies. This type of network creates many transfers and involves transfer times. However, it provides moderate in-vehicle travel time and shorter waiting time. This type of the network is good when the transfer penalty is low and the demand is not very high.

The transfer-avoidance network consists of fewer routes with relatively high frequencies, but the average route length is longer than that of the transfer-oriented network. This type of network provides fewer transfers due to longer and more circuitous routes, and provides less transfer time and less waiting time due to higher frequencies. However, more in-vehicle travel time due to more circuitous and longer routes is required. This type of network is reasonable when the transfer penalty is high and demand is low.

The directly-connected network consists of a greater number of routes with shorter lengths. It provides the shortest in-vehicle travel time of all three types of networks and fewer transfers due to the greater number of directly-connected routes. However, it requires the longest waiting time of all three types because 
of relatively lower frequencies. The type of network is good when the demand is high enough so each route can have reasonably high frequencies. Also, this type of network is recommended when the transfer penalty is high.

\section{References}

Baaj, M. H., and Mahmassani, H. S. 1991. An Al-based approach for transit route system planning and design. Journal of Advanced Transportation 25, 2: 187210.

Ceder, A. and Israeli, Y. 1998. User and operator perspective in transit network design. Paper No. 980267, Transportation Research Board, 77th Annual Meeting, Washington, DC.

Chien, S., Yang, Z., and Hou, E. 2001. Genetic algorithm approach for transit route planning and design. Journal of Transportation Engineering 127, 3: 200-207.

Dantzig, G. B. 1967. All shortest routes in a graph. Théorie des graphes. Proceedings of the International Symposium, 91-92, Rome 1966, Dunod, Paris.

Dijkstra, E. W. 1959. A note on two problems in connection with graphs. Numerische Mathematik, 1, 269-271.

Hasselström, D. 1981. Public transportation planning, Ph.D. Dissertation, Department of Business Administration, University of Gothenburg, Sweden.

Lee, Young-Jae. 1998. Analysis and optimization of transit network design with integrated routing and scheduling, Ph.D. Dissertation, University of Pennsylvania, Philadelphia, PA.

Lee, Young-Jae, and Vuchic, V. R. 2005. Transit network design with variable demand. Journal of Transportation Engineering 131, 1: 1-10.

Mandle C. E. 1979. Evaluation and optimization of urban transportation networks. Presented at the 3rd European Congress on Operations Research, Amsterdam, Netherlands.

Newell, G. F. 1979. Some issues relating to the optimal design of bus routes. Transportation Science 13, 1.

Pattnaik, S. B., Mohan, S., and Tom, V. M. 1998. Urban bus transit network design using genetic algorithm. Journal of Transportation Engineering 124, 4: 368375. 
Rea, J. C. 1971. Designing urban transit systems: An approach to the route-technology selection problem. No. UMTA-URT-49(70)-71-6. Urban Transportation Program, University of Washington, Seattle, WA.

Shih, M, Mahmassani H. S., and Baaj, M. H. 1998. A planning and design model for transit route networks with coordinated operations. Paper No. 980418, Transportation Research Board, 77th Annual Meeting, Washington, DC.

Whiting, P. D., and Hillier, J. A. 1960. A method for finding the shortest route through a road network. Operations Research Quarterly 11: 37-40.

\section{About the Author}

YOUNG-JAE LEE (yjlee@eng.morgan.edu) is an assistant professor at the Institute for Transportation at Morgan State University. He received his Ph.D. (transportation) from the University of Pennsylvania's Department of Systems Engineering. He holds an M.S.E. transportation engineering) from the Department of Systems Engineering at the University of Pennsylvania, as well as an M.S.E. and B.S. from the Department of Civil Engineering, Urban Engineering Division, at Seoul National University, Seoul, Korea. 


\title{
A Study of the Impact of APTS on Service Quality Perceptions of Elderly and Disabled Riders
}

\author{
Julian M. Benjamin \\ North Carolina A\&T State University
}

\begin{abstract}
New transportation technology that directly impacts consumers should be evaluated by the people who are affected. Automated dispatching has become standard practice for paratransit services. This article summarizes a study analyzing consumer response to the Mobility Manager at a demonstration site in Winston-Salem, North Carolina.

The Mobility Manager was applied to the TransAID demand-responsive mini-bus service for people who are elderly or who have disabilities. Survey data from two questionnaires, before and after the implementation of the Mobility Manager for the same subjects, were used to examine travel behavior and perceived service quality. These travelers reported service improvements such as easier telephone access and shorter travel times. The respondents' travel patterns after implementation of the Mobility Manager remained stable. This article also provides econometric estimates of the change in the number of trips as a function of the change in travel attributes affected by implementation of the Mobility Manager. Changes in the number of trips by survey respondents were treated as a Poisson random variable. Results from a Poisson regression show that the primary beneficiaries of the Mobility Manager were riders with disabilities. Perceived service attributes that significantly affected changes in trips were length of trip, number of stops picking up additional passengers, and physical comfort.
\end{abstract}




\section{Study Background}

The Advanced Public Transportation Systems (APTS) program of the Federal Transit Administration in the 1990s involved projects that demonstrated the application of advanced technologies to transit systems (Casey et al. 1991). The APTS program evaluated these new technologies in practical demonstration projects. The system selected as the site for this study was the mini-bus dial-a-ride for special populations in Winston-Salem, North Carolina. As one of the APTS demonstration sites, new transit technologies including automated computer dispatch, automatic vehicle location, and smart cards were tested and evaluated. Taken together, these technologies made up the Mobility Manager, a geographic information system combined with a management information system. The Mobility Manager assisted the transit agency in scheduling, routing, billing, and administration tasks.

The technology was tested in a mini-bus system called TransAID, which was part of the public transit system of Winston-Salem (WSTA). Winston-Salem is a small city (2000 U.S. census population of 182,874) and is part of the Piedmont Triad, which consists of three cities with similar size about 30 miles apart in north central North Carolina. TransAID is a public paratransit system with curb-to-curb dial-aride service.

TransAID services are provided in eight 15-passenger mini-buses (vans) that are equipped for non-disabled passengers and 11 vans equipped for wheelchairs. Weekday hours of operation in Winston-Salem and in Forsyth County are 5:30 A.M. to 6:30 P.M. Limited service is provided for dialysis patients on Saturdays.

\section{Study Design}

The evaluation of this project used procedures summarized in "Evaluation Guidelines for the Advanced Public Transportation Systems Operational Tests" (Casey and Collura 1993). These techniques were based on methodologies developed for the earlier UMTA demonstration program. Subsequently, there have been many advances in travel analysis procedures that have particular relevance to project evaluations. These findings were summarized by Benjamin (1994) and included travel activity diaries, stated preference techniques applied to complex decisions, the application of computer technology to data gathering, and the application of new econometrics procedures. This study investigated the application of many of these procedures to the evaluation of APTS by applying them in a case study. 
Results of the stated and revealed preference elements of the before study were reported in Ben-Akiva et al. (1996). These study methods are combined into a before and after study design in this article.

\section{Study Objectives}

The objectives of this study were twofold. First, the study provided before and after comparisons of perceived service quality improvements from using the WSTA Mobility Manager. These improvements include various aspects perceived by users including telephone answering, travel time, and impacts on consumer travel behavior. Second, we considered the decision by TransAID passengers to take additional trips to determine the extent to which the implementation of Mobility Manager induced more ridership via the enhancement of service attributes.

\section{Before and After Surveys}

The before survey was completed in the summer of 1994 just before the phase 1 demonstration project started. The survey was designed to collect both baseline evaluation data and consumer demand information from current riders. The survey consisted questions in four areas: current travel behaviors, current transit system performance, stated anticipated travel behaviors after the APTS was implemented, and subject demographics.

The after study took place two years later following implementation of the Mobility Manager and replicated the before questions except for the stated preference travel questions.

Current travel behavior was recorded during the week prior to contact with the respondent. Detailed questions were asked about travel by trip purpose for each day of the week. Trip making for an entire one week period was investigated because of the low trip rate by the elderly and persons with disabilities; 78 percent of these respondents reported in the before study that they traveled by TransAID only once during the study week.

Questions on current transit service quality consisted of measures of the method used to contact TransAID to reserve a trip to and from home, responsiveness of the telephone service, and vehicle travel time. Each question asked about the last time that TransAID was used so that measures of service quality could be averaged across subjects. These questions were tailored to the anticipated improvements in the quality of service by the Mobility Manager, which would make it more efficient to schedule trips and make travel time shorter as a result of more efficient routing. 
Questions on future responses included scenarios that represented different hypothetical services. In anticipation of service improvements by the Mobility Manager, questions addressed how far in advance vans must be reserved, the ability to confirm calls immediately, travel time, and time required to call for return trips after the Mobility Manager was placed in to operation.

\section{Respondent Descriptions \\ Response Rate and Attrition}

The before study questionnaire was completed by 266 respondents. Of this total, 176 respondents were reported to still be TransAID riders by the Winston-Salem Transit Authority (WSTA) at the time of the after study. For the after study, the 176 subjects were initially contacted by mail. Current phone numbers were obtained for 162 respondents, and 100 surveys were completed. The 62 subjects who did not respond consisted of:

- 12 for whom there was no answer after five callbacks,

- 8 who had passed away,

- 14 who reported that they no longer use TransAID,

- 13 whose phone numbers were disconnected,

- 9 who did not live at the most recent phone numbers,

- 2 whose phone numbers had been changed to nonpublished numbers,

- 2 who had no recollection of their last trip on TransAID, and

- 2 who refused to participate.

\section{General Socioeconomic Statistics}

The initial data analysis was presented by Benjamin (2000). During the before study, TransAID served people with disabilities ( $2 / 3$ of the survey respondents), children under 12 years of age (30 respondents), and adults 65 years of age or older (162 respondents). The largest percentage of attrition occurred for younger riders (e.g., 50 riders before, 2 riders after), which may be due in part to HeadStart children entering public schools. The next largest attrition rate was for those over 65 years of age and was partly due to mortality and to changes in dwelling places for this age group.

Most people reported having a high school education in both studies, with the highest attrition rate for those reporting only elementary education. This, again, 
may have been due to the HeadStart youngsters. Among all the users, only 5 out of 272 respondents were employed in the before study and only 2 in the after study. Among those reporting to have a disability in the before study, 95 were sight impaired, 101 were hearing impaired, 81 noted that the nature of their disability was "difficulty in reaching and grasping," 139 had difficulty walking, and 83 used a wheelchair. In the after study, the largest group had difficulty walking (65 of 101).

\section{Service Usage and Quality Before Mobility Manager}

Van Service Usage Patterns for Initial Respondents. The larger number of the responses before the Mobility Manager provided information for a more detailed analysis of service utilization and quality. In the before study, 45 percent of the respondents rode TransAID the week prior to the first survey but only 30 percent rode it during the second survey. The trips reported were unequally distributed among days of the week. The largest number traveled on Monday (47\%) with other trips distributed among the remaining days of the week. Only 2 percent of the sample reported riding on Saturday, and there was no service provided on Sunday. Similar results were reported in the second survey. (These travel patterns are illustrated for the last trip in Table 3.)

In a summary of trips made according to disability type and trip purpose, for the first trip taken, 76 percent of these users traveled for medical reasons. The majority of people rode for medical reasons in each disability group in the before and after studies, and the disability group with the largest percentage of medical trips was for those who had difficulty walking. Virtually all of the trips were round-trips, and most people traveled only once during the week. The average number of one-way trips reported during the survey week was 3.6. About one third of the respondents made a second round-trip, and about one fourth made more trips. Thirty-seven subjects made five round-trips, and only one subject reported making a sixth trip (for medical purposes) before and, at most, five round-trips after.

\section{Service Quality Before Mobility Manager}

All questions about quality of service referred to the last time the service was used. This section summarizes responses before implementation of the Mobility Manager. Almost 80 percent of the respondents said that the last time they called for service they did not get a busy signal, only 14 percent felt rushed, 5 percent complained of lack of courtesy, and 6 percent reported a lack of accuracy. Respon- 
dents reported talking an average of 2.8 minutes and holding for a mean of about 1 minute.

The vehicle usually arrived on time (65\%), although the vehicles were frequently either early (14\%) or late (20\%). The mean time of early pick-up was 3.9 minutes; the mean late pick-up time was 8 minutes. However, 29 percent of the riders indicated that the vehicle had failed to pick them up at some time in the past. For the last return trip, the van arrived at the destination within 5 minutes of schedule 200 times but there was a reported late arrival of one hour or more by 17 people.

Riders reported an average in-vehicle travel time of 22.2 minutes, with a standard deviation of 22.1 minutes. While traveling, respondents observed an average of 4 people in their vans. When they arrived early, it was only for an average of 1.5 minutes; when the vehicle arrived late, the average reported time was 9.1 minutes, with a standard deviation of 25.6 minutes.

During the week before the first survey, 26 percent of the respondents had ridden the fixed-route transit an average of 1.4 times, indicating that there could be some shift to the fixed-route mode. Sometime in the past, 10 percent of the respondents reported that they had been in an accident on the vehicle and that assistance was required. It took an average of 34 minutes for assistance to arrive, with two hours being the longest wait.

\section{Van Service Usage Patterns}

Practically all the trips (more than $95 \%$ ) taken by children under 18 in the survey group were for educational (other) purposes. This proportion is unique to this age group, and adults between 18 and 65 years old also had a significant amount (about 20\%) of educational trips. That the youngest group has such a high proportion of educational trips fits in with the fact that TransAID was designed in part to serve families with children attending HeadStart programs. Van service reservation patterns for this age group indicate that for close to 60 percent of the trips taken, the van service was not called, implying that the service was scheduled in advance and worked like a school bus that picks up at home. For the remaining 40 percent, the service was requested a minimum of 24 hours in advance. As in the other age groups, the proportion of users reserving the van the same day as the scheduled trip was negligible ( $0 \%$ for children under 12 , under $5 \%$ for all the other respondents).

For respondents above 65 years old, at least 60 percent of the trips were made for medical purposes. More than 50 percent of the trips were reserved 24 hours in 
advance. Other trip purposes for this group were for shopping and nutrition, each representing close to 10 percent of the trips, indicating that TransAID was helping with some of their daily activities.

\section{Comparison of Before and After Surveys}

A comparison of results for those who took both surveys was calculated for key questions in the study. The HeadStart children in the first phase all aged out of using these services before the second phase and were therefore not included in any analysis based on the after data. Table 1 lists some responses to key questions asked before the Mobility Manager and responses by the same people in the after survey.

\section{Table 1. Perceived Effects of APTS}

\begin{tabular}{|l|l|c|}
\hline Reported Before & Reported After by Same Respondents & After Percent \\
\hline Picked up early/late & Picked up on time & $21 \%$ \\
\hline Picked up early/late & Same & $13 \%$ \\
\hline & Lower travel time & $57 \%$ \\
\hline Dropped off late & Same & $37 \%$ \\
\hline $\begin{array}{l}\text { Called more than 24 hours in } \\
\text { advance }\end{array}$ & Same & $80 \%$ \\
\hline & Lower phone time & $57 \%$ \\
\hline Not polite on phone & Same & $90 \%$ \\
\hline Busy signals & More busy signals & $80 \%$ \\
\hline
\end{tabular}

The extent the implementation of the Mobility Manager favorably impacted service quality perceptions by riders was not absolutely definitive. The following sample proportions, with t-statistics in parentheses, suggest that the implementation of the Mobility Manager may have impacted favorably on service quality perceptions. Of those respondents reporting that TransAID last picked them up early or late in the first survey, 21 percent $(t=5.1)$ reported that TransAID last picked them up on time in the second survey, 5 percent $(t=2.3)$ reported that TransAID last picked them up early in the second survey, and 8 percent $(t=2.9)$ reported that TransAID last picked them up late in the second survey. Given the 
travel times reported in the first survey, 57 percent $(t=11.5)$ of the respondents in the second survey reported spending less time riding TransAID from their home. For respondents who reported in the first survey that were dropped off at their destination late, only 37 percent $(t=7.6)$ reported that TransAID dropped them off late in the second survey. Of those respondents in the first survey reporting that they did not request their last trip on TransAID at least 24 hours in advance, 80 percent $(t=20)$ reported scheduling their last trip at least 24 hours in advance in the second survey. For reported times spent talking to TransAID officials on the telephone in the first survey, 57 percent $(t=11.5)$ reported spending less time talking in the second survey. Of those respondents in the first survey who reported that TransAID officials were not polite on the telephone, 90 percent $(t=$ 30) reported they were polite in the second survey.

Although fewer people reported traveling on TransAID in the second survey, of those who rode TransAID in the first survey, 85 percent reported traveling slightly more frequently by TransAID after the Mobility Manager. However, a chi-square test revealed that there was no significant difference for the total group in trip rates for different trip purposes and days of the week.

To the extent that perceptions of quality were related to the attributes measured in the sample proportions cited above, one implication was that the Mobility Manager had a favorable impact. Such an implication was, of course, only suggested by the reported sample proportions. Further caution was warranted by the fact that there was some evidence suggesting that perceptions of service quality were lower for respondents in the second survey in some areas. For example, of those respondents in the first survey reporting the number of busy signals when attempting to contact TransAID officials on the telephone, 80 percent $(t=20)$ reported an increase in the number of busy signals in the second survey.

\section{Effects of Mobility Manager on Ridership}

\section{Trips as a Function of Travel Attributes}

Presumably, consumer response to the implementation of Mobility Manager should have resulted in an increased number of trips. If, for example, consumers, as utility maximizers, realized higher utility as a result of enhanced travel attributes, the extent to which the implementation of Mobility Manager enhanced travel attributes on TransAID should induce more ridership. Five questions in the followup survey were designed to measure travel attributes such as ease of scheduling, 
physical comfort, and trip length. Each question provided answers on a five-point integer scale, with 1 indicating strong agreement and 5 indicating strong disagreement. ${ }^{1}$

Both surveys recorded the number of trips on TransAID by respondents. To determine the effect of the Mobility Manager on ridership, we posit the relationship between the change in number of trips and the service attributes plausibly affected by Mobility Manager as follows:

$\Delta$ Trips $=\mathrm{T}_{\mathrm{i}}=f($ Travel Attributes $)$

$$
=f(\text { Easy, Long, Stops, Riders, Comfort })
$$

where:

Easy

is the extent to which it was easy to schedule a trip on TransAID

Long

represents the extent to which it takes long to complete a trip on TransAID

Stops indicates the extent to which TransAID makes many stops for other passengers

Riders signifies the extent to which there were too many passengers on TransAID

Comfort is the extent to which a passenger was comfortable while riding TransAID

All variables were based on the perception of the respondent in the second survey, after implementation of the Mobility Manager.

The rate of incidence of the number of trips was modeled as the arrival rate in a random Poisson process. This modeling approach is discussed in the Supplemental Material section.

\section{Results}

Table 2 presents the mean and standard deviation for the dependent and independent variables. Column 1 in Table 3 reports the Poisson regression estimates 
of equation (1). ${ }^{2}$ As a goodness-of-fit measure, Table 3 also reported the value of Pseudo- $\mathrm{R}^{2}{ }^{3}$ All of the parameter estimates conformed to a priori expectations and were significant except for the variables Riders and Comfort. Column 1 also reports the estimated coefficient $\alpha$, which was generated from testing equation (1) for mean variance equality, a restriction required for a Poisson random variable. ${ }^{4}$ The insignificance of $\alpha$ at any reasonable level of significance implied that $T_{i}$ could have been modeled as a Poisson random variable. The sign on Easy suggested that the more difficult scheduling a trip was on TransAID, the higher the probability of additional ridership by a respondent. This, of course, seems rather implausible, but it may capture the effects of riders willing to tolerate difficulty scheduling as a result of it being positively correlated with other favorable attributes associated with TransAID after the implementation of the Mobility Manager. Long was negative and significant, suggesting that the probability of ridership increased with decreases in trip duration. The positive and significant sign on Stops indicated that the probability of ridership increased as the number of passenger pick-ups decreased. The insignificance of Rider and Comfort suggested that the probability of ridership changes was not affected at all by perceptions of the number of passengers and their comfort.

Table 2. Summary Statistics

\begin{tabular}{lccccc}
\hline Variable & Mean & $\begin{array}{c}\text { Standard } \\
\text { Deviation }\end{array}$ & Minimum & Maximum & N \\
\hline $\begin{array}{l}\text { Number of } \\
\text { Additional Trips }\end{array}$ & & & & & \\
$\left(\mathrm{T}_{\mathrm{i}}\right)$ & 1.46 & 4.74 & 0 & 33 & 99 \\
Easy & 1.78 & .767 & 1.0 & 5.0 & 99 \\
Long & 2.28 & .858 & 1.0 & 5.0 & 99 \\
Stops & 3.24 & .959 & 1.0 & 5.0 & 99 \\
Riders & 4.12 & .824 & 1.0 & 5.0 & 99 \\
Comfort & 1.0 & 1.11 & 1.0 & 5.0 & 99 \\
\hline
\end{tabular}

Note: Two observations were lost due to survey respondents not responding to the questions quiring a categorical response 
Table 3. Poisson and Negative Binomial Regression Estimates

\begin{tabular}{|l|l|l|l|l|}
\hline Variable & $(1)$ & $(2)$ & $(3)$ & $(4)$ \\
\hline Constant & .498 & .254 & .209 & .192 \\
& $(.626)$ & $(.412)$ & $(.752)$ & $(.153)$ \\
\hline Easy & -.276 & -.193 & -.627 & -.432 \\
& $(.148)^{*}$ & $(.112)^{*}$ & $(.178)^{* * *}$ & $(.234)^{*}$ \\
\hline Long & -.306 & -.257 & -.384 &. .223 \\
& $(.113)^{* * *}$ & $(.129)^{* *}$ & $(.122)^{* * *}$ & $(.163)$ \\
\hline Stops & 2.22 & 1.35 & 2.82 & 1.75 \\
& $(.303)^{* * *}$ & $(.783)^{*}$ & $(.325)^{* * *}$ & $(.521)^{* * *}$ \\
\hline Riders & .002 & .002 & .067 & .032 \\
& $(.105)$ & $(.157)$ & $(.127)$ & $(.148)$ \\
\hline Comfort & .037 & .032 & .300 & .248 \\
& $(.108)$ & $(.234)$ & $(.121)^{* * *}$ & $(.127)^{*}$ \\
\hline Pseudo-R & .231 & .284 & .293 & .302 \\
\hline Sample Size & 99 & 99 & 83 & 83 \\
\hline$\alpha$ & 4.93 & $\ldots$ & 3.32 & $\ldots$ \\
& $(3.62)$ & $\ldots .$. & $(3.02)$ & $\ldots$ \\
\hline V & $\ldots .$. & 1.02 & $\ldots$ & 1.37 \\
& & $(.95)$ & & $(1.03)$ \\
\hline NR & $\ldots$ & .063 & $\ldots$ & .054 \\
\hline$\chi^{2}$ & $\ldots$ & .095 & $\ldots$ & .073 \\
\hline
\end{tabular}

Note: Standard errors were in parentheses.

* Significant at the .10 level.

** Significant at the .05 level.

*** Significant at the .01 level.

The adequacy of the Poisson specification in equation (1) for modeling additional trips on TransAID suggested that the implementation of the Mobility Manager engendered additional trips by enhancing the utility of riders as a result of shorter trips (Long), and a fewer number of stops per trip picking up other passengers (Stops).

Given that approximately 84 percent of the sample consisted of TransAID riders who self-reported some type of disability, the insignificance of the variables Riders and Comfort could have reflected a failure to control for the handicap status of TransAID riders. To explore this possibility, a discriminate analysis was conducted to determine which of the TransAID riders' handicap status can discriminate between those respondents who reported taking more trips on TransAID in the 
second survey and those who did not. The discriminant analysis revealed that the handicap status of TransAID riders did indeed provide explanatory power for discriminating between two groups, with handicapped riders more likely to report taking additional trips on TransAID in the second survey.

Column 3 in Table 3 shows the results of a Poisson regression estimated for the sample of riders who self-reported having a disability. As was the case for the Poisson specification in column 1 , the sign and significance of $\alpha$ and $\chi^{2}$ for testing Poisson specification in column 3 against the negative binomial in column 4 , suggests the adequacy of the Poisson specification over the sample of riders self-reporting a disability. The results in column 3 differed from the results in column 1 in that the variable Comfort was positive and significant. The variable Riders was still positive but insignificant. Apparently for riders with disabilities, the level of comfort was proportional to the number of passengers on TransAID. Thus, to the extent that the Mobility Manager was able to reduce the number of passengers per trip on TransAID, it induced additional trips by TransAID riders with disability. For public transit riders with disabilities that restricted mobility and/or required visits for medical care, it seems reasonable that ease of scheduling and physical comfort would have been important factors determining the desirability of public transit. Thus, the results reported in Table 3 suggest that the Mobility Manager, to the extent that it improved the attributes associated with travel on TransAID, and increased ridership, did so for disabled passengers with disabilities by enhancing the passenger utility attributes of trip length, number of stops picking up other passengers, and rider comfort.

\section{Conclusions}

The new technology used by TransAID directly affected consumers, and it was that effect that is reported in this study. The van service was used primarily by people above 65 years old to take medical trips ( $1 / 3$ of all trips reported in the survey). The use of the TransAID vehicles in part reflects the preferences and constraints of the riders and reflects trip purpose, weekday, and time-of-day restrictions by funding agencies.

Several key findings resulted from the survey. First, there was substantial attrition. The total attrition here was 63 percent. Of these subjects, there were only two who refused to participate (less than 1\%). Attrition may be due to changes in travel behavior over time, substitution of other modes, or the transient nature 
of this population. The remaining people included a large number who moved or changed phone numbers. This suggests that future research on new transit technologies, such as the Mobility Manager, should over sample the relevant population.

Second, the results of the second survey suggested that implementation of the Mobility Manager in Winston-Salem improved customer satisfaction with stable ridership on TransAID. The data suggest that the Mobility Manager impacted favorably on perceived service quality evidenced by shorter travel times, improved customer service through fewer telephone difficulties such as being put on hold, and decreased late drop-offs. However, overall ridership decreased because of attrition, but riders reported stable individual use of the service between the two surveys. Restrictions from funding agencies may have combined with consumer preferences and constraints for limited changes in travel patterns.

The Poisson regression results suggest that the Mobility Manager enhanced the attractiveness of travel by TransAID. For respondents with disabilities who highly rated comfort and ease of service, the Mobility Manager increased the use of TransAID.

Reactions of other travelers who began riding TransAID during the study period were assumed to be similar. Results were viewed in light of the sampling restrictions and the small population size. The results reported here must be interpreted as findings from retrospective questions. Although questions were asked about the last trip taken and the last week, the ability to recall details may have been limited for some members of these special groups. Finally, this case study suggests that the potential usefulness of a technology such as the Mobility Manager, from the consumers' perspective, is its ability to improve the perceived quality of service. Given the linkage between perception of service quality and ridership, future research on new transit technologies should explore which technologies will best increase ridership. 


\section{Appendix}

As the number of trips was reported as a count variable in both surveys, we specify the change in the number of trips $\left(T_{i}\right)$ as a Poisson random variable:

$$
\operatorname{Prob}\left(T_{i}=n\right)=f(T i)\left[\exp \left(-\lambda_{i}\right) \lambda_{i}^{n}\right] / n !
$$

where:

$T_{i}$ is the additional number of trips on TransAID reported by respondent $I$

$n$ equals $0,1,2, \ldots . \mathrm{N}$

$e \quad$ is 2.71828

$\lambda_{i} \quad$ represents the expected value of $T_{i}=$ Variance of $T_{i}$

A regression model was formulated by specifying the Poisson parameter $\lambda_{i}$ as a deterministic function of the presumed exogenous variables Easy, Long, Stops, Riders, and Comfort, with an unknown parameter vector $\beta$. We estimate the following specification:

$$
\lambda i=\exp \left[\beta_{0}+\beta_{1} \text { Easy }+\beta_{2} \text { Long }+\beta_{3} \text { Stops }+\beta_{4} \text { Riders }+\beta_{5} \text { Comfort }\right]
$$

A Poisson specification such as equation (1) was a member of the class of Generalized Linear Models (GLM), the parameters will be estimated with a nonlinear weighted least squares maximum likelihood procedure. ${ }^{5}$ The log likelihood for the number of additional trips $\mathrm{T}_{\mathrm{i}}$ is:

$$
L(\beta)=\Sigma\left[T_{i} !-\exp \left(X_{i} \beta\right)+T_{i} X_{i} \beta\right]
$$

where:

$X_{i} \quad$ is a vector of exogenous variables

The gradient and Hessian, respectively, are:

$$
\begin{aligned}
& \partial L(\beta) / \partial \beta=\Sigma\left[X_{i}^{\prime}\left(T_{i}-\exp \left(X_{i} \beta\right)\right)\right]=0 \\
& \partial^{2} L(\beta) / \partial \beta \partial \beta^{\prime}=\Sigma\left[-X_{i}^{\prime} X_{i} \exp \left(X_{i} \beta\right)\right]<0
\end{aligned}
$$


The first order condition was nonlinear in $\beta$ and can be estimated with a numerical maximum likelihood procedure, or by an iterative nonlinear least squares procedure. Because the Hessian was negative definite, convergence to a unique solution was assured.

To further assess the explanatory power and adequacy of a Poisson regression specification for additional trips by passengers on TransAID, column 2 of Table 4 reported and tested the results of a Poisson specification versus a negative binomial specification of equation (1). ${ }^{6}$ The negative binomial specification was tested as an alternative to the Poisson specification with a Lagrange Multiplier Test, where the Poisson specification was viewed as the restricted model. ${ }^{7}$ The insignificance of the $\chi^{2}$ for the Lagrange Multiplier Test statistic $N R^{2}$ in column 2 indicates that the restricted Poisson regression specification cannot be rejected against the negative binomial alternative.

\section{Endnotes}

${ }^{1}$ The questions related to the Regression Model specifications were as follows:

a. It was easy to schedule a trip on TransAID.

b. It does not take long to complete a trip on TransAID.

c. TransAID made many stops picking up other passengers.

d. There were too many passengers on TransAID vehicles.

e. I am physically comfortable when riding TransAID.

${ }^{2}$ All results were obtained with the use of LIMDEP (Version 7.0) Econometric Software.

${ }^{3}$ Specifically, the goodness-of-fit measure was the Pseudo- $R^{2}$ of McFadden (1974) defined as $R^{2}=1-\left(\log L_{\Omega}\right) /\left(\log L_{\omega}\right)$, where $L_{\Omega}$ was the maximum of the likelihood function when maximized with respect to all of the parameters, and $L_{\omega}$ was the maximum of the likelihood function when maximized with respect to a constant term only.

${ }^{4}$ If dependent variable Ti has a Poisson distribution, the mean of the dependent variable $T_{i}$ was $\lambda_{i}=\lambda_{i}\left(X_{i}, \beta\right)$. Cameron and Trivedi (1990) show that a test for mean-variance equality was based on the hypothesis test: $H_{0}: \operatorname{var}\left(T_{i}\right)=\lambda_{i}$ versus the alternative: $H_{A}: \operatorname{var}\left(T_{i}\right)=\lambda_{i}+\alpha g\left(\lambda_{i}\right)$, where $g\left(\lambda_{i}\right)$ was a function specified to equal 
$1, \lambda_{i}$, or $\lambda_{i}{ }^{2}$. A test for mean-variance equality was a t-test for the significance of $\alpha$ in the auxiliary regression: $\Sigma w_{i} g\left(\lambda_{i}\right)\left\{\left(T_{i}-\lambda_{i}\right)^{2}-T_{i}-\alpha g\left(\lambda_{i}\right)\right\}=0$, where $\Sigma w_{i} g\left(\lambda_{i}\right)$ was a weight based on a consistent estimate of $\beta$-the fitted value for example. If the $t$-test on the coefficient $\alpha$ was insignificant, the null hypothesis of mean-variance equality cannot be rejected, suggesting the adequacy of a Poisson specification for the dependent variable-additional number of trips on TransAID.

${ }^{5}$ See Nelder and Wedderburn (1972) and Price (1995).

${ }^{6} \mathrm{~A}$ negative binomial random variable can be viewed as a realization of random variable from a specific compound Poisson distribution (Cameron and Trivedi 1986), where the mean varies linearly with the variance-or there was overdispersion. The overdispersion parameter in a negative binomial regression can be obtained from an auxiliary regression of the form $\left[\left(T_{i}-\lambda_{i}^{2}\right] / \lambda_{i}-1=v \lambda_{i}+k_{i}\right.$, where $v$ was the overdispersion parameter, and $k_{i}$ was a heteroskedastic stochastic error term. A negative binomial regression specification results when the estimate of $v_{i}$, was added as a variable to the Poisson regression specification.

${ }^{7}$ The Lagrange Multiplier Test procedure was based on an auxiliary regression where the residuals of the Poisson regression were regressed against all the variables initially included in the Poisson specification plus the estimated overdispersion parameter $v$. This was an approach suggested by Engle (1982), and we implement it here by viewing the Poisson specification as a restricted model, and the negative binomial specification as an unrestricted model. The test-statistic, distributed as a chi-square $\left(\chi^{2}\right)$ with degrees of freedom equal to the difference in the number of parameters between the negative binomial and Poisson regression specifications, was determined by the product of the unadjusted $R^{2}$ from the auxiliary regression times the number of observations $(N)$. If $N x R^{2}$ exceeds the critical value of the chi-square statistic, the null hypothesis that the overdispersion parameter $v$ has a zero coefficient that would have to be rejected.

\section{Acknowledgments}

This project was funded in part by the Urban Transit Institute of North Carolina A\&T State University, which was funded in part by U.S. Department of Transportation. Valuable research assistance was provided by William Nelson, a student in the transportation program at North Carolina A\&T State University. We also thank the manager of the Winston-Salem Transit Authority, Nedra Woodyethe, and the manager of TransAID, Suzanne Telechea, for their assistance with this 
project and Professor John Stone of NC State University for his assistance with the before study questionnaire. We also thank Dr. Gregory Price for his assistance with the data analysis.

\section{References}

Ben-Akiva, M., J. Benjamin, G. Lauprete, and A. Polydoropolou. 1996. Impact of Advanced Public Transportation Systems on Travel by Dial-a-Ride. Transportation Research Record 1557: 72-77.

Benjamin, J. 1994. Current trends in data gathering. Final Report. Prepared for the USDOT/FHWA.

Benjamin, J. 1995. Initial data analysis of the phase 1 before survey. Unpublished memorandum.

Cameron, A. C., and P. K. Trivedi. 1986. Econometric models based on count data: Comparisons and applications of some estimators. Journal of Applied Econometrics 1: 29-53.

Cameron, A. C., and P. K Trivedi. 1990. Regression based tests for overdispersion in the Poisson model. Journal of Econometrics 46: 347-364.

Casey, R., and J. Collura. 1993. Evaluation guidelines for the Advanced Public Transportation Systems operational tests. USDOT/FTA Report Number FTAMA-26-0007-94-2.

Casey, R., L. Labell, S. Prensky, and C. Schweiger. 1991. Advanced public transportation systems: The state of the art. USDOT/FTA Report No. DT-VNTSC-UMTA91-2.

Engle, Robert F. 1982. A general approach to Lagrangian Multiplier diagnostics. Annals of Econometrics, 20: 83-104.

LIMDEP 7.0: User's manual and reference guide. 1995. Econometric Software Inc., Bellport, NY.

McFadden, Daniel. 1974. The measurement of urban travel demand. Journal of Public Economics 3: 303 -328.

Nelder, J. A., and R. W. Wedderburn. 1972. Generalized linear models. Journal of the Royal Statistical Society 135: 370-384. 
Price, G. N. 1995. The determinants of entry for black-owned commercial banks. Quarterly Review of Economics and Finance 35: 289-302.

\section{About the Author}

JULIAN BeNJAmin (benjamin@ncat.edu) is a professor in the Department of Economics and Transportation/Logistics at North Carolina A\&T State University. He received his Ph.D. from the Department of Civil Engineering at the State University of New York at Buffalo. His research has focused on special transportation and travel demand analysis. He has many publications in these areas with several that look at the application of demand analysis to planning services in a special transportation agency. He is a former member of the GATE (an early special transportation agency) Board of Directors. 


\title{
Improving Metropolitan Transportation Efficiency With FAST Miles
}

\author{
Patrick DeCorla-Souza, Federal Highway Administration
}

\begin{abstract}
In America's large and severely congested metropolitan areas, carpools and express bus service could attract many more riders if they could operate between residential areas and job centers on free-flowing highways that provide premium service opportunities. FAST Miles attempts to eliminate recurring congestion on limited-access highway systems using a potentially more publicly acceptable form of road pricing, along with an integrated multimodal strategy to encourage shifts of solo-driving commuters to alternative modes. FAST Miles allocates to motorists a limited number of free miles for use in peak periods on limited-access highways. Every motorist would get a share of free peak-period use of FAST highway facilities "already paid for" through his or her taxes through free FAST Miles credits. Total outstanding credits would be limited to ensure that the metropolitan highway system does not get congested and that express bus services operate faster, providing better levels of service at a lower cost.

The concept would include new express bus and carpooling services, improved passenger collection and distribution services at bus transfer stations, free transit trial periods, web-based multimodal trip-planning programs, and individualized marketing of alternative modes at employment centers and in residential areas. Preliminary sketch analysis suggests that FAST Miles could be self-financing. It also would introduce new possibilities for public-private partnerships.
\end{abstract}




\section{Introduction}

Several metropolitan planning organizations have proposed networks of premium-service bus/high-occupancy vehicle (HOV) lanes or high-occupancy toll (HOT) lanes to create free-flowing traffic conditions for buses and HOVs. However, funds available to invest in complete networks of such facilities are inadequate due to high costs for highway facility expansion and special direct access ramps that are needed to provide safe access for buses. For example, a feasibility study for a network of HOT lanes in the Twin Cities of Minnesota suggests that tolls could pay for only 15 to 55 percent of the cost of building the lanes (Cambridge Systematics, Inc. and URS Corporation 2005). In some cases, limited rightsof-way and environmental and community impacts preclude highway expansion altogether, leaving some segments where buses would need to run in mixed traffic on congested highways.

This article presents a new concept called FAST Miles that seeks to create a complete premium-service express bus and HOV network without an immediate need for highway expansion, while at the same time providing new incentives for HOV and transit use through improved passenger collection and distribution services at residential and employment ends of the commute trip. The word FAST in FAST Miles is not used as an acronym, but simply represents the fast highway service provided by this concept.

\section{The FAST Miles Concept}

One cellular phone plan offered in the United States (i.e., Verizon) allows an unlimited number of free calls during off-peak periods and weekends, but limits free minutes on weekdays during the peak daytime period. Customers pay per minute charges for calls above the free limit during peak periods. The phone company is able to eliminate daytime congestion. This reduces the need to add expensive new capacity to serve discretionary calls during peak periods and encourages people to make these calls during off-peak times.

This phone service charging concept may be transferable to public services subject to peak demands, such as transportation. FAST Miles is such a concept. It allocates to motorists a limited number of free miles for use in peak periods on freewaytype limited-access highways called FAST highways. Every motorist would get a share of peak-period use of FAST highway facilities "already paid for" through his or her taxes through free FAST Miles credits. Total outstanding credits are limited 
to ensure that the metropolitan highway system does not get congested and that express bus services operate faster, providing better levels of service at lower cost.

All metropolitan-area motorists would be provided with an electronic transponder-a device that would capture miles driven on limited-access highways during the morning and afternoon peak periods. ATM-like machines now dispense transponders in sticker form for as little as $\$ 5$ each in Puerto Rico. Out-of-towners could obtain transponders from such machines at visitor centers or through the mail. With a nationally coordinated FAST Miles program, "sticker" transponders could be made available to all motorists nationwide.

Each licensed motorist would get a personal FAST Miles account that would be replenished daily with free credits for a limited number of free peak-period highway miles for that day. Additional miles could be purchased at rates that would depend on congestion levels. Rates per mile would be set high enough to dissuade discretionary trip-makers from peak-period use. This would help assure that demand does not exceed supply of congestion-free road space available and would help prevent the breakdown of the free flow of traffic. The extent of the highway system on which peak-period highway mileage charges would apply would be determined based on the extent of existing congestion on the system.

Mileage charges would apply only to limited-access FAST highways and only during peak periods. Charges are generally not practical on surface arterials. To charge for use of surface arterials, transponder readers would generally be needed on every block to prevent motorists from attempting to evade charges by diverting to parallel streets at charging points. This would increase implementation costs significantly. Therefore, with FAST Miles, tolls would not be charged on surface streets at any time of the day.

Congestion levels vary both by highway segment location and by the specific time of travel within the peak period. Therefore, free miles would be charged to motorists' accounts at a discounted rate during those times and on those segments that have less heavy demand. Conversely, free mile "surcharges" would be applied to more heavily used segments and at more heavily used times (i.e., motorists would need to use their free miles at a higher rate than actual miles driven).

Those participating in carpools and vanpools could link their FAST Miles accounts. This might be accomplished, for example, by registering with the metropolitan ridesharing agency. This would allow those who currently drive solo in single- 
occupant vehicles (SOVs) and have long commute trips to avail themselves of additional free miles by sharing the ride. Transit operators could attract longdistance suburban commuters by providing a fare credit equal to the value of the commuter's free FAST Miles if the commuter links his or her FAST Miles and transit fare card accounts.

If desired, trading systems could be set up, so that motorists who do not use their free miles would be able to cash in on their unused miles (DeCorla-Souza 1994). However, this would reduce the number of free miles that could be offered to those who currently use the highways in peak periods, potentially increasing opposition from them. Also, it may be negatively perceived as providing "windfall profits" to those who currently do not use the highway system during peak periods.

Long-distance commuters who value their time highly may still choose to drive alone and pay for extra miles. Surplus revenue from extra-mile payments could be dedicated to uses that would benefit these commuters. For example, relatively low-cost improvements such as signal coordination may be implemented on alternate nonpriced surface streets that long-distance commuters might choose to use to avoid extra highway mileage charges. Transit operators may be provided with public subsidies equal to the value of FAST Miles credits turned in to them by those patrons who commute long distances on transit. FAST highways may be expanded or transit capacity in the corridor enhanced, whichever is more costeffective, to accommodate their higher rates of peak use. Park-and-ride facilities, pedestrian and bicycle access (including bike rental facilities at bus stations), and shared-ride taxi services may be provided in suburban residential communities and at employment centers to facilitate the use of carpools or transit.

Providing incentives for use of non-SOV modes reduces vehicular travel demand. Those long-distance commuters who choose to drive alone and pay for the privilege will benefit from reduced vehicular travel demand resulting from mode shifts, because rates they would have to pay for extra miles would be lower. Rates would be lower because prices needed to eliminate recurring congestion would be lower when vehicular travel demand is reduced.

The FAST Miles concept would in effect produce what has been termed a "Fast And Intertwined Regular" (FAIR) highway network-a metropolitan highway system with two classes of service: a FAST network of free-flowing limited-access highways allowing for efficient and effective operation of express bus services; and a regular network of surface arterials (DeCorla-Souza 2005). 


\section{Can Demand for Highway Use Be Reduced?}

Traffic volume-speed relationships suggest that reducing existing peak-period highway traffic levels by relatively small amounts, as little as 10 percent, can eliminate recurring highway congestion (Transportation Research Board 2000). Drivers in the Washington, D.C. metropolitan area notice this phenomenon in August when peak-hour traffic is reduced by only small amounts due to some commuters being on vacation. Californians observe it on days when only state government employees are off work due to a state holiday (Wachs 2003). In such situations, there is not sufficient time for "equilibrium" with regard to traffic congestion to be restored (i.e., people who previously changed their mode, route, or time of travel choice due to congestion do not immediately get back on the highways during the peak periods to take advantage of the reduced congestion).

FAST Miles, when combined with improved modal alternatives, would provide a new incentive for a relatively small number of solo drivers with long commutes to reduce their highway use during peak periods by seeking alternative commuting arrangements. Solo drivers whose highway trip lengths exceed their free FAST Miles allocation would be more likely to consider carpooling, taking transit, telecommuting more often, driving during off-peak periods or on non-FAST facilities, or-in the longer term-moving closer to their jobs. Charges for extra miles would reduce the incentive for others, such as those long-distance commuters who previously changed their travel behavior due to congestion, to get back on the highway in peak periods to take advantage of free-flowing traffic conditions.

According to a recent Washington Post-ABC News poll (Langer 2005; Washington Post 2005), one third of those who drive to work alone in the Washington D.C. metropolitan area say they could take transit but do not. If they were to choose transit, SOV commuter traffic might be reduced by 33 percent. Nationwide, while just 8 percent of commuters currently carpool, 20 percent of solo drivers say that they would be interested in it-enough to take at least 10 percent of SOV commute vehicles off the road, assuming that each solo driver would share the ride with one other solo driver; or as much as 20 percent if it is assumed that all those solo drivers would join an existing carpool.

Achieving the relatively small reduction in peak-period traffic required to achieve free-flowing traffic conditions might not be as difficult as conventional wisdom might suggest. The U.S. Department of Transportation's 2001 National Household Travel Survey (U.S. Department of Transportation 2004) suggests that, in metropolitan areas with more than half a million people, one-way commute trips 
more than 20 miles long make up only 13 to 17 percent of all commute trips, but account for 37 to 45 percent of commute miles traveled. If heavy highway usage by these longer trips can be reduced by one third by encouraging use of transit and carpooling, this would amount to only about 4 to 6 percent of all commute trips. But such a relatively small reduction could decrease commute vehicle miles traveled by 12 to 15 percent, possibly sufficient to restore free-flowing traffic conditions in peak periods.

The National Household Travel Survey also found that only 50 percent of trips are work-commute related in the morning peak period, while less than 30 percent are work-commute related in the afternoon peak. This suggests that many peakperiod trips may be discretionary in nature. These trip-makers may be more easily dissuaded from using highways during peak periods and may have more flexibility to shift their time of travel to off-peak periods. In fact, on a set of two tolled bridges in Lee County, Florida, when a discount of just 25 cents was offered for travel before and after the heaviest travel periods, more than 70 percent of motorists eligible for the discounts chose to shift their time of travel to the discount periods at least once a week (Berg et al. 1999).

\section{Costs to Implement FAST Miles}

\section{Costs for Toll Collection, Credit Distribution, and Traffic Management}

Table 1 presents estimates of typical costs to implement FAST Miles in a large metropolitan area-Washington, D.C. This metropolitan region has about 4 million people. About two thirds of residents are licensed drivers and each driver generates about 3.8 vehicle trips each weekday (U.S. Department of Transportation 1999). Thus, a total of about 10 million vehicle trips are generated each weekday. Almost 40 percent of travel occurs in peak periods (U.S. Department of Transportation 1999). This means that about 4 million vehicle trips are carried on the regional highway system in peak periods. At an average trip length of 11.84 miles (U.S. Department of Transportation 1999), about 48 million vehicle miles of travel occur on the highway system during the morning and afternoon peak periods.

In Washington, D.C., about 42 percent of travel is carried on limited-access highways (U.S. Department of Transportation 2003). It is estimated that about 20 million vehicle miles are carried on the limited-access highway system in peak periods. The average distance traveled by the 4 million peak-period trips on the limitedaccess highway system may thus be calculated as almost 5 miles. (This average 


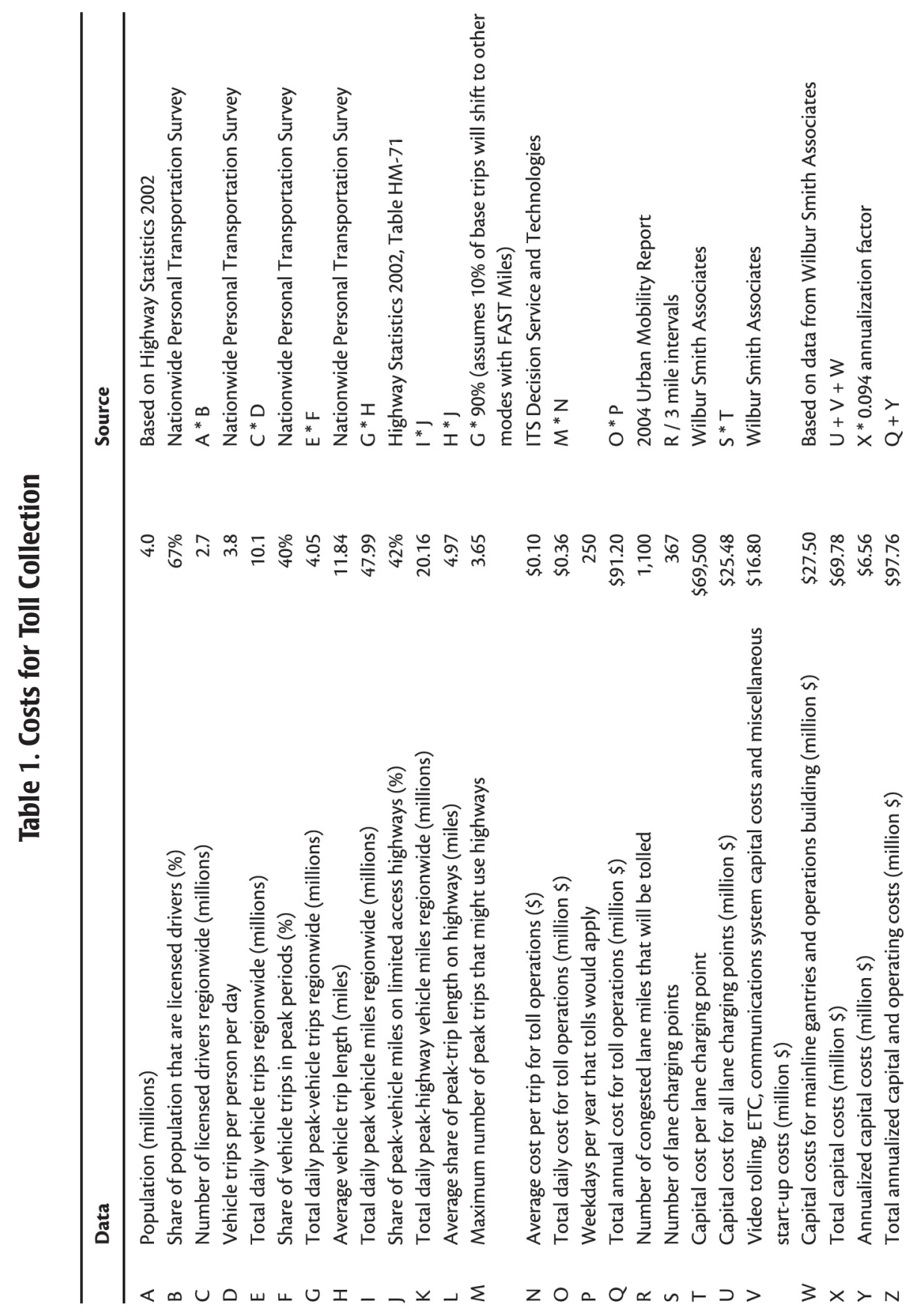


includes some trips that may not use the limited-access highway system at all.) Conservatively assuming that all of the 4 million trips currently use the limitedaccess highway system for a part of their trip lengths, and that 10 percent of these trips would shift to alternative modes with FAST Miles, a maximum of about 3.65 million trips would use the highway system daily during peak periods.

Costs for toll collection are estimated at 5 to 10 cents per trip by ITS Decision, Service and Technologies (2005). Toll collection costs will decrease with large-scale implementation. However, administration of a FAST Miles system may be more complex and therefore more costly than a typical toll collection system, due to dispensing of daily credits, flexible use of credits on transit, etc. Therefore, costs for the FAST Miles system are estimated at the high end, at about 10 cents per trip, including costs for traffic monitoring and management. Therefore, a FAST Miles system in Washington, D.C., with 3.65 million peak-period highway trips would cost about $\$ 365,000$ per day to operate, or about $\$ 91$ million over the 250 weekdays each year that the FAST Miles system would be in operation-not an insignificant cost.

Table 1 also provides estimates for toll collection capital costs based on cost data for open road tolling provided by Wilbur Smith \& Associates. It is assumed that the FAST highway network will employ open road tolling, with toll charging points located at approximately 3-mile intervals along 1,100 lane miles of congested FAST highway segments in the Washington, D.C. metropolitan area (Schrank and Lomax 2005), resulting in the need for 367 lane-charging points.

Capital costs per lane-charging point are estimated at $\$ 46,000$ for Electronic Toll Collection (ETC) costs and $\$ 23,500$ for Video Enforcement System (VES) costs, or a total of $\$ 69,500$ per lane-charging point, resulting in total costs of $\$ 25.5$ million for the whole FAST highway network. Video tolling hardware and software, ETC equipment, system software, communications system, other equipment, and miscellaneous installation, project management and training costs are estimated at a total of $\$ 16.8$ million. Mainline gantry costs are estimated at $\$ 25$ million and operations building costs at $\$ 2.5$ million.

Total capital costs are estimated at $\$ 70$ million. Annualized at a 7 percent discount rate and 20-year payback period, these costs amount to about $\$ 6.5$ million per year. Total annualized capital and operating costs thus amount to almost $\$ 98$ million. 


\section{Costs for New Express Bus Service}

Estimates of express bus service costs are presented in Table 2. It is assumed that new express bus service would be introduced during peak periods, from 6 A.M. to 9 A.M. and from 4 P.M. to 7 P.M. (i.e., about six hours a day). It is estimated that this service would operate on the approximately 300 miles of limited-access highways in Washington, D.C. (i.e., about 600 route miles for both directions), at an average frequency of one bus every three minutes (i.e., an average of 20 buses an hour). It is assumed that each bus would travel an additional 20 percent of route miles off the freeway network to pick up and drop off passengers. Total revenue miles of service each day would be 86,400 route miles. Assuming an average bus speed (including intermediate stops for pick ups and drop offs) of $20 \mathrm{mph}$, total revenue hours of service per day would be 4,320 .

At an average bus speed of $20 \mathrm{mph}$, each bus would serve 120 revenue miles each day. Operating 86,400 revenue miles each day would require 720 buses. At a cost of about $\$ 340,000$ per bus (American Public Transit Association 2005), capital costs for buses would be $\$ 245$ million, or an annualized cost of about $\$ 35$ million assuming a 7 percent discount rate and 10-year bus life.

Based on cost data for Seattle, Washington (McDonald 2003), bus operating costs for a typical large metropolitan area may be estimated at $\$ 90$ per revenue hour. Due to the higher labor costs for split shifts and use of part-time labor for peakperiod service, costs for a typical express bus network are estimated to be from 1 to 10 percent higher than for conventional operations (Charles River Associates $2001)$, or a maximum of about $\$ 100$ per revenue hour. Operating costs would be $\$ 432,000$ per day or about $\$ 108$ million per year assuming weekday operations only (i.e., 250 days per year excluding holidays).

Total annualized costs for capital and operation of new express service are thus estimated at about $\$ 143$ million. This estimate does not include infrastructure costs for bus stops and shelters, bus storage, and maintenance facilities, etc. However, some cost savings would be realized with regard to operation of the existing transit system. Also, some existing transit infrastructure could be utilized for the new system.

Assuming a 10 percent reduction in peak-period vehicle trips due to pricing, a total of 0.4 million SOV trips would need to be shifted to either transit or HOV. Assuming that half of these trips are carried on transit, with the remaining shifting to carpools, about 0.2 million new transit person trips would need to be served. At an average transit passenger trip distance of 10 miles, 2 million passenger miles 


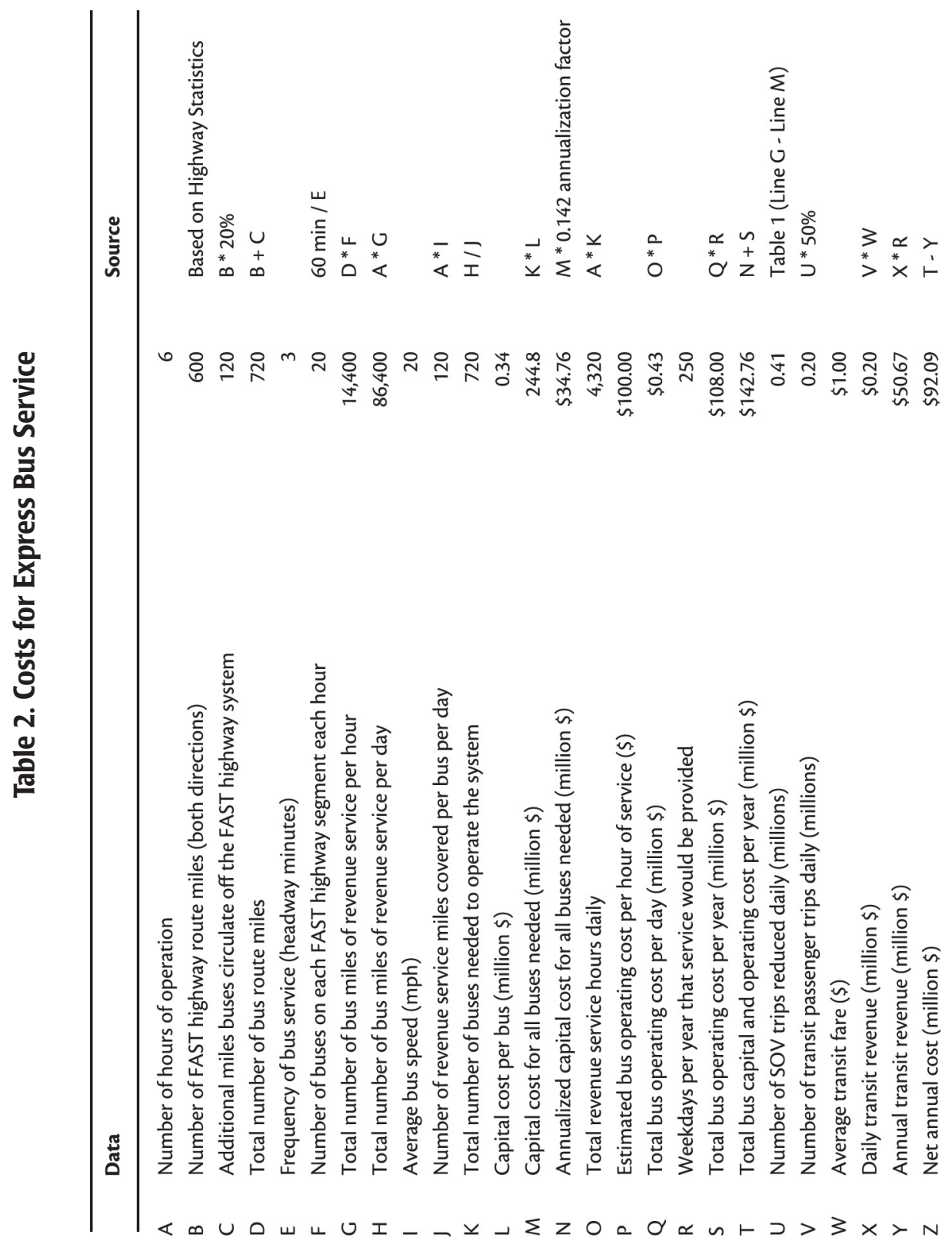


would be served. A shorter average transit trip length relative to auto trip length (i.e., 11.84 miles) was assumed to account for the additional driving distance for park-and-ride transit trips. On average, 23 passengers would be served per bus mile (i.e., 2 million passenger miles/86,400 revenue miles per day).

Revenues from transit passengers, conservatively assuming a fare of $\$ 1.00$ per trip, would amount to about $\$ 200,000$ per day, or about $\$ 50.6$ million per year for 250 days of service. Net annual transit agency costs per year would be about $\$ 93$ million.

\section{Financial Feasibility}

Table 3 presents estimates of potential toll revenue. As estimated above, FAST highways in Washington, D.C., would carry about 3.65 million peak-period highway trips, generating about 18 million vehicle miles per day. Assuming a set-aside of 3 million vehicle miles (i.e., about 17\%) for purchase by those who need extra miles, including nonresidents who would not be eligible for a free allocation, about 15 million miles would be traveled for free. Far more free miles could be offered to motorists, however, since many drivers will likely not use all their free miles during peak hours.

The average rate that solo drivers are charged during peak periods for use of the HOT lanes on $1-15$ in San Diego is about 25 cents per mile (i.e., about $\$ 2.00$ for the 8-mile trip) based on annual revenue of about $\$ 2.4$ million and an average of 5,000 paying solo driver trips on each of 250 weekdays (U.S. Department of Transportation 2004). Paying drivers are only a small fraction of the approximately 55,000 auto drivers who use $\mathrm{I}-15$ during the AM and PM peak periods each weekday (Supernak 2001). Like paying I-15 HOT lane users, many paying FAST highway motorists would be comparing travel times on alternate free routes with travel times on FAST highways in deciding whether to use FAST highways. However, they may be willing to pay higher toll rates for extra miles, because traveling an extra mile may allow them to avail of additional "free" travel time savings through use of their FAST Miles credits. For the purpose of revenue estimation, we may conservatively assume an average charge of 25 cents per mile (comparable to I15) for each of the 3 million extra miles available for purchase under a FAST Miles system. Thus, tolls paid for extra miles would bring in $\$ 750,000$ daily, or about $\$ 188$ million annually, over 250 weekdays. This amount is comparable to the total costs of about $\$ 191$ million estimated above for operating the FAST Miles program, 


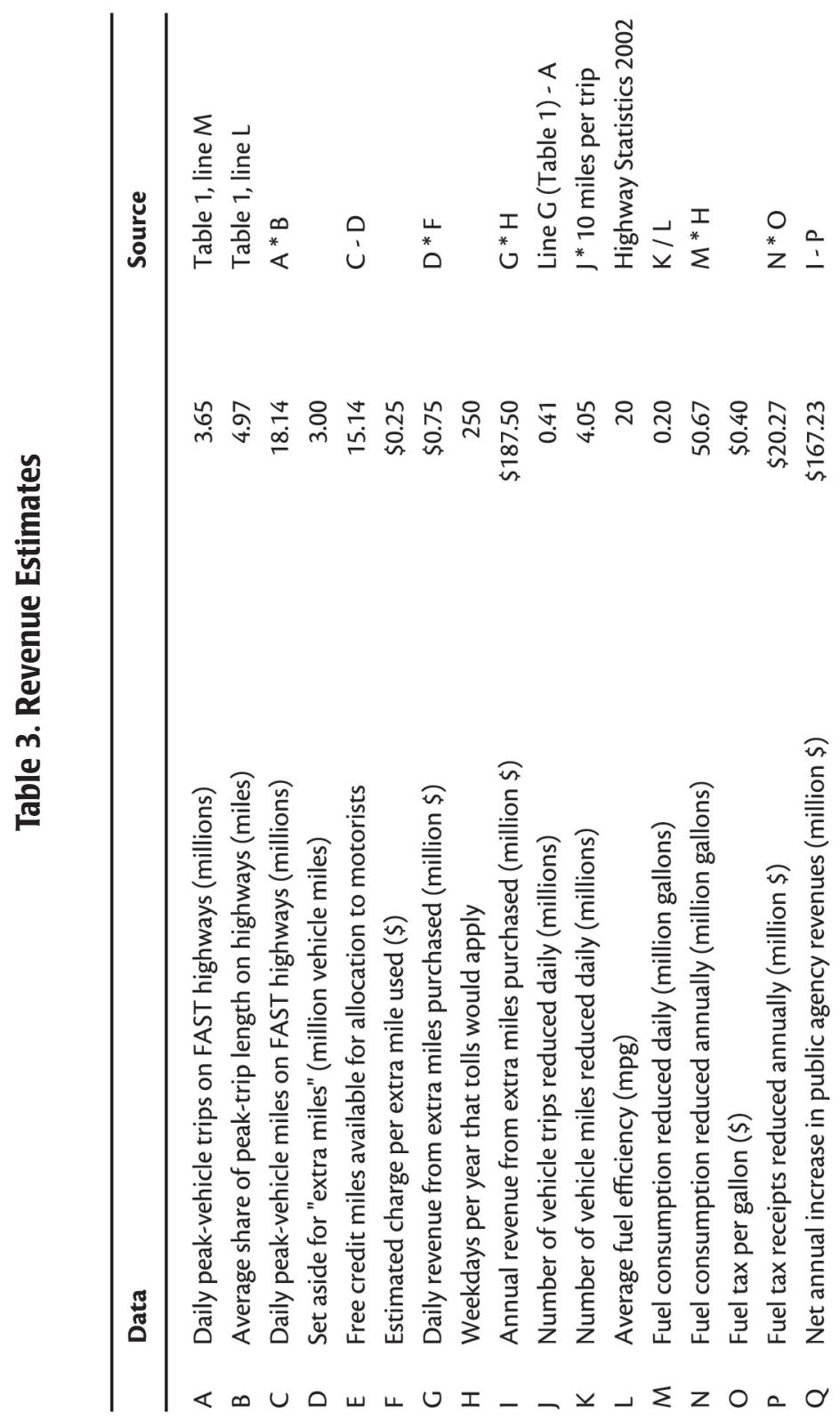


including costs for toll collection, credit distribution and traffic management (i.e., about $\$ 98$ million annually) and costs for new express bus service (i.e., about $\$ 93$ million annually).

However, there would be concomitant fuel tax revenue losses to state and Federal governments due to reductions in fuel consumption. This would result from the reduction in vehicle miles traveled as well as elimination of excess fuel consumption that previously resulted from stop-and-go traffic on the highways. At the current average state and Federal total fuel tax rate of about 40 cents per gallon and fuel efficiency of about 20 miles per gallon, these revenue losses are estimated at about $\$ 20$ million annually. This estimate assumes that the daily reduction of 0.4 million vehicle trips would result from a shift to carpools and transit with an average of 10 miles of the total previous SOV trip length of 11.84 miles carried on the carpool and transit portions of the commute trip. It also ignores reduced fuel consumption due to free-flowing traffic conditions.

\section{Benefits from FAST Miles}

With FAST Miles, the entire limited-access highway system would serve the purpose of a "fixed guideway" for transit. HOVs would get premium service free of charge on FAST highways when those participating in a carpool link together their FAST Miles accounts. Therefore, the need for tax dollars to support public investment in special express bus and HOV lanes would be eliminated, including costs for additional pavement and rights-of-way for new special-purpose bus/HOV lanes, for lane separation, for special ramps to provide access to and egress from the lanes, and for enforcement of vehicle occupancy requirements for carpools.

Maximum vehicle flow on limited-access highways occurs when highway speeds are 55 to $65 \mathrm{mph}$ (Chen and Varaiya 2002). Vehicle throughput on a severely congested freeway may be reduced significantly due to the increase in vehicle density and the concomitant drop in speeds. When traffic volumes reach a certain threshold level-approximately 2,000 vehicles per lane per hour or a vehicle density of about 35 vehicles per lane per mile-traffic flow breaks down, and speed as well as vehicle throughput decrease precipitously. This has been termed "the freeway congestion paradox" (Chen and Varaiya 2002). Even though demand may decrease after the peak period, the highway does not recover its full vehicle throughput capability until much later, because queued vehicles from previous hours keep vehicle density high and speeds slow. By ensuring that traffic flow does 
not break down in the first instance, FAST Miles may actually increase highway vehicle throughput in peak periods.

The variably tolled express lanes in the median of SR 91 in Orange County, California, demonstrate the ability of pricing to maximize highway throughput by keeping traffic at free-flow speeds. Speeds are 60 to $65 \mathrm{mph}$ on the priced express lanes. In the peak hour, they carry almost as many vehicles as do the congested free lanes even though there are twice as many free lanes (U.S. Department of Transportation 2004). Pricing the express lanes allows twice as many vehicles to be served per lane in the peak hour, at three to four times the speed on the free lanes. Almost half the public investment in SR 91's free lanes is simply wasted in peak hours. FAST Miles, however, can restore to full use the public investment that is being wasted every day in major metropolitan areas on congested highways, during critical times of the day when the investment is most needed.

A rough idea of the magnitude of travel time savings benefits to motorists on FAST highways may be obtained by a few simple calculations, as demonstrated in Table 4. When there are no incidents or accidents, typical speeds on highways in a large metropolitan area such as Washington, D.C., average 40 miles per hour in the peak periods (Safirova et al. 2003). FAST Miles would restore free-flow speeds averaging 60 miles per hour, except when collisions or incidents block traffic. Under normal conditions, this means that an average 5-mile limited-access highway trip would save a half-minute per mile, or 2.5 minutes over its entire trip length. Metropolitan areas are forecasted to experience increasing levels of congestion in the future. If average peak-period speeds were to drop to $30 \mathrm{mph}$ (from the current $40 \mathrm{mph}$ average), time savings to FAST highway motorists would double to 1 minute per mile driven, or 5 minutes over a 5-mile FAST highway trip.

The U.S. Department of Transportation (2002) estimates that an hour of travel time is valued at an average of about $\$ 12$ for all types of personal travel (or about $\$ 11.20$ in 2000 dollars). Thus, a single 5-mile highway trip would save about $\$ 0.50$ in travel time costs today based on 2.5 minutes saved, and as much as $\$ 1.00$ in the future based on 5 minutes saved. The 3.65 million FAST highway trips would save $\$ 1.8$ million to $\$ 3.6$ million per day, or almost $\$ 0.5$ billion to $\$ 1$ billion over 250 weekdays each year-not an insignificant benefit, and several times the estimated costs for implementing and operating FAST Miles.

Eliminating recurring congestion would also have additional benefits for express bus riders. The reliability of both transit and highway trip times would increase significantly. The value of travel time reliability has been estimated at 100 percent 


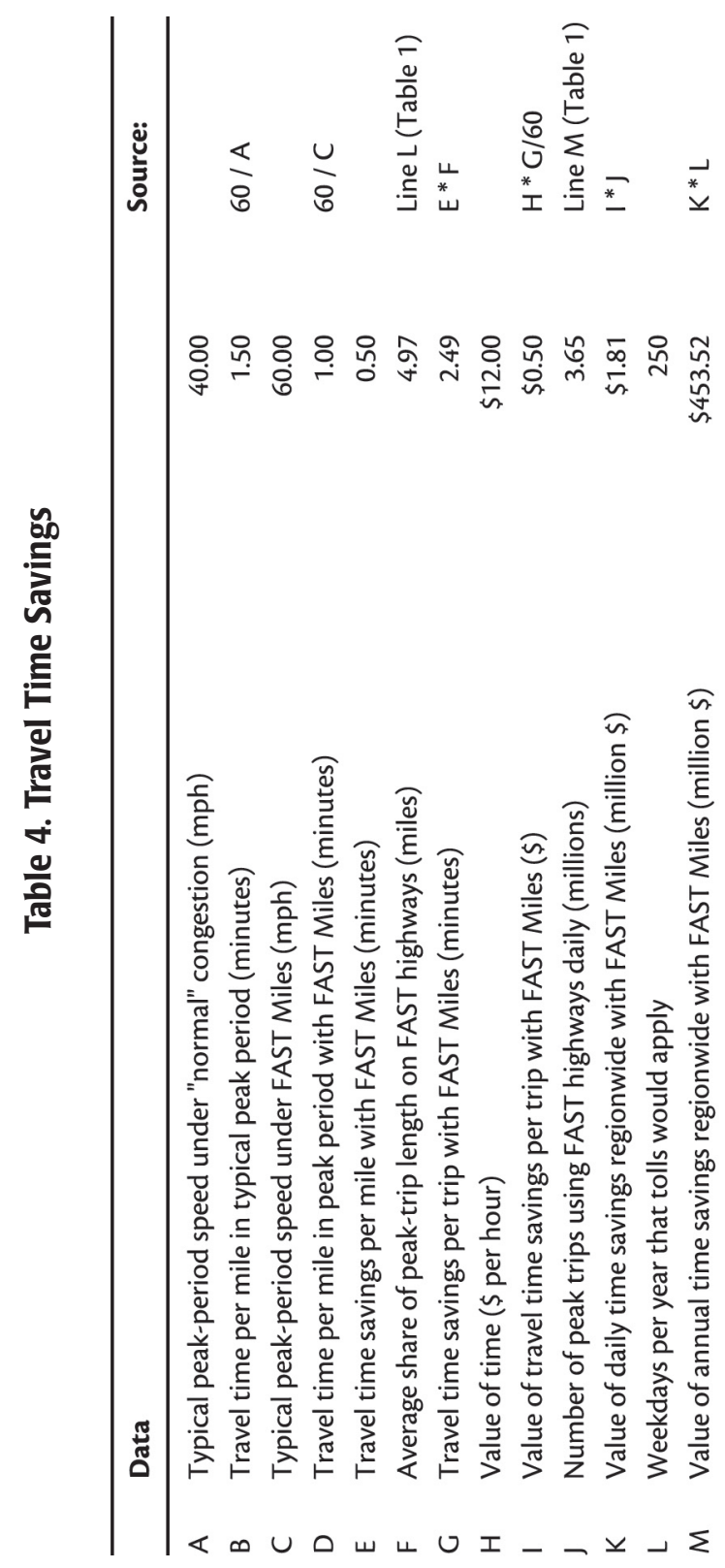


to 250 percent of the value of travel time savings (Brownstone and Small 2003; HLB Decision Economics Inc. and University of California at Irvine 2001). Eliminating recurring congestion will tend to reduce other delays, such as those caused by incidents, accidents, and road construction, since queues caused by such events will be shorter. Also, fuel consumption would be reduced. Thus, if benefits to transit riders, and additional benefits to motorists in the form of fuel savings, accident savings, and travel time reliability improvements are accounted for, total benefits to travelers on the FAST network would exceed by far the benefits estimated above based on motorist travel time savings alone.

Long-distance travelers who change their travel behavior in response to implementation of FAST Miles may suffer some disbenefits. Those travelers that respond by changing their travel route may also cause additional delays to other motorists on those routes. The key to ensuring that these disbenefits are minimized is to ensure that levels of service on alternative modes (mainly transit and HOV) are enhanced as much as possible so that the aggregate "disutility" of cost, travel time, and inconvenience of these modes (including access and egress) is no higher than the aggregate disutility of cost, travel time, and inconvenience of driving alone on congested highways prior to establishment of FAST Miles.

Disbenefits may also accrue to those priced off the FAST highways and those using parallel alternative routes in the vicinity of FAST highways, due to added delays that may result from diversions to these routes. However, negative impacts from traffic diversion can be minimized through use of surplus FAST Miles revenue for investments in advanced arterial signal systems. This will help accommodate traffic diversions, if any. Due to increased vehicle throughput on free-flowing freeways, however, diversions from arterials to FAST highways may exceed any diversions from FAST highways to arterials. Empirical evidence from SR 91, as discussed earlier, suggests that the higher throughput on the two priced lanes (per direction) allows more traffic to be carried through the corridor than would have been possible if all six lanes (per direction) were free. Since FAST highways are expected to carry more vehicles than they did under congested conditions, the burden of traffic on parallel arterials may actually be reduced.

As travel demand increases in the future, extra mile charge rates will also rise, providing more FAST Miles revenue-and making appropriate investments in highway expansion and transit and HOV services, including access to and egress from transfer locations, more financially feasible. 
By reducing vehicular travel, FAST Miles would lead to lower automobile pollutant emissions and improve metropolitan air quality. Urban sprawl may be discouraged if people choose to live closer to their jobs in order to reduce FAST Miles charges, rather than choosing to live far from urban centers to take advantage of free highways and lower housing prices, as many do now.

On the other hand, the choice to live further away from dense urban centers may become more appealing to some as a result of the provision of new express bus services and ancillary access and egress improvements, new opportunities to form carpools, an increase in FAST highway vehicle throughput due to elimination of high levels of recurring congestion, and improved levels of highway service due to elimination of traffic flow breakdowns. Creation of new transportation capacity, whether through new transit and HOV investments or through elimination of inefficiencies on the existing highway system, does have the potential to induce new development further away from city centers.

To reduce this effect, it will be important for government agencies to forewarn those choosing to live far from urban centers that FAST Miles charges for extra miles may increase in future, especially if new transportation capacity does not keep pace with growth in peak-period vehicular travel demand. This is exactly the situation currently being experienced with regard to toll rates on the SR 91 express lanes in Orange County. The facility serves commuters from the rapidly growing suburban community of Riverside County, and maximum toll rates for the 10-mile segment have increased from about $\$ 2.5010$ years ago to almost $\$ 8.00$ today due to rapid growth in travel demand in the corridor.

\section{Public Acceptance}

How will the public react to FAST Miles charges? Table 5 presents the major public acceptance issues associated with road pricing and how FAST Miles attempts to address them.

The public appears to have little confidence in the effectiveness of adjustable tolling as a traffic reduction strategy. The Washington Post-ABC News poll cited earlier (Langer 2005) found that only 7 percent of people believe that such tolling is very effective as a traffic remedy. However, carpooling and transit are believed to be very effective by 39 percent and 42 percent of people, respectively. Since FAST Miles is an integrated multimodal strategy that would include significant incentives for carpooling and transit, the public may have greater confidence in 
Table 5. Public Concerns

\begin{tabular}{|l|l|}
\hline \multicolumn{1}{|c|}{ Public Concern with Road Pricing } & \multicolumn{1}{c|}{ How FAST Miles Addresses the Concern } \\
\hline $\begin{array}{l}\text { Public does not believe adjustable tolls are } \\
\text { effective }\end{array}$ & $\begin{array}{l}\text { Adjustable tolls are combined with transit and } \\
\text { HOV improvements that have high public support }\end{array}$ \\
\hline Public opposes "new" charges for road use & $\begin{array}{l}\text { Tolls apply only to those who use more than their } \\
\text { fair share of peak highway capacity, and tolls are } \\
\text { only charged if the payer gets congestion-free service }\end{array}$ \\
\hline $\begin{array}{l}\text { Public is concerned about government } \\
\text { knowing where and when they travel }\end{array}$ & $\begin{array}{l}\text { Private operator operates tolling, and deletes all } \\
\text { travel data at day's end }\end{array}$ \\
\hline $\begin{array}{l}\text { Public is concerned about equity for low } \\
\text { income motorists }\end{array}$ & $\begin{array}{l}\text { All motorists get an equal share of free credit } \\
\text { miles; only motorist who use the freeways heavily } \\
\text { during peak periods would have to pay more }\end{array}$ \\
\hline $\begin{array}{l}\text { Neighbors are concerned about diversion of } \\
\text { traffic to free roads }\end{array}$ & $\begin{array}{l}\text { New transit and HOV options will reduce total } \\
\text { traffic, and FAST highways will carry more traffic, } \\
\text { reducing the traffic burden on parallel arterials }\end{array}$ \\
\hline
\end{tabular}

the effectiveness of FAST Miles. While only 29 percent of those surveyed favor adjustable tolls, 51 percent support HOV lanes (Langer 2005). With FAST Miles, the entire highway system would, in effect, be transformed into an HOV system that provides premium service for HOVs, express buses, and paratransit services. Therefore, the FAST Miles concept may get a higher level of support from the public than adjustable mileage charges by themselves would.

However, some people may still oppose the "new" charges, especially those who currently drive alone for long distances. Their concerns may be alleviated somewhat by guaranteeing that no charges will be made to their FAST Miles accounts for any miles for which they did not get congestion-free service.

Some may be concerned about the new ability of the government to monitor their vehicle movements. These public concerns may be alleviated if a private operator is hired to run the system and the government does not control the data, as in the case of credit card companies. Additionally, the private operator could be required to discard all data daily at the end of the afternoon peak period, saving only the gross amount of money charges incurred by each account holder on that day. Motorists may request that their daily usage data be forwarded to them electronically at the end of each day before being erased from the system, so they could check for accuracy of charges.

Will elected officials and the public perceive FAST Miles as equitable? Road pricing schemes that have been implemented to date tend to require motorists to 
bear new charges if they want to avail themselves of premium highway service. Consequently, premium-service facilities, such as the SR 91 express lanes in Orange County, California, have disproportionately higher use by high-income motorists (U.S. Department of Transportation 2004). On the other hand, with FAST Miles most highway travelers would be guaranteed a reliable and congestion-free trip for free, with all motorists allocated an equal number of free miles regardless of income level. If a trading system were put in place to permit buying and selling of FAST Miles credits, low-income motorists, who tend to drive fewer miles, could cash in on their unused miles. If some revenues were dedicated to subsidizing bus service, which is used more often by low-income travelers, this would also enhance equity.

With FAST Miles, those who have long commute trips and choose to continue to drive solo would, through charges for extra miles, pay for highway capacity expansion to accommodate their more intense usage, or to accommodate some travel demand on transit and in carpools, including costs for access and egress improvements at transit stations and carpool park-and-ride facilities. Shifts in mode of travel encouraged by these improvements would free up existing highway capacity to accommodate the remaining long vehicle trips more efficiently. The rest of the public would not have to pay for disproportionately higher demands placed on the highway system in peak periods by a few trip-makers - either through congestion delays imposed upon them, as under the existing system; or through new taxes or tolls that are often proposed to pay for new capacity to relieve that congestion. Opposition to new charges based on the perception of "double taxation" would be weakened. Every motorist would get a share of peak-period use of FAST highway facilities "already paid for" through his or her taxes. Those who would like to avail of greater use would have a choice to do so by paying for it.

Won't commuters with longer trips simply divert to free roadways and cause additional congestion on them, infuriating local residents? The public is well aware that when tolls are raised on existing tollways, some drivers divert to free alternatives. However, FAST Miles does not simply involve new charges; a package of reasonably convenient transit and HOV options is included to make simple diversion to free roadways less appealing to the solo driver. Research by Washbrook (2002) suggests that, while improvements in travel time for carpools and transit by themselves do not generally achieve a high level of mode shift, these improvements can be extremely effective when combined with an increase in charges for road use or parking. When new highway charges are combined with carpooling and transit 
improvements, traffic may actually be reduced on parallel arterials because some arterial travelers who were previously deterred by freeway congestion may shift back to free-flowing FAST highways whose vehicle throughput has increased (as on the SR 91 express lanes), at the same time that corridor vehicular demand is reduced due to increased use of alternative modes.

\section{Public-Private Partnership Possibilities}

A new model for partnerships with the private sector could be used to implement and operate FAST Miles and supporting transit and carpool systems. Private operators of FAST highways could be paid by public agencies based on the number of free-flowing vehicle miles of travel provided in peak periods, with appropriate reductions in fees for those vehicle miles that are not congestion-free (DeCorlaSouza and Barker 2005). For example, the private partner may be paid for a vehicle trip carried at $45 \mathrm{mph}$ on the facility at three quarters of the rate that would apply if the trip were carried at $60 \mathrm{mph}$. Operators would thus have an incentive to ensure that the entire pricing scheme is set up to optimize vehicle throughput on the highway system at the highest speeds.

All revenues from extra mileage charges would go to public agencies. Thus, private operators would have no incentive to keep extra mile rates higher than they need to be for the purpose of managing demand, and would instead have an incentive to keep the rates as low as possible to maximize use without degrading levels of service. Potential private operators could be selected based on open competition. Criteria for selection could include the lowest fee per free-flowing vehicle mile they would be willing to accept as compensation for their services.

Technologies to count vehicle occupants (such as through heat sensing) are currently in the experimental stage. In the future, as such technologies come to market, it may be possible to enter into more comprehensive agreements with private sector toll and transit operations consortiums to manage the entire multimodal transportation system. The consortium would be paid for performance with respect to the metropolitan community's goal of maximizing mobility and access. Fees would be based on the number of persons carried on FAST highways and their speed of travel during peak periods. This would provide an incentive to the private sector to make the most cost-efficient modal investments and to promote and encourage ridesharing and transit use. An example of such a private operation, with a public sector role in planning, regulation, and monitoring, may be seen in 
Rome, Italy. The city's public transport and private automobile mobility services have been combined into a single private company called ATAC (translated in English as Agency for Bus and Rail Transport in the Municipality of Rome). Private automobile mobility services provided by this company include normal highwayrelated Intelligent Transportation System services as well as the operation of the downtown access control system, which charges fees for private vehicle entry into Rome's historic district to control congestion and air pollution.

To encourage increased private provision of new transit services, private operators of transit services could be made eligible for subsidies based on FAST Mile credits turned in by their patrons. For example, assuming a market value of 25 cents per credit mile, if a patron turned in 10 free miles per day from his or her FAST Miles account, the transit operator would be eligible for a total public payment of $\$ 2.50$ per day (i.e., \$1.25 per one-way trip). Private entrepreneurs would thus have incentives to establish targeted paratransit or vanpool services to cater to the needs of long-distance commuters. These incentives may be particularly appropriate in markets where existing public transportation is inadequate.

Private provision of services for access and egress at transit stations and carpool transfer locations may be encouraged by allowing the use of FAST Miles credits as payment for service, with reimbursements provided by the public sector. Private businesses may be encouraged to establish and operate bike rental services, shuttle bus services, and shared-ride taxi services at transit transfer locations, if FAST Miles credits can be used by their customers to pay for their services.

\section{Phasing In FAST Miles}

It is important that an enhanced transit system be in place before the FAST Miles credit/charging program goes into operation. Introducing monetary prices for rush-hour use of highways by itself will have a very limited impact if transit travel options are not already available and well understood by the traveling public. This may present a "chicken-and-egg" problem with regard to funding, since transit investments will need to be made and services will need to be established before revenues from FAST Miles operation begin to kick in. Thus, it will be important to secure in advance the public funding needed. A possible source might be the issuance of bonds backed by the future stream of revenues after FAST Miles implementation. 
However, the critical time advantages needed for success of transit services are difficult to provide before free-flowing traffic conditions are created by FAST Miles. Creative ways to develop travel time advantages for transit may be needed. One potential solution is to establish an extra transit lane on proposed FAST highways by restriping the highway to allow shoulder use as a transit lane, during rush hours. For example, a "rush-hour lane" has been implemented on I-66 outside Washington, D.C.'s Beltway, and such rush-hour lanes are more extensively used in the Netherlands.

With bus lanes and express bus services in place in advance of FAST Miles implementation, commuters will have an opportunity to understand and experience some of the travel time advantages that a full-fledged FAST Miles system might provide after the entire highway is free-flowing. To increase public understanding of the new and enhanced transit system, it will be important to implement complementary travel demand management programs, such as:

- Free transit trial periods (as in Seattle, Washington)

- Web-based pre-trip planning programs (as in the Netherlands) that allow commuters to compare the door-to-door travel times and costs of alternative modal combinations, as well as alternative start times for their commute trips

- Individualized marketing programs (such as in Lund, Sweden), where commuters are visited in their homes or at their job sites by transportation advisors who discuss the various travel options available to them

\section{Concluding Thoughts}

FAST Miles attempts to use free market principles on highway systems to encourage transit and HOV use and to eliminate recurring highway congestion. There appears to be sufficient discretionary use of solo driving on the highway system to induce significant changes in motorists' travel choices. This could reduce vehicle demand below the volumes at which highway traffic flow breaks down. While implementation and operating costs could be significant, benefits in a large metropolitan area could exceed public costs for operating FAST Miles by several orders of magnitude. Also, FAST Miles could be self-financing. It could introduce new possibilities for public-private partnerships for the efficient and effective provision of transportation services, including highway and bus operations, and passenger collection and distribution services. 
New road user charges would be packaged with incentives for transit and carpool use, which have higher levels of public support than road pricing by itself. FAST Miles would provide an equal amount of premium service free of charge to motorists of all income levels and impose new charges for use of existing highways on only those who choose to use highways far more than others during peak times when highway space is scarce. However, concerted efforts will need to be made to involve the public in the detailed development of the concept to alleviate their concerns. FAST Miles and its benefits are complex and difficult to explain in a sound byte.

Metropolitan Planning Organizations may be best positioned to conduct the type of extensive public involvement needed to alleviate the public's concerns and to develop more detailed concepts with public participation. A pilot demonstration of the concept may be needed to convince the public of its merits. Implementing FAST Miles will be no easy task. The highly successful congestion-charging scheme established in central London in 2003 is smaller in scale than a regionwide application of FAST Miles would be. Yet it took many years of preparation, bold political leadership, and a favorable institutional setting to establish the central London scheme.

\section{Acknowledgments}

The author would like to acknowledge helpful comments on the FAST Miles concept from Jeffrey Lindley, Eric Gabler, and Bruce Spear of the Federal Highway Administration (FHWA) and several colleagues at the Office of the Secretary (OST) of the U.S. Department of Transportation. However, the author alone is responsible for any errors or omissions, and the views expressed are those of the author alone and not necessarily those of the U.S. Department of Transportation or the FHWA. 


\section{References}

American Public Transit Association web page accessed August 29, 2005 at: http:// www.apta.com/research/stats/bus/buscost.cfm.

Berg, J. T., K. Kawada, M. Burris, C. Swenson, L. Smith, and E. Sullivan. 1999. Value pricing pilot program. TR News 204: 3-10. Transportation Research Board.

Brownstone, David, and Kenneth A. Small. 2003. Valuing time and reliability: Assessing the evidence from road pricing demonstrations. Forthcoming in Transportation Research Part A. Available on web (accessed May 6, 2004) at: http://www.socsci.uci.edu/ ksmall/VOT-VOR-AEA11.pdf.

Cambridge Systematics, Inc. and URS Corporation. 2005. MnPass system study. Final Report. Prepared for the Minnesota Department of Transportation.

Charles River Associates, Inc. 2001. Part time operators: The trends and impacts. TCRP Report 58, TRB, NRC, National Academy Press, Washington DC.

Chen, Chao, and Pravin Varaiya. 2002. The freeway-congestion paradox. Access (20).

DeCorla-Souza, Patrick. 1994. Applying the cashing out approach to congestion pricing. Transportation Research Record 1450: 34-37. Transportation Research Board.

DeCorla-Souza, Patrick. 2005. FAIR highway networks: A new approach to eliminate congestion on metropolitan freeways. Public Works Management \& Policy 9 (3): 196-205. SAGE Publications.

DeCorla-Souza, Patrick, and William G. Barker. 2005. Innovative public-private partnership models for road pricing/ BRT initiatives. Journal of Public Transportation 8 (1). Center for Urban Transportation Research.

HLB Decision Economics Inc. and University of California at Irvine. 2001. The value of reliability in congested conditions. National Cooperative Highway Research Program Report 431. Transportation Research Board.

ITS Decision, Service and Technologies. 2005. Web site accessed May 6, 2005: http://www.calccit.org/itsdecision/serv_and_tech/Electronic_toll_collection/ electron_toll_collection_report.html. 
Langer, Gary. 2005. ABC news poll: Traffic in the United States: A look under the hood of a nation on wheels. ABC News, February 14. Available at: http://abcnews.go.com/Technology/.

McDonald, Douglas B. 2003. Measures, markets and mileposts. The Gray Notebook for the Quarter Ending March 31, 2003: 33. Washington State Department of Transportation.

Safirova, E., K. Gillingham, I. Perry, P. Nelson, W. Harrington, and D. Mason. 2003. Welfare and distributional effects of road pricing schemes for Metropolitan Washington, DC. Discussion Paper 03-57. Resources for the Future. Washington, DC.

Schrank, David, and Timothy Lomax. 2005. The 2005 urban mobility report. Texas Transportation Institute. Available at: http://mobility.tamu.edu/ums/report/.

Supernak, Janus. 2001. I-15 Congestion Pricing Project Monitoring and Evaluation Service, Task1: Phase II Year Three Traffic Study. Prepared for the San Diego Associations of Governments.

Transportation Research Board. 2000. Highway capacity manual.

U.S. Department of Transportation and Federal Highway Administration.1999. Summary of travel trends: 1995 Nationwide personal transportation survey.

U.S. Department of Transportation. 2002. Memorandum on revised departmental guidance for valuation of travel time in economic analysis. Washington, DC. 2002. Available at: http://ostpxweb.dot.gov/policy/safety/VOT_Guidance_ Revision_1.pdf.

U.S. Department of Transportation. 2003. Highway statistics 2002. Table HM-71: $\mathrm{V}$-43. Washington, DC.

U.S. Department of Transportation. 2004. National household travel survey 2001. Available at: http://nhts.ornl.gov/2001.

U.S. Department of Transportation. 2004. Report on the value pricing pilot program through March 2004. Available at: http://knowledge.fhwa.dot.gov/cops/hcx. nsf/All+Documents/AD276ECC2E3A077885257005006B5614/\$FILE/March\%20 2004\%20Report\%20of\%20Congress.pdf.

Wachs, Martin. 2003. Congestion in cities-Where, when, what kind, how much. Traffic Congestion: Issues and Options. Presentation at the Conference held in Washington DC, June 26-27. UCLA Extension Public Policy Program. 
Washbrook, Kevin. 2002. Assessing the potential of road and parking charges to reduce demand for single occupancy vehicle commuting in the Greater Vancouver region. Research Project No. 298. School of Resource and Environmental Management, Simon Fraser University.

Washington Post. 2005. Riding Metro. March 6.

\section{About the Author}

Patrick DeCorla-Souza (Patrick.DeCorla-Souza@fhwa.dot.gov) is team leader for Highway Pricing and System Analysis in the Office of Transportation Policy Studies at the Federal Highway Administration (FHWA) in Washington, D.C. He manages FHWA's Value Pricing Pilot Program. In this capacity, he works with public and private sector partners in 15 states to implement innovative road-pricing strategies. He has published extensively on topics relating to road pricing, air quality, travel demand modeling, land use strategies, benefit-cost analysis, and cross-modal evaluation. Mr. DeCorla-Souza chairs the Transportation Research Board's Joint Subcommittee on Road Pricing. 


\title{
Smart Feeder/Shuttle Bus Service: Consumer Research and Design
}

\author{
Y. B. Yim, University of California at Berkeley \\ Avishai (Avi) Ceder, Technion-Israel Institute of Technology
}

\begin{abstract}
While long-haul express transit is gaining ridership, consumers are increasingly experiencing limited access to express transit due to saturated parking at and around stations. The smart shuttle concept was introduced to provide easy access to express transit. Smart shuttles will be equipped with advanced public transit system technologies to track shuttle vehicle locations and disseminate up-to-the-minute shuttle arrival information to consumers. The first step toward deployment of the smart shuttle service was a market study of short-haul feeders. This article presents the results of a telephone survey of randomly-generated Castro Valley households. Castro Valley is a suburban community in the San Francisco Bay Area, and many residents commute by BART (Bay Area Rapid Transit). The survey suggested that three fifths of the survey participants were likely to take the shuttle to the BART station. The interest in using the smart shuttle service is strongly associated with gender, auto ownership, ethnicity, and employment status. Females were more interested in taking a shuttle than males. Employed people were more likely to use BART because of the shuttle. Households without a car or with fewer cars were more interested in taking a shuttle. The cost, travel time, and reliability of the service are the most important attributes in the design of a shuttle. The subsequent phase of this research will be a field test of the smart shuttle with optimal routing solutions. The value of the research is the evaluation of the field test, which will assess the improvement of BART access and the cost-effectiveness of the short-haul feeder operation. Ideally, this smart feeder/
\end{abstract}


shuttle system will provide advanced and attractive service that operates reliably and relatively rapidly and acts as part of the passenger door-to-door chain with smooth and synchronized transfers. In order to approach the design of this innovative feeder/shuttle system, new integration and routing concepts are presented based on the consumer research.

\section{Introduction}

A growing concern for public transportation is its inability to encourage people to switch their mode of transportation from solo driving to shared driving. As cities expand, transit ridership decreases while auto ownership increases. Although overall transit ridership is declining in cities, an encouraging trend is increased ridership in long-haul express bus or rail transit. When long-haul express transit systems were built in the 1970s and 1980s in California, parking facilities were also provided for riders to park their cars and ride a train. The concept of "park and ride" was readily accepted by the public, and a large number of commuters preferred to take an express bus or train to avoid rush-hour traffic and prohibitive parking costs. As regional economies grew and more jobs became available, commuters increasingly relied on the express transit service (e.g., in the San Francisco Bay Area). In 1999, the Bay Area Rapid Transit (BART) carried 285,000 commuters each weekday, compared to 255,000 in 1992 (11.7\% growth over seven years). Automobiles continued to be the major access mode to BART. Approximately 80 percent of the park-and-ride BART customers parked in the BART parking lot while the remaining 20 percent were parked off-site around the BART station on residential streets. As the BART parking lots became full as early as 7:00 A.M., the overflow vehicles took up space on residential streets, inviting an increasing number of neighborhood complaints around the BART stations.

Some BART riders claimed that they have had to switch back to driving because of the severe access problems with BART. All 39 BART stations have access problems. Although local buses are able to serve BART stations at certain times, they do not necessarily meet the needs of BART customers' schedules. Local bus and BART schedules are not well synchronized and, thus, transfer times are often unnecessarily long. Long waits are one of the major reasons people do not want to travel by public transit.

A smart shuttle/bus is an alternative travel method to personal vehicle or bus transit for short-haul feeders. The smart shuttle concept has the potential for 
improvement of transportation accessibility for those who may not want to drive or take a bus to express transit stations. Features of the smart shuttle will include both fixed- and flexible-demand responsive systems based on the time and location of the service, use of Advanced Public Transit Systems (APTS) technologies for timely dissemination of the shuttle arrival time, and economical operation of the smart shuttle system. Smart shuttle vehicles will be tracked via automated vehicle identification (AVI) system and Global Positioning System (GPS). Ideally, smart shuttles would provide attractive feeder and distributor services with advanced transportation technologies contributing to transit operations that are reliable, productive, and efficient. Smart shuttles could possibly provide door-todoor service with smooth and seamless operation and synchronized scheduling between long- and short-haul transit operations.

The short-haul feeder study as a whole has four broad objectives:

1. latent demand study (or market study) of short-haul feeders,

2. design of innovative routing strategies,

3. deployment of a smart shuttle for a field test, and

4. evaluation of the smart shuttle system.

The latent demand study is being performed using the survey research method. The routing strategy study was done with simulation. The field test and evaluation will be done following the first two studies.

This article presents the findings of the latent demand study, which is concerned with consumer response to a smart shuttle system for short-haul feeders. The article provides an understanding of the user side of short-haul feeder service. The study investigated service attributes that would attract consumers. The decision to take transit will depend on trade-offs between personalized transit and the personal vehicle. If the goal of a demand responsive transit service is to capture the driver population, a personalized transit service needs to be as convenient as a personal vehicle. If the goal is to improve the transit service for those who are captive transit users, personalized transit needs to be better than fixed-route service.

The central issue is what attributes of personalized transit will attract consumers and what segment of the population will use it. The target population of potential users could include commuters, the elderly, persons with disabilities, and children. 
The present study investigated desired attributes that will attract consumers. Key research questions were:

1. What kind of service features will likely attract consumers enough for them to switch from their single-occupancy vehicle (SOV) to a smart shuttle?

2. Who will use it and why?

The objectives of the latent demand study are:

- to assess the travel characteristics and profiles of potential users of the smart shuttle with respect to socioeconomic variables, and

- to identify attributes necessary to support the smart shuttle system, including acceptable waiting time, number of stops, size of shuttle vehicles, travel time, and fare structure.

The findings of the demand study were considered in the design of the Castro Valley' smart shuttle system to improve BART station accessibility with new integration and routing concepts.

Castro Valley, a community within the incorporated County of Alameda in California was selected for a field test. The reasons for selecting Castro Valley were:

- The community is one of the fastest growing suburban communities in northern California.

- BART and Alameda Contra Costa Transit (AC Transit) serve Castro Valley.

- The community experiences severe access problems to the Castro Valley BART station.

- Castro Valley has a severe shortage of parking around the BART and AC express transit stations.

- There is a growing concern with overflow parking on neighborhood streets.

While the innovative routing strategies are explained in this work, the simulation study for these strategies for the Castro Valley community is presented by Ceder and Yim (2002).

\section{Background}

An important issue regarding a smart shuttle is its design based on a good understanding of user needs and desires and how new technologies can enhance the 
smart shuttle service. In the past, dial-a-ride or door-to-door paratransit played a vital role in North American transit planning in providing equitable transportation services to elderly and handicapped persons. But these concepts do not offer transit services accessible to the entire population that needs mobility (Borndorfer et al.1999; loachim et al.1995). Two user types were identified by Melucelli et al. (2001), "passive users" and "active users." Passive users make use of traditional transit (i.e., boarding and alighting at compulsory stops). No reservation is necessary since vehicles are guaranteed to serve each compulsory stop within a given time window. Active users ask for a ride while boarding or alighting at an optional stop. Active users must issue a service request and specify pick-up and drop-off stops as well as earliest departure and latest arrival times. In this study, transit vehicles have to be rerouted and scheduled to satisfy as many requests as possible, complying with passage-time constraints at compulsory stops, while between two compulsory stops optional stops can be activated on demand. The method used in this study integrates mathematical programming tools into a search framework, taking advantage of the particular structure of the problem formulation.

Dial-a-ride problems customarily use classical vehicle routing heuristics as described in Laporte (1992), Shen et al. (1995), Savelsbergh and Sol (1995), and Cordeau et al. (2000). These methods are rooted in arc and node manipulation, which generally is based on insertion, deletion, and exchange of stops in and out of a current tour. The computation of an upper bound in finding the optimal diala-ride solution is not a trivial issue. The linear relaxation of any arc-based integer linear programming model provides, to some extent, a loose bound. Therefore, heuristics are necessary to cope with practical routing problems.

The findings of the demand study presented in this article are used to construct simulation models for the development of routing strategies and generation of optimal solutions to the smart shuttle services problem. A few studies make use of simulation as a tool to devise satisfactory routing and scheduling solutions. Two types of simulation studies can be traced in the literature. The first type is the research conducted by Wilson et al. $(1970,1971)$ for evaluating various heuristic routing rules and algorithms used in a computer-aided routing system. These studies were developed for mainframe computers and have limitations in handling large-size road networks with different routing strategies. The second research type, by Fu (2001) and his team, considered the use of advanced technologies. Their studies use a simulation model, Sim-Paratransit, which was developed to evaluate advanced paratransit systems with AVL (automatic vehicle location) 
and CAD (computer-aided dispatch) systems. The ability to track continuously a transit vehicle's location enables the use of intelligent paratransit systems that contribute to the operation of the paratransit systems at a significantly improved level of productivity and reliability (Fu 2001).

Other advanced technologies include Advanced Traveler Information Systems (ATIS). ATIS is aimed at providing timely and accurate traveler information and bus or shuttle arrival. Although nearly a decade of ATIS research has been undertaken, very few projects have investigated the potential application of ATIS to fixed-route transit services. In the past, most federally-sponsored ATIS Field Operational Tests or Model Deployment Initiatives were directed at assisting drivers in ways of changing their travel behavior with advanced traveler information. The potential application of ATIS technologies to the bus transit service is significant, yet ATIS research in the transit area has lagged behind driver-oriented ATIS studies. Many transportation policy-makers and practitioners believe that transit users can benefit from getting real-time bus or shuttle information. The present study uses ATIS technologies for the Internet dispatch of up-to-the-minute smart shuttle arrival time so that end-users can readily retrieve shuttle information via the Internet. Synchronized BART and shuttle arrival times will also be posted via variable message signs at BART stations and other selected locations along shuttle routes. Low-tech technologies also will be used. Cellular phones will be used for the flexible-route flexible-schedule strategies. A customer will call the driver with his or her location, then the driver deviates from the standard route schedule and picks up the customer.

One of the reasons that people are reluctant to take transit is the uncertainty associated with bus arrival times. ATIS can disseminate real-time bus schedule information to those who are regular transit users as well as to the occasional transit rider. ATIS bus schedules also can attract those who have seldom or never used transit. When the risk of taking transit is reduced to an acceptable level, people will shift from driving to riding bus transit. Moreover, reasonably accurate arrival times or travel times would increase the confidence level of bus transit operators.

Like fixed-transit service, demand responsive transit service suffers from low ridership and high operating costs. As was evidenced in most demonstration projects, demand responsive transit service was not cost-effective, with two factors contributing to this. From the operator perspective, either the design concept had flaws or appropriate computer technologies were not available to efficiently operate the system. From the user perspective, operators did not consider the needs of 
the users. Most of these systems provided the services without asking what type of demand responsive service would attract consumers. While recognizing the importance of operating system efficiency, advanced routing algorithms or computing technologies may not necessarily generate increased ridership.

Previous field tests of demand responsive transit services showed their inability to draw enough consumers to support the system even with public subsidies. Dial-aride in the Boston area, a service that was later tested in other urban regions, had similar problems of low ridership and high operating cost (Multisystems 1977; Dave Systems 1977; Huron River Group, Missouri Transportation Associates, Bishop Engineers 1977; Maine Department of Transportation 1986; TransVision Consultants 1993). The reason was simply that the system was not attractive to consumers. For consumers to be attracted to the new dial-a-ride service, it had to be better than what they were using (i.e., light rail, bus transit, personal vehicle) (Urban and Hauser 1993). Yet there is little understanding of consumer behavior regarding what will make people favor demand responsive transit over other modes of transportation.

With the advance of computer and communications technologies, it is now possible to improve the demand responsive transit system with up-to-the-minute bus/shuttle arrival time and seamless operations between a short-haul feeder and long-haul express systems.

\section{Methodology}

Studies on why people do or do not use transit are numerous. Some people may have no option but to take transit (captured riders without a car), and others may take transit because the cost of parking is prohibitive or taking transit is more convenient than driving. We know a great deal about who the BART customers are and who the AC Transit customers are and why they use these services; however, we do not know why people would use smart shuttles. Since smart shuttles currently do not exist in the Castro Valley community, our objective is to discover consumer reaction to this new proposed service.

To obtain the needed consumer information, the study used the survey research method. The test market was identified as being within a 2-mile radius of the Castro Valley BART station. Four hundred telephone interviews were completed in this market area using a random-digit-dial sample based on the 1990 census tract information. (The 2000 census tract information was not available at the time of 
this market research.) During the last two weeks of September 2001, telephone interviews were conducted using the Computer Aided Telephone Interview (CATI) technique. The criteria used for screening survey participants were that the potential participants had to:

- be 18 years old or older,

- be a permanent resident of the house called,

- say BART was a possible means of transportation for them, and

- commute or make their most frequent trip away from home by some means other than walking or bicycling.

The margin of error for a 400 -respondent sample is +5.0 percent at the 95 percent level of confidence.

The survey questions included the following topics:

- trip characteristics,

- mode of access transportation to BART,

- willingness to use a smart shuttle,

- willingness to pay for the service,

- desired attributes in the shuttle service, and

- demographic characteristics of survey respondents.

The study identified features that would attract consumers in terms of the routing characteristics (i.e., intermediate stop options, express service), travel time, waiting time, number of stops, and willingness to pay for the shuttle service.

\section{Survey Results}

The results of the survey are presented in several parts. These include (1) demographic characteristics, (2) willingness to use the smart shuttle service, (3) willingness to pay for the service, and (4) attributes that would enhance the shuttle service.

Demographically, the sample was predominantly white, highly educated, and financially well off. The sample is a representation of those who live in the suburbs of the San Francisco Bay Area. This part of Alameda County is among the middle- and upper-middle income communities in the Bay Area and commuters typically drive to well-paying professional or highly-specialized jobs in Oakland or San Francisco. 
Most people have the flexibility to choose a transportation mode to get to work, school, or other destinations. However, some people are constrained by their jobs, schools, or other reasons, making it infeasible to consider certain travel modes. Survey participants were asked whether they had transportation options using public transportation. When the respondent did not have the option of taking BART, the survey was terminated. Surveying those with an option to take BART was important because the research interest was to assess the market for a shuttle service.

Of the participants, 64 percent commuted to work, 7 percent to school, and 2 percent both equally. More than 57 percent of the participants have flexibility in the time they start work. More than 80 percent start their work before 9 A.M. while less than 20 percent start work after 10 A.M. Among commuters, nearly four fifths (78\%) of the respondents drove to work alone while only 8 percent carpooled and 19 percent took public transit. Ten percent of the public transit users were those who parked their cars and rode BART.

Travel characteristics of commuters were significantly different from noncommuters $(p<.05)$. Among noncommuters, more people tended to drive alone than commuters (85\%), and few people carpooled (8\%), took public transit (5\%), and used the park-and-ride facility (2\%). Two thirds (37\%) of the noncommute trips were made for shopping, 10 percent were for driving children, 10 percent were for attending medical or dental appointments, and 18 percent were for social or recreational events. The remaining 19 percent were for personal business.

Most (72\%) of those who commuted with BART drove to the BART station by personal vehicle. Only 3 percent carpooled and 17 percent walked to the BART station. The median commute time by BART was 38 minutes, and the median travel time to get to the BART station was 10 minutes. The mean cost of public transit per day was \$4.50; per week, \$31.23; and per month, \$71.82.

More than 80 percent of respondents said that parking was free for them; 13 percent said they personally pay for parking; 5 percent reported that their company pays for parking; and 2 percent noted both they and their company pay their parking. However, there was no strong association between the parking situation and the mode of transportation, at least in this survey. The survey also showed that the cost of parking was relatively lower than the parking price in the central part of San Francisco or Oakland. The mean parking cost per day was \$8.11; per week, \$32.50; and per month, \$133.16. 
One of the critical problems for BART operation is access to BART. Recently, some residents of Castro Valley have said that they would consider using BART for their commute to work or school but the parking lot at the station always seems full, and it is difficult to find any other suitable parking near enough to the station. The question was how many people do not take BART because of the parking situation. Of those commuters who do not use BART, 16 percent said that they do not take BART because of the parking situation; 84 percent said they do not take BART for some other reason.

\section{Demand for a Shuttle Service}

After a brief description of a BART shuttle service was read to participants, they were asked to respond to the question how interested were they in using the shuttle service. Afterwards, they were asked about the cost of the service wait times, van size options, number of stops for pick-ups and drop-offs-all of which are important attributes for designing a shuttle. Participants were then asked how likely was it that they would use the service, given that the cost of the shuttle, wait time, trip time, and scheduling were acceptable.

\section{Interested in Using a Shuttle}

The survey asked the following question about a neighborhood shuttle service to provide easy access to BART: "Suppose a shuttle service were available that provided round-trip transportation to the closest BART station from a pick-up location near your home. The service would use comfortable, air-conditioned vans, and pick-ups would be scheduled for convenient times throughout the day and would be coordinated with BART train schedules. How interested would you be in this type of shuttle service, without considering the cost?" Using a 1-to-5 scale where "1" meant "not at all interested" and " 5 " meant "very interested," one quarter of the respondents said that they are very interested in using the shuttle service and one third said they are not at all interested in using the service. Approximately half of the respondents stated that they are interested in using the shuttle service to the BART station (Table 1).

Among the reasons for no interest in using the shuttle were:

- The BART station is close enough to walk (24\%)

- Need a car for work and errands (25\%)

- BART is not convenient (38\%) 


\section{Table 1. Interested in Using a Shuttle}

\begin{tabular}{llrr}
\hline Scale & Response Category & Percent & $\begin{array}{r}\text { Combined } \\
\text { Percent }\end{array}$ \\
\hline 5 & Very interested & 24.9 & \\
4 & Somewhat interested & 12.3 & 53.1 \\
3 & May be interested & 15.9 & \\
2 & Somewhat uninterested & 13.9 & 46.9 \\
1 & Not at all interested & 33.0 & \\
\hline
\end{tabular}

Interestingly, more than 70 percent of the BART users travel at least 1 mile to get to a BART station, while only 27 percent live within a six-block radius of a BART station. There was no association between the distance from the BART station and driving to the BART station. People living three or four blocks from the BART station drove to the station. People living miles from the BART station mostly drove to the BART station. Very few took public transit or carpooled.

Approximately 40 percent of the participants expressed a high likelihood of using the shuttle service. They also said they would be more likely to use BART if a shuttle service were available. When asked how many days a week participants thought they would use BART because of the shuttle service, they responded that they would use BART eight or more times a month.

\section{Attributes}

Several attributes were investigated with respect to the design of the shuttle service. Among them were the number of pick-ups and drop-offs, the size of a shuttle vehicle, acceptable number of riders, travel time, and wait time.

Important Attributes for Shuttle Design. For designing a shuttle service, we asked respondents to name the three most important attributes in order of priority. Participants said that the most important attribute was the cost of the shuttle service (mean 2.29). The second most important was overall travel time, including the waiting time for the shuttle either at BART or the pick-up location (mean 2.29). The third most important was the on-time reliability of the service at the pick-up location or at the BART station (mean 1.61).

Pick-ups and Drop-offs. When asked the maximum number of pick-ups that should be allowed per trip to the BART station, most people expected four to five 
pick-ups (median five pick-ups) on the way to the BART station. Similarly, they expected four to five drop-offs on the way home (median five drop-offs).

Maximum Number of Riders in a Van. When asked the maximum number of people each van should hold, respondents said that approximately 10 riders (median) on each trip would be desirable.

Travel Time. When asked if the average travel time to the BART station were slower than it currently is, would they still use the BART shuttle service? nearly one third (29\%) said they would take the shuttle, while half (53\%) said they would take the shuttle if it takes about the same time. Only 12 percent said they would take it if it were faster. When asked if the average travel time to the BART station were 20 minutes longer than it takes currently to get to the BART station, would they use the shuttle to the BART station? one fifth (20\%) responded that they would use it if it took 20 minutes longer, 20 percent said they would if 15 minutes longer, 40 percent said they would if 10 minutes longer, 20 percent responded they would if 5 minutes longer. The survey suggests that people are willing to accept a longer travel time using a shuttle for whatever the benefits they perceive.

Arrival Time and Schedule Information. One of the reasons that people are hesitant to take transit is the uncertainty associated with bus arrival times. ATIS can disseminate real-time bus schedule information to those who are regular transit users as well as to the occasional transit rider. ATIS bus schedules also can attract those who seldom or never used transit in the past. When the risk of taking transit is reduced to an acceptable level, people will shift travel mode from driving to bus transit. Reasonably accurate arrival times or travel times would increase the confidence level of bus transit operators. A strong relationship between transit agencies and ATIS could help Metropolitan Planning Organizations (MPOs) to improve the overall Bay Area transportation system. The MPO's largest concern is how to change mode choice decisions from SOVS to high-occupancy vehicles (HOVs).

Cost. The cost question for riding a shuttle was constructed to ask about the highest price first and then subsequently lower prices. For the question: "Suppose the cost for the shuttle service were $\$ 1$ per one-way trip, how likely would you be to use this service? Would you say that you definitely would use the service, probably would use this service, might or might not use the service, probably would not use the service, or definitely would not use the service?" Responses showed that approximately two thirds (61\%) of the respondents would be interested in taking a shuttle at the price of $\$ 2$ for a one-way trip, and half said they would be interested if the cost were $\$ 1$. 
As expected, consumer interest in using the shuttle service is highly elastic with respect to the cost of the shuttle service (Table 2, Figure 1). However, it is found that the price elasticity is not directly proportional to the cost of the shuttle service. Willingness to use the service is significantly different between the low and the high cost of the shuttle service $(p<.05)$.

Frequency of Using the Shuttle Service. When asked how often they would be willing to use the shuttle service if the cost were acceptable, most respondents said that they would use the service two to three times a week (mean 2.57, median 2).

Table 2. Willingness to Pay for the Shuttle Service

\begin{tabular}{llrrrrrr}
\hline Scale & Response & $\mathbf{\$ 5}$ & $\mathbf{\$ 4}$ & $\mathbf{\$ 3}$ & $\mathbf{\$ 2}$ & $\mathbf{\$ 1}$ & $\mathbf{5 0 c}$ \\
\hline & & $(\%)$ & $(\%)$ & $(\%)$ & $(\%)$ & $(\%)$ & $(\%)$ \\
5 & Definitely would & 4.4 & 1.8 & 3.5 & 8.1 & 14.8 & 7.0 \\
4 & Probably would & 12.5 & 10.6 & 21.6 & 32.9 & 36.4 & 27.9 \\
3 & Might/might not & 19.4 & 18.6 & 24.6 & 30.9 & 33.0 & 41.9 \\
2 & Probably would not & 32.6 & 39.4 & 28.1 & 16.1 & 11.4 & 14.0 \\
1 & Definitely would not & 31.1 & 29.6 & 22.5 & 12.1 & 4.5 & 9.3 \\
\hline & Statistical significance & & $\mathrm{p}<.05$ & $\mathrm{p}<.05$ & $\mathrm{p}<.05$ & $\mathrm{p}<.05$ & $\mathrm{p}<.05$
\end{tabular}

Figure 1. Willingness to Pay for the Shuttle Service

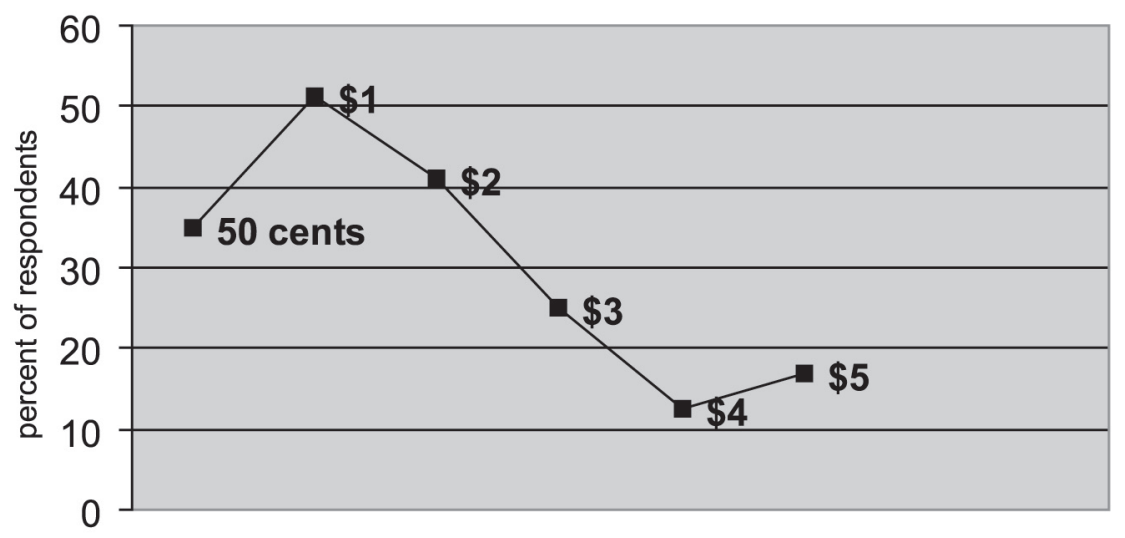


Wait Time. Questions about wait time were posed at the same time as the cost of the shuttle service. It was asked if the waiting time is 20 minutes, 15 minutes, 10 minutes, and 5 minutes, how likely would the participants be to use the shuttle service? The answers were precoded in five scale responses: "definitely would," "probably would," "might/might not," "probably would not," and "definitely would not." The survey showed that the longer the wait time, the less willing people are to take the shuttle, but there was not a significant difference between a 10-and a 5-minute wait time (Table 3, Figure 2). This suggests that half of the shuttle users are willing to accept a 5- to 10-minute wait time.

Payment Method. Participants were asked "How would you prefer to pay for the service if you were to use the shuttle service?" More than 55.4 percent were inter-

Table 3. Willingness to Wait for the Shuttle Service

\begin{tabular}{llrrrr}
\hline Scale & Precoded Response Category & $\mathbf{2 0} \mathbf{~}$ in & $\mathbf{1 5} \mathbf{~}$ in & $\mathbf{1 0} \mathbf{~}$ in & $\mathbf{5 ~} \mathbf{~ m i n}$ \\
\hline & & $(\%)$ & $(\%)$ & $(\%)$ & $(\%)$ \\
5 & Definitely would & 8.9 & 3.4 & 11.2 & 10.0 \\
4 & Probably would & 26.8 & 25.7 & 40.8 & 41.7 \\
3 & Might/might not & 21.5 & 25.2 & 28.0 & 35.0 \\
2 & Probably would not & 21.6 & 24.0 & 10.4 & 6.7 \\
1 & Definitely would not & 21.2 & 21.7 & 9.6 & 6.7 \\
\hline
\end{tabular}

Figure 2. Willingness to Wait for a Shuttle Ride

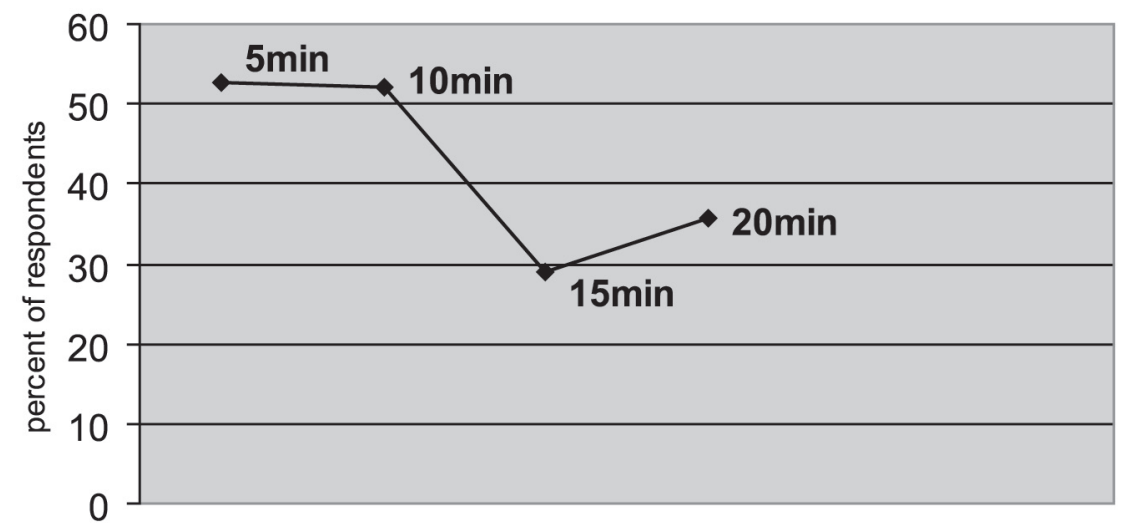


ested in paying for the service on a per-user basis. Only 11.2 percent responded in favor of the weekly-fee basis and 31.2 percent said they would work with a monthly subscription arrangement.

Preferred Means of Receiving Information about the Shuttle. When asked about how they would prefer to receive information about the shuttle service, including the shuttle schedule, cancellation, and new services, 62 percent of the respondents said that they would like to receive the information from a pamphlet. Approximately one third (30.9\%) would like to receive it through the Internet, and only 5.9 percent would like to retrieve it by telephone.

Providing transit information through the Internet is more cost-effective than over the telephone because Internet technology is widely deployed and does not require human operators. Automation for telephone information still requires technical improvement. The survey showed that nearly three quarters $(73 \%)$ of the participants had Internet access at home and 54 percent at work. While only 58 percent had personal cellular phones, 81 percent had a personal computer at home, and 59 percent had one at work.

Benefits of the Shuttle. Because the question "What would be the biggest benefits personally of using the shuttle service?" was an open-ended question and accepted up to three responses, the percentages shown in this section are not mutually exclusive. A variety of personal benefits of the shuttle service were mentioned. Among the personal benefits were:

- convenience, including no need to park (25\%), avoid walking in bad weather $(2 \%)$, avoid wear on vehicle (21\%), and others (30\%),

- safety, including reduced stress and anxiety ( $8 \%$ ), less chance of an accident (2\%), avoidance of traffic fights (18\%),

- travel time savings (14\%),

- less cost (18\%),

- reduced pollution (7\%), and

- chance to meet people and socialize (2\%).

The survey suggested that most people perceive benefits from the shuttle service. It would be convenient for them and could save travel cost and time and increase safety and reduce stress. 
Respondents also mentioned that there would be a great deal of social benefit to be gained from the shuttle service. Among the societal benefits were:

- reduction of traffic congestion (52\%),

- reduction of air pollution (40\%),

- easier to get around, greater mobility, greater accessibility (29\%),

- less crowded parking lots at the long-haul express transit station (10\%),

- saving of money and lower taxes (7\%), and

- reduction in accidents (8\%).

\section{The Likelihood of Using the Shuttle Service}

After a series of questions about design attributes were posed, including the acceptable fare, wait time, the number of pick-ups and drop-offs, and the size of a shuttle vehicle, participants were asked again: "If the shuttle service cost what you are willing to pay and has acceptable wait times, trip length, and scheduling times how likely do you think you would be to use the shuttle service to get to and from the BART station?" Using the 5-point scale where "1" meant "not at all likely" and " 5 " meant "very likely," 57.2 percent said they would be likely to use the shuttle service and 29.2 percent said they may use it. Only 13.7 percent said they were not likely to use the service. This response is significantly different $(P<.05)$ from the earlier question concerning how interested respondents were in using the shuttle service without considering the cost. The latter responses, after learning about the shuttle attributes, were far more receptive to the shuttle service than the former responses (Table 4). In the latter case, nearly 60 percent of the respondents said that they would be likely to use the shuttle, while in the former case the same sample indicated that less than 40 percent would be interested in using the shuttle.

In response to the interest in using the shuttle, there was no difference between commuters and noncommuters. Similarly, there was no difference between commuters and noncommuters in their likelihood of using the shuttle after learning more about its design.

When asked whether they think they would be more likely to use BART because of the shuttle service or whether it would make no difference in how frequently they use BART, 43.3 percent of those surveyed said that they would be more likely to use BART if a shuttle is provided, 23.3 percent said much more likely, 17 percent 
Table 4. Comparative Response $(\mathrm{P}<.05)$

\begin{tabular}{llcc}
\hline Scale & $\begin{array}{c}\text { Precoded response } \\
\text { category }\end{array}$ & $\begin{array}{c}\text { How would you be } \\
\text { interested in using } \\
\text { the shuttle? }\end{array}$ & $\begin{array}{c}\text { How likely would you } \\
\text { use the shuttle? }\end{array}$ \\
\hline & & $(\%)$ & $(\%)$ \\
5 & Very interested & 24.9 & $30.3 \%$ \\
4 & Somewhat interested & 12.3 & 26.9 \\
3 & May be interested & 15.9 & 29.2 \\
2 & Somewhat uninterested & 13.9 & 12.2 \\
1 & Not at all interested & 330 & 1.4 \\
\hline
\end{tabular}

said somewhat more likely, and 56.8 percent said that the shuttle would not necessarily cause them to take BART more often.

The analysis showed that public interest in taking a shuttle service was closely associated with gender, automobile ownership, ethnicity, and employment status. Females were more interested in taking a shuttle than males $(P<.05)$. Employed people were more likely to use BART because of the shuttle service $(P<.05)$. Households without a car or with fewer cars were more interested in taking a shuttle ( $P$ $<.05)$. People among the Asian-American, Hispanic, Native American, and mixed race groups were marginally more interested in taking transit than the white or black race ( $\mathrm{p}=.058)$. However, further analyses showed that the likelihood of taking a shuttle was not closely associated with gender, automobile ownership, ethnicity, and employment status. There was no difference between commuters and noncommuters in their interest or the likelihood of taking a shuttle for the BART service. Nonetheless, the study found that availability of parking at their workplace was closely associated with taking BART $(P<0.05)$.

\section{Smart Feeder/Shuttle Design: Routing Strageties}

Once the major elements of the smart feeder/shuttle transit service are defined, attention should be given to smart routing strategies. These strategies represent the flexibility and, to some extent, part of the attractiveness of the transit system. Ten routing strategies were investigated in this work:

1. fixed route with a fixed schedule (timetable) and fixed direction;

2. fixed route with a flexible (demand-driven) schedule, fixed direction; 
3. fixed route with a flexible schedule, bidirectional;

4. fixed route, flexible schedule, fixed direction, with a possible short-turn;

5. fixed route, flexible schedule, bidirectional, with a possible short-turn;

6. fixed route, flexible schedule, fixed direction, with a possible shortcut;

7. fixed route, flexible schedule, bidirectional, with a possible shortcut;

8. fixed route, flexible schedule, fixed direction, with possible short-turn and shortcut;

9. fixed route, flexible schedule, bidirectional, with possible short-turn and shortcut; and

10. flexible (demand responsive) route with a flexible schedule.

Fixed direction means that the shuttle will always maintain the same direction of travel (same sequence of stops), whereas bidirectional allows for having the flexibility to select the direction based on real-time demand information. The term "shortcut" means that, based on certain loading threshold and synchronization criteria, the shuttle will not continue its fixed route and, instead, will use the shortest path (minimum travel time) to arrive at the train station. The loading threshold is a given (input) number of passengers on board the shuttle. The synchronization criterion means matching the shuttle's new (shortcut) arrival time with an earlier train than that originally planned if the entire route is completed. The term "shortturn" means that based on certain loading threshold and synchronization criteria, the shuttle will not continue on its fixed route. Instead, it will turn around and arrive at the train station in the opposite direction, with the possibility of picking up passengers who were too late to be picked up when the shuttle passed through the station previously. The loading threshold and synchronization criteria for the short-turn strategy (including the consideration of more pick-ups) are the same as for the shortcut strategy. Each strategy allows the flexibility of the other; that is, the loading threshold of the shortcut strategy is higher than the loading threshold of the short-turn strategy. If the latter is reached and there is the possibility of picking up $x$ passengers (after turning around), where $x$ is equal to or greater than the difference between the two loading thresholds, then the short-turn strategy is recommended.

Figure 3 depicts the 10 strategies on a small network with two shuttle routes, one with a dashed line and one with a dotted line. The clock on the upper-right-hand side exhibits the fixed schedule (in only one strategy); when crossed with $x$, it means a flexible schedule situation. Arrows in both directions of the route means 
Figure 3. Routing Strategies Considered on a Small Network Example

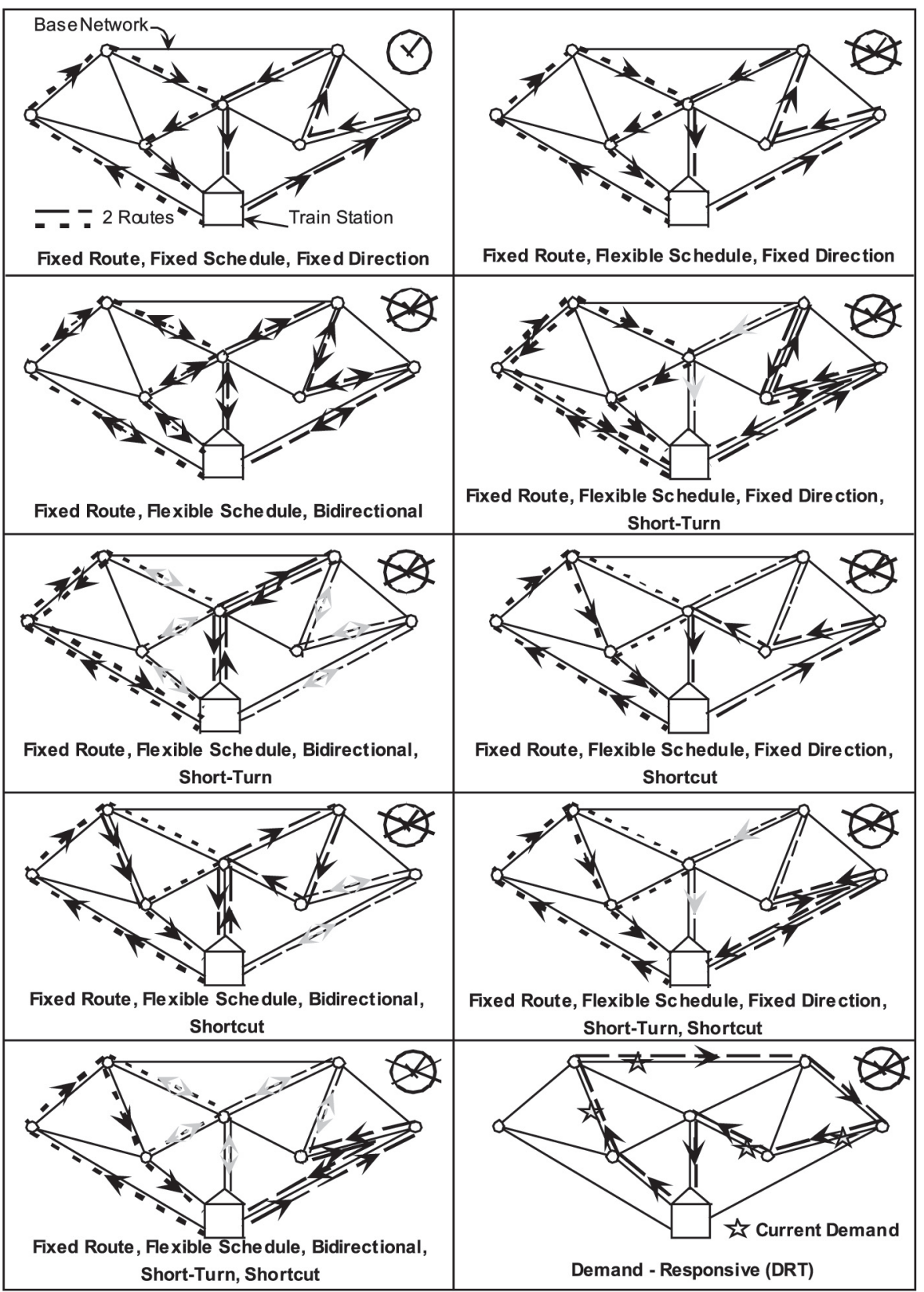


a bidirectional situation. It can be seen in Figure 3 that the lines with the arrows deviate from the fixed route in the shortcut strategy. The arrows turn around at a certain point of the network in the short-turn strategy, while both representations appear in the strategy involving a possible combination of shortcut and short-turn runs,. The last strategy is for a DRT-type of service, allowing for the creation of a new route every time, based on the trip bookings.

The idea of covering almost all possible practical routing strategies stemmed from the need to arrive at user desires and understandings. Certainly, there is no intention that all strategies be used at the same time; rather, the idea was to examine which strategy was best for a given demand pattern and magnitude while taking into consideration the real-time traffic situation in the area of the shuttle's trips. A simulation model was devised for that purpose. This simulation tool, explained in Ceder and Yim (2002), enables a comparison of the various strategies, based on the following measures:

- sum of total time (in passenger-hours) from passenger pick-up to traindeparture times,

- sum of total time (in passenger-hours) riding the shuttle vehicle,

- sum of total waiting time (in passenger-hours) for the train,

- sum of total waiting time (in passenger-hours) for the shuttle vehicle, and

- total number of transit vehicles (by number of seats) required to meet the demand.

These measures of travel and waiting times and number of vehicles characterize the effectiveness and efficiency of each strategy. Certainly, the strategy selected for a given demand is the one with the minimum weighted travel and waiting times (user perspective) and the minimum number of vehicles (operator perspective). These routing strategies underwent a simulation process explained and interpreted in Ceder and Yim (2002).

Once the analysis of the feeder/shuttle service is completed, we recommend the next step should be a pilot study, the implementation of which can follow, for example, the 12 steps shown in Figure 4. These 12 steps of Figure 4 can serve as a framework for a master plan of a pilot where each outcome of a previous step becomes an additional input to the next step except for step 6 .

The pilot master plan starts with a demand analysis by time of day and day of week to find the origin-destination pattern and consumer oriented features. The second 


\section{Figure 4. Overview of Feeder/Shuttle Pilot Master Plan}

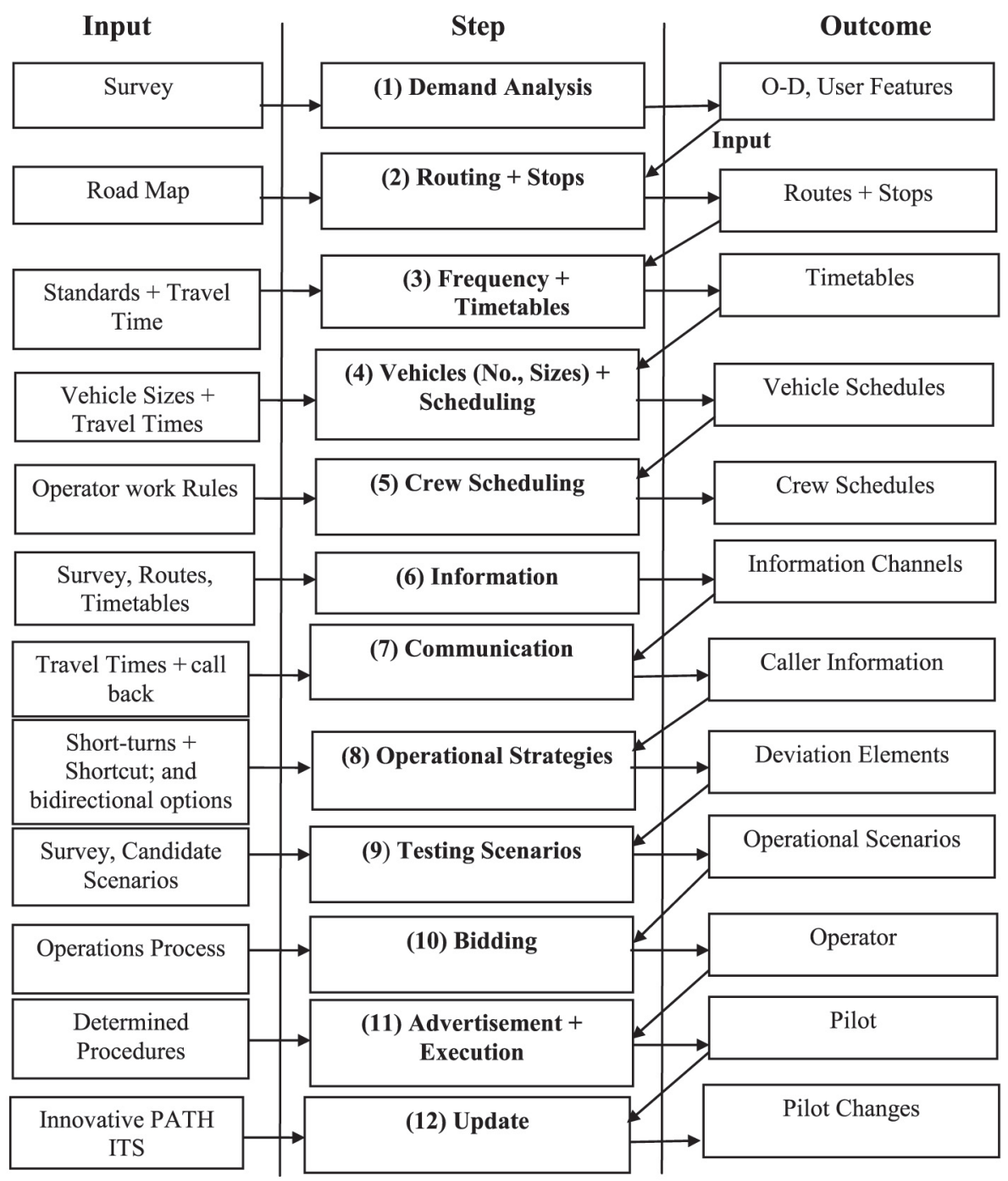

step is to design the fixed routing and stop system and the third-to determine the base frequencies and timetables for each route. The fourth step is to determine the number and size of the feeder/shuttle vehicles and to create the chains of trips (vehicle schedules) which will serve the fifth step of constructing the crew schedules. 
The pilot plan continues in step 6 with the establishment of effective information channels and instruments (e.g., telephone center, internet, newspapers, radio, TV, mail leaflets) which will lead to the development of a user-friendly communication procedures between the users and the operator in the next step. Step 8 constructs the DRT operational strategies without the use of the fixed routing/stop/schedule system. Step 9 determines the testing scenarios of the pilot while step 10 presents the process to select an adequate operator. Step 11 uses proper advertisement tools to approach an operable pilot, and, finally, the last step of the plan aims at improving the instruments, procedures and strategies with the use of innovative ITS (Intelligent Transportation Systems) elements.

\section{Conclusions}

This article documented the survey results of Castro Valley, a suburban community in the San Francisco Bay Area of California that is experiencing rapid growth of housing developments along with the elderly and the young. There was evidence in the survey of demand for a smart shuttle service, as approximately half of the commuters with the option to take BART would be likely to use such a smart shuttle service. There was no strong association between age or income group and the likeliness of using the shuttle service. However, interest in using the service is closely associated with gender, auto ownership, and ethnicity and employment status.

The study suggests that there is a strong potential for the deployment of a smart shuttle service in Castro Valley. The present study fills the gap in our understanding of a potential market for a short-haul feeder system to support the long-haul express transit. The Castro Valley study is our first field test in the San Francisco Bay Area. The field test of the smart shuttle project is expected to be deployed in the near future following interest among some of the Bay Area cities. The value of the innovative transit service is in evaluation. The evaluation of the field test will provide valuable insights into the technical validity of the smart shuttle and the cost-effectiveness of the system.

In addition, this work attempts to construct a new idea for designing an integrated smart feeder/shuttle bus service. Ideally, this smart bus system will provide advanced and attractive feeder and distributor services that operate reliably and relatively rapidly, and are part of the passenger door-to-door chain with smooth and synchronized transfers. Ten different routing strategies are proposed with 
all the combinations of fixed/flexible routes, fixed/flexible schedules, one or bidirectional concepts, and shortcut (shortest path) and/or short-turn (turn around) concepts. Finally a 12-step implementation framework is shown to bridge between the consumer research results and realization of the smart feeder/shuttle bus design.

\section{Acknowledgments}

This is to acknowledge with deep grief that, after the completion of this paper, the first author, Dr. Y. B. Yim, passed away. Her death was a shock and loss to all who knew her personally and professionally. This paper is yet another remembrance of Dr. Yim's many achievements and contributions to the transportation community.

\section{References}

Borndorfer, R., M. Grotschel, F. Klostemeier., and C. Kuttner. 1999. Telebus Berlin: Vehicle scheduling in a dial-a-ride system. In N.H.W. Wilson, ed., ComputerAided Transit scheduling, lectures notes in economics and mathematical systems 471. Berlin: Springer, 391-422.

Ceder, A., Y.B. Yim. 2002. Integrated Smart Feeder/Shuttle Bus Service, UCB PATH Program publication.

Comsis Corporation (1988). Cost analysis methodology for demand responsive service, Urban Mass Transit Administration and the Maryland Department of Transportation.

Cordeau, J.-F., G. Laporte, and A. Mercier. 2000. A unified tabu search heuristic for vehicle routing problems with time windows. Technical Report CRT-2000-03. Montreal: Centre de Recherche sur les Transports, University of Montreal.

Dave Systems, Inc.1977. An integrated public transportation system for the cities of Fremont, Newark, and Union City, the Tri-City Transit Implementation Project.

Fu, L. 2001. Simulation model for evaluating intelligent paratransit systems. Transportation Research Record 1760. Washington, DC: TRB National Research Council, 93-99. 
Huron River Group, Missouri Transportation Associates, Bishop Engineers. 1977. Dial-a-ride study: Report No.1, Dial-a-ride service potential in the Kansas City Metropolitan Region.

loachim, I., J Derosiers, Y. Dumas, M. Solomon, and D. Villeneuve. 1995. A request clustering algorithm for door-to-door handicapped transportation. Transportation Science 29: 35-139.

Laporte, G. 1992. The travelling salesman problem: An overview of exact and approximate algorithms. European Journal of Operational Research 59: 231247.

Maine Department of Transportation. 1986. An analysis and action strategy for select surface passenger transportation services in Maine.

Melucelli, F., M. Nonato, T.G. Crainic, and F. Guertin. 2001. Adaptive memory programming for a class of demand responsive transit systems. In Stefan Voss and Joachim R. Danuna, eds., Computer-aided scheduling of public transport. Lectures notes in economics and mathematical systems 505. Berlin: Springer, 253-273.

Multisystems, Inc. 1977. State of Wisconsin Urban Mass Transit Demonstration Program: Merrill project, Final Report.

Savelsbergh, M.W.P., and M. Sol. 1995. The general pickup and delivery problem. Transportation Science: 17-29.

Shen, Y., J.-Y. Potvin, J.-M. Rousseau, and S. Roy. 1995. A computer assistant for vehicle dispatching with learning capabilities. Annals of Operations Research 61: 189-211.

TransVision Consultants Ltd. 1993. Evaluation of Handyline: Vancouver's automated paratransit information system. BC Transit.

Urban, G., and J. Hauser. 1993. Design and marketing of new products, 2nd ed. Englewood Cliffs, NJ: Prentice Hall.

Wilson, N.H.M., J.M. Sussman, B.T. Higonnet, and L.A. Goodman. 1970. Simulation of a computer-aided routing system (CARS). Highway Research Record 318. Washington, DC: HRB National Research Council, 66-76.

Wilson, N.H.M., J.M. Sussman, H. K. Wong, and B.T. Higonnet. 1971. Scheduling algorithms for a dial-a-ride system. Cambridge: Massachusetts Institute of Technology. 


\section{About the Authors}

Y. B. YıM obtained her B.Arch. (architecture/structural) at the University of Washington, M. Arch. (architecture/urban design) at the University of Washington, M.C.P. (city planning) at the Harvard University, and Ph.D. (Transportation Engineering) at the University of California at Berkeley. She was a member of: Intelligent Transportation Society of America ATIS Committee, Transportation Research Board Committee on User Information Systems, Western Regional Science Association, and Transportation Research Board. Dr. Yim has written articles and reports on numerous transportation-related topics, including traveler information and travel behavior, demand responsive transit systems, evacuation planning and emergency service, and consumer research in transit.

Avishal (Avi) Ceder (ceder@tx.technion.ac.il) obtained his B.Sc. (1971) at the Technion (industrial and management engineering), and M.Sc. (1972) and Ph.D. (1975) at the University of California at Berkeley (major in transportation with emphasis on operations research and human factors). Dr. Ceder has served in the Technion since 1975 and MIT-Boston as a Visiting Professor since 1981. He is a Principal Investigator at the Technion and is or was involved with teaching and research projects at the University of California at Berkeley, M.I.T, Hong Kong University of Science and Technology, Hong Kong Polytechnic University, University of Tokyo, University of Rome, and at the Graduate School of Business, Sydney University, focusing on public transport operations and service planning, operations research, intelligent transportation systems, traffic safety and control, and logistics.

Dr. Ceder has written more than 100 articles in refereed journals, book chapters, proceedings and has authored three books: Network Theory and Selected Topics in Dynamic Programming, System Analysis as an Introduction to Operations Research, and Public Transport: Operations and Service Planning (Lecture Notes). In addition, he served as chief scientist of the Israel Ministry of Transport, Israel delegate at the Transport Program of the European Community, president of the Israel Association of Transportation Research, and a member of various organizing committees of international symposia and workshops. 
